\title{
Therapeutic strategies targeting Kv10.1 in PDAC
}

\author{
Doctoral Thesis \\ In partial fulfillment of the requirements for the degree \\ 'Doctor rerum naturalium (Dr. rer. Nat) ' \\ In the Molecular Medicine Study Program \\ At the Georg-August University Göttingen
}

Submitted by

Farrah Zahed

Born in Mysore, India

Göttingen July 2016 


\section{Members of the thesis committee}

\section{Supervisor:}

Prof. Luis Pardo

Max Planck Institute for Experimental Medicine

Department of Molecular Biology of Neuronal Signals, Göttingen

Second committee member

Prof. Frauke Alves

Max Planck Institute for Experimental Medicine

Department of Molecular Biology of Neuronal Signals, Göttingen

Third committee member

Prof. Dieter Kube

Universitätsmedizin Göttingen

Abtl. Hämatologie und Onkologie, Göttingen

Date of Disputation: 20.09.2016 


\section{Affidavit}

Here I declare that my doctoral thesis entitle 'Therapeutic strategies targeting Kv10.1 in PDAC' has been written independently with no other sources and aids than quoted.

Farrah Zahed

Göttingen, July 2016 


\section{ACKNOWLEDGMENT}

First and foremost, I would like to express my deepest gratitude to Professors Walter Stühmer and Luis A Pardo for giving me the opportunity to work on this project and be part of the 'IonTraC'. I would especially like to thank Professor Pardo for his systematic guidance and efforts in training me. His input has been invaluable. He has been a pleasure to work with and has been very supportive during the entire process. Both Professor Stühmer and Professor Pardo have gone beyond their role as supervisors and have been and will always be to me; great mentors.

I would also like to thank Dr. Franziska Hartung without whose work my project could not have been executed so smoothly. Her work on designing and producing 'scFv62TRAIL ${ }^{\text {Lys, }}$ has been pivotal. Her advice and feedback have also been invaluable.

I would also like to thank the technical support of the lab for their help and resources throughout experimentation; Victor Diaz, Kerstin Dümke, and Annette Sporning. Michael Kothe for his help and assistance with the animal experiment, Urschi Kutzke for RT-PCR experiments and Bärbel Heidrich for her help with cell culture, Dr. Sabine Martin for helping me with IHC and whose encouragement came when I needed it the most, Dr. Verna Cázares Ordonez for going out of her way to help me find Kv10.1 when it suddenly decided to go for a holiday $:$ during the last few months of my PhD, Naira Movisisyan for helping out with western blot and for being a friend. I would also like to thank Dr. Joasia Bielanska, Dr. Camilo Gomez, and Dr. Jorge Fernández. In addition to being valuable colleagues they also made work and our time together at the lab so much more enjoyable.

A big thanks to Ute for going above and beyond to make my stay comfortable and helping me in so many different ways. I would like to thank Nandhini for providing me support and 
being a true friend. I would also like to thank a few other special people who came my way through the years: Mona, Kirstin, Narine, Albert, Melanie, and Jana.

I would like to acknowledge Dr.Pradip Majumdar of Mitra Biotech, for being a great former boss and providing me the encouragement and support during my application process to pursuing a doctorate program.

The last 9 years have been a roller-coaster ride and I could not have made it through without my best friend, Ashwin Narayanan. He has been there for me through thick and thin, lifted my spirits and always made me believe I could do anything. I consider myself very lucky for having such a gem of a friend. Having another good friend in my life, Louis, made it easier. I would like to thank him for his support and friendship. I would also like to thank my siblings for unconditionally being there for me.

And last but not least my deepest appreciation and gratitude goes out to my wonderful parents for their endless support and encouragement to follow, 'my life's calling'; both spiritually and professionally. Without them I could never have come so far. I dedicate this $\mathrm{PhD}$ thesis and all success and good things that will follow to my parents.

"Most people say that is it is the intellect which makes a great scientist. They are wrong: it is character" - Albert Einstein 


\section{CONTENT}

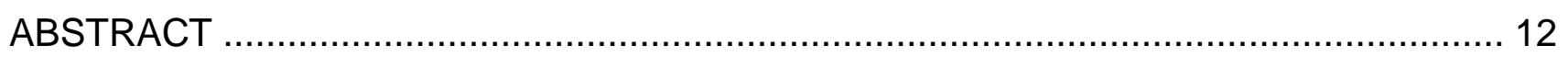

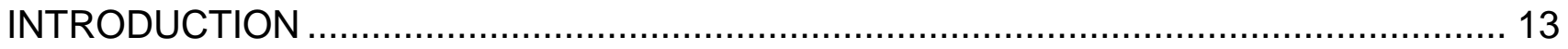

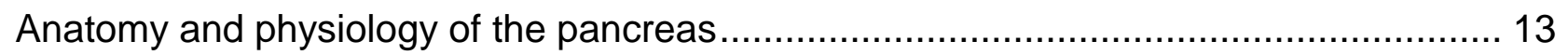

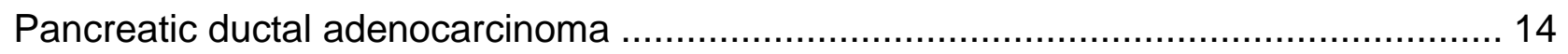

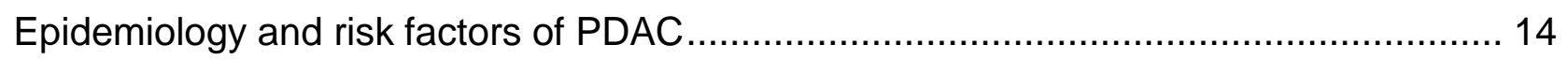

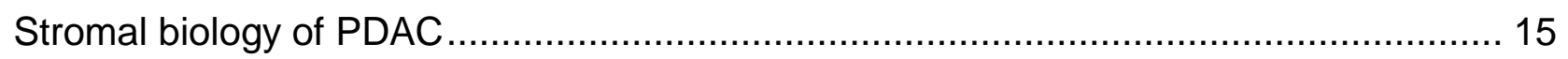

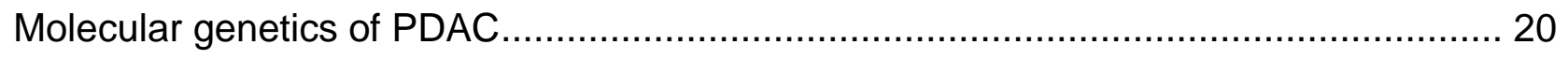

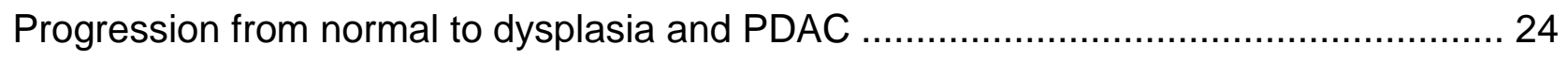

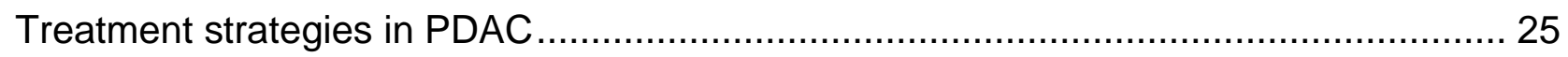

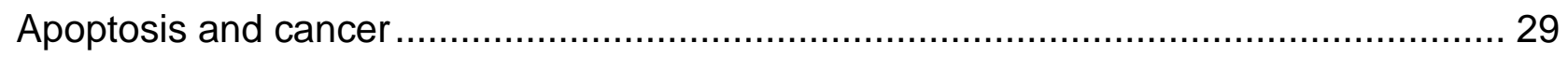

Bi-functional antibody specific to Kv10.1 fused to apoptosis inducing sTRAIL ................ 32

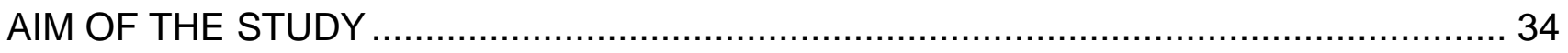

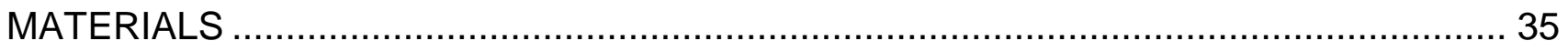

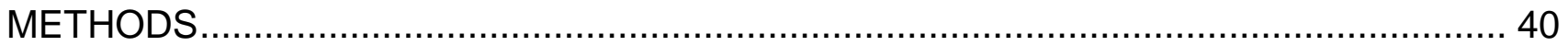

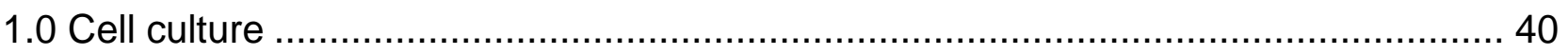

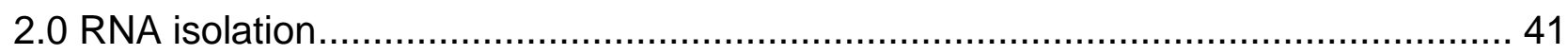

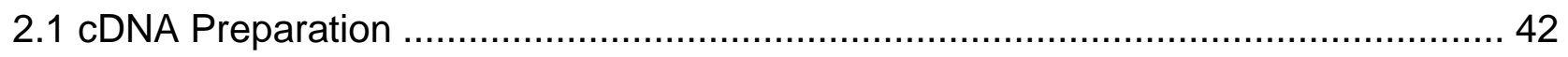

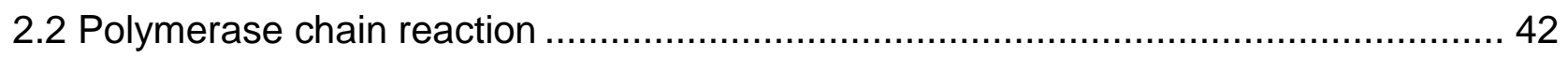

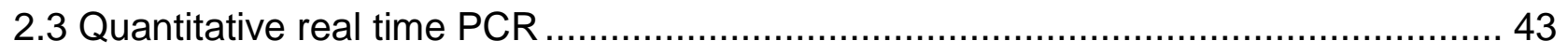

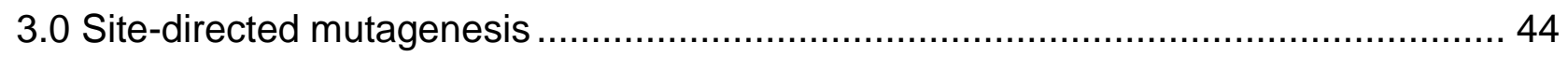

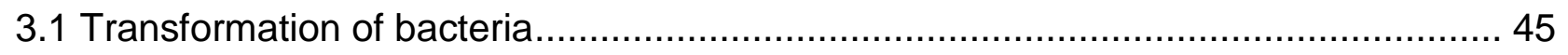

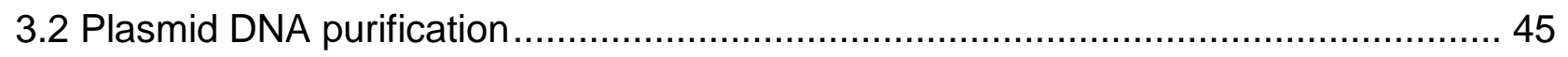

3.3 Endotoxin-free (EF) plasmid DNA purification .................................................... 46

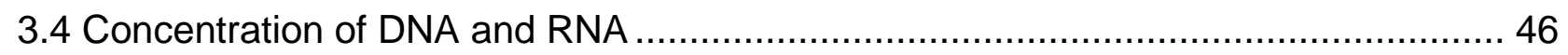

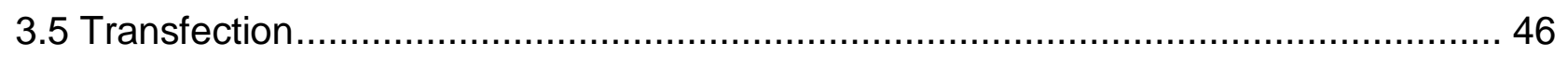

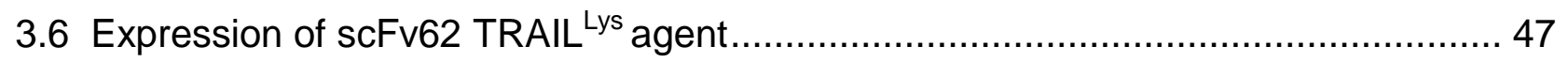


4.0 Lent-X Lentiviral Expression System (Clontech) …............................................... 48

5.0 Characterization of stably transfected cell lines.................................................... 50

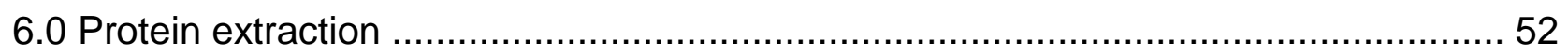

6.1 Protein quantification with BCA Protein Assay .................................................. 52

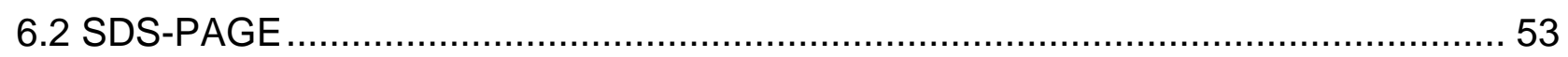

7.0 Immunofluorescence : Immunohistochemistry …….......................................... 54

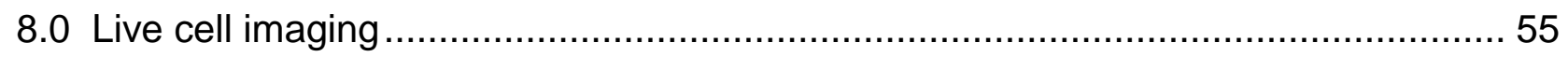

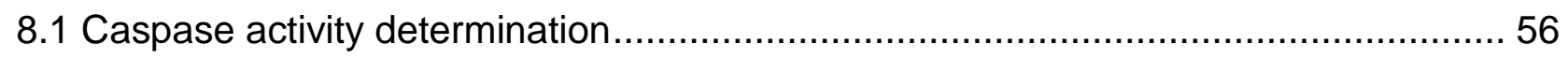

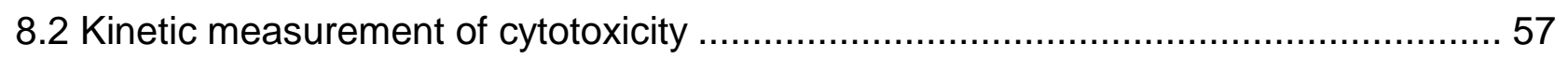

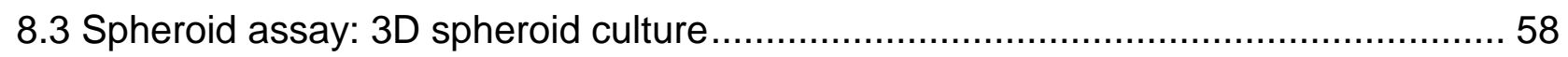

9.0 Annexin V-FITC/PI apoptosis Assay using Flow cytometry .................................... 59

10.0 Live cell fluorescent imaging of Annexin V staining of PS .................................. 60

11.0 TRAIL and IL-8 concentrations were determined by Enzyme-linked Immunosorbent

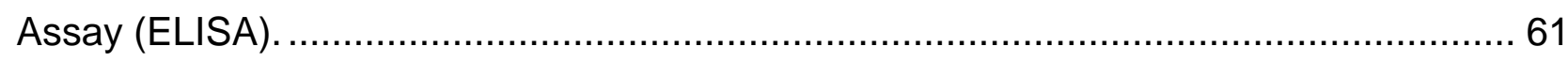

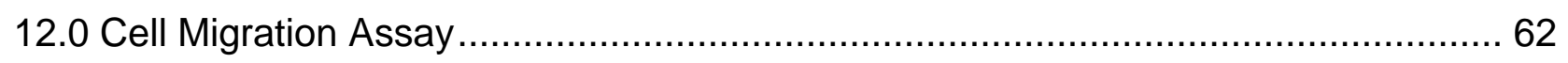

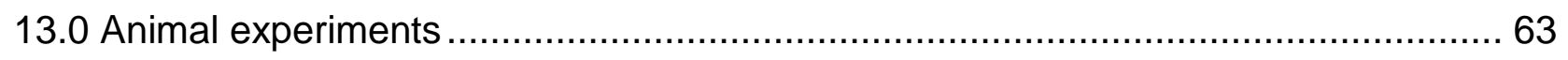

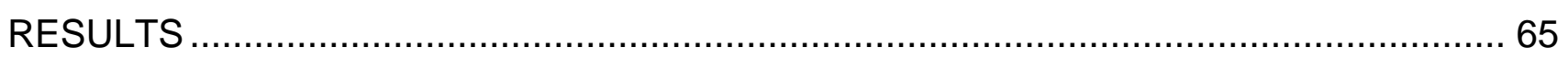

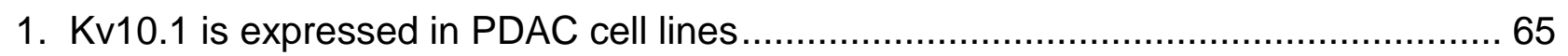

1.2 Expression of Kv10.1 in PDAC cell lines at the protein level ....................................6

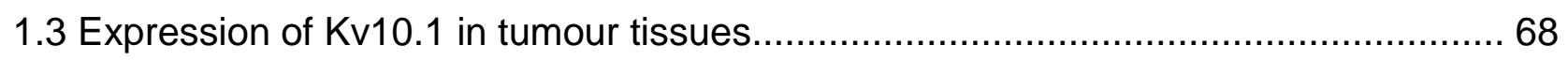

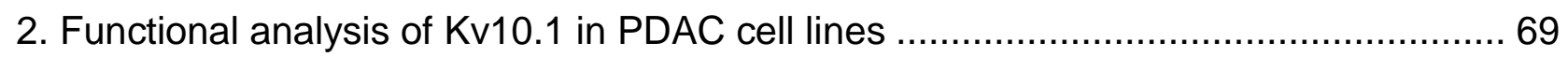

3. Effects of scFv62TRAIL ${ }^{\text {Lys }}$ and Gemcitabine on PDAC cell lines in single 2D culture. 73

3.1 Effect of ScFv62TRAIL ${ }^{\text {Lys }}$ on PDAC cell viability .................................................. 74

3.2 Cell death induced by combination treatment is largely due to apoptosis ................. 77

3.3 TRAIL is required to induce apoptosis under combination treatment ........................ 83

3.4 One-hour exposure to scFv62TRAIL ${ }^{\text {Lys }}$ is sufficient to trigger apoptosis ................. 84

4. Effects of ScFv62TRAIL ${ }^{\text {Lys }}$ and Gemcitabine on PDAC cell lines co-cultured with stellate

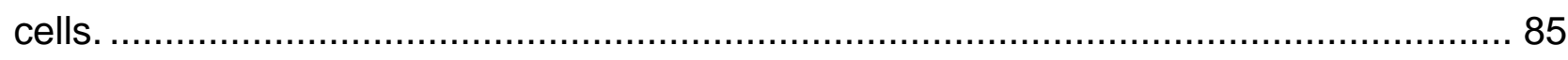


4.1 sTRAIL, scFv62-TRAIL Lys , and Gemcitabine trigger minimal apoptosis in RLT-PSC cells

4.2 RLT-PSC sensitize PDAC cells towards combination treatment ............................ 88

5. scFv62TRAIL ${ }^{\text {Lys }}$ does not increase expression of IL-8 ........................................... 93

6. Effects of ScFv62-TRAIL ${ }^{\text {Lys }}$ on PDAC cells in 3D cultures .......................................... 94

6. Combination therapy reduced the rate of tumour growth in vivo ............................. 100

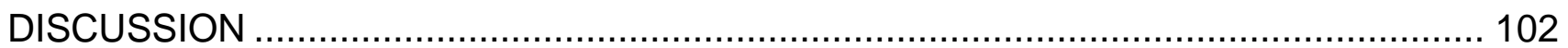

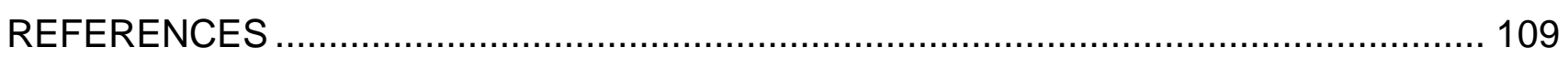

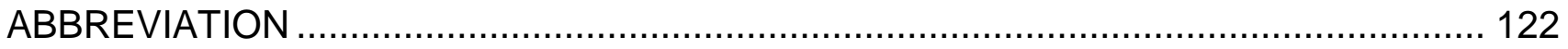

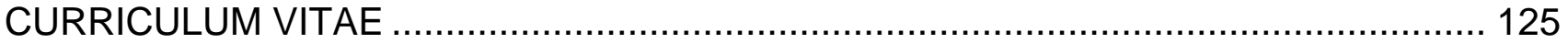

\section{FIGURES}

Figure 1: Anatomy of an adult pancreas (Shih et al. 2013).

Figure 2: Desmoplasia in PDAC. Pancreatic cancer cells and duct cells boost each other's proliferation rate and regulate the accumulation of ECM deposition, angiogenesis and the immune surveillance (Pandol et al. 2009). 15

Figure 3: Schematic representation of tumour-stroma interaction during PDAC development (Hernandez-Munoz et al. 2008).....

Figure 4: The core signaling pathways that are altered in PDAC (Mihaljevic et al. 2010).. 20 Figure 5: Progression model of PDAC: From normal epithelial to low-grade PanIN, and to High-grade PanIN accompanied by the various genetic alteration.

Figure 6: Apoptotic pathway: Intrinsic pathway (Mitochondrial pathway) and Extrinsic pathway (Death receptor pathway) (Adapted from (Hamacher et al. 2008).

Figure 7 : Tumour Necrosis Factor (TNF) - related inducing ligand (TRAIL) apoptotic signaling pathway (Adapted from (Johnstone et al. 2008) 
Figure 8 : Labeling of stellate cells and cancer cells for co-culture experiments. RLT-PSC cell's nuclei labeled with pBRY-nuclear mCherry-IRES-PURO (left) and Capan-1 labeled with (shRNA pGIPZ-hEag1 vsvg envelope) and/or Capan-1 (Non-silencing pGIPZ lentiviral control vector) (right). 50

Figure 9: Real-time PCR confirming knock down of Kv10.1 in Capan-1. 51

Figure 10: Real-time PCR confirming over expression of Kv10.1 in cancer cell lines. 51

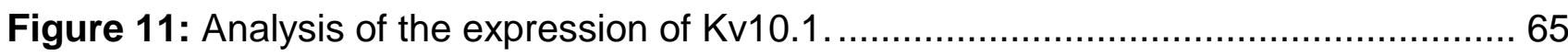

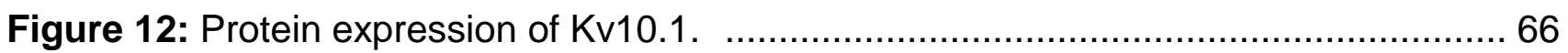

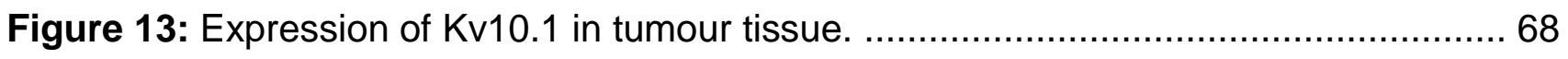

Figure 14: Effect of knock down of Kv10.1 on proliferation. ......................................... 69

Figure 15: Effect of knock down of Kv10.1 on migration............................................. 70

Figure 16: Reduction of rate of proliferation in Kv10.1 ................................................ 71

Figure 17: The rate of migration of Capan-1 cells was not affected by stable Kv10.1

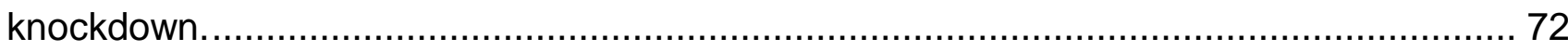

Figure 18: Kv10.1 over expressing cells show a cell line specific effect. ......................... 72

Figure 19: No significant effect of Kv10.1 on the rate of migration. ................................ 73

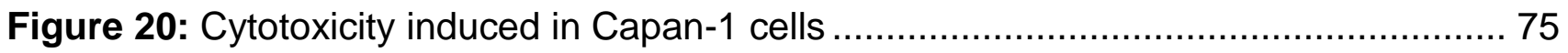

Figure 21: Cytotoxicity induced in BxPC-3 cells. ....................................................... 75

Figure 22: Increase in Caspase-3/7 activity observed in Capan-1 cells when treated with ScFv62TRAIL ${ }^{\text {Lys }}$ in combination with Gemcitabine........................................................ 77

Figure 23: High Caspase-3/7 activity induced in BxPC-3 cells when treated with

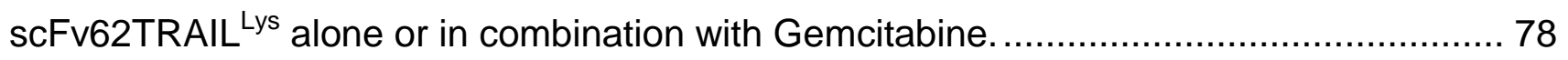
Figure 24: Fluorescence is significantly reduced in the presence of Caspase- inhibitors. . 79 Figure 25: Immunoblot analysis of cleaved Caspase -3 ............................................. 80

Figure 26: Increase apoptotic cells determined by flow cytometry................................. 81

Figure 27: Annexin $\vee$ binding in Capan-1 measured in live cell imaging. ......................... 82 
Figure 28: Annexin $\mathrm{V}$ binding in BxPC-3 in live cell imaging. 83

Figure 29: scFv62 without TRAIL ${ }^{\text {Lys }}$ does not induce apoptosis in Capan-1 cells.............. 84

Figure 30: 1-hour incubation with ScFv62TRAIL ${ }^{\text {Lys }}$ is sufficient to trigger apoptosis. ......... 85

Figure 31: Caspase-3/7 activity did not increase in RLT-PSC up to 30 hours.................. 86

Figure 32: Immunoblot analysis of Cleaved Caspase-3............................................. 87

Figure 33: Gemcitabine inhibits proliferation of RLT-PSC cells. .................................... 88

Figure 34: Caspase-3/7 activity doubled in Capan-1 cells when co-cultured with stellate

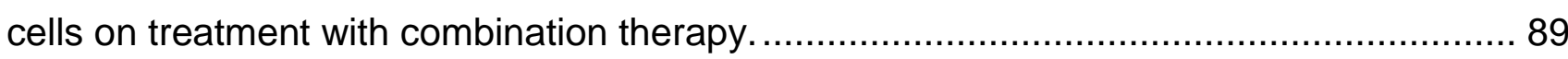

Figure 35: Stellate cells (RLT-PSC) tolerated the different treatments. ............................ 90

Figure 36: Caspase-3/7 activity in BxPC-3 co-cultured with stellate cells........................ 91

Figure 37: RLT-PSC in co-culture with BxPC-3 tolerated the different treatments............ 92

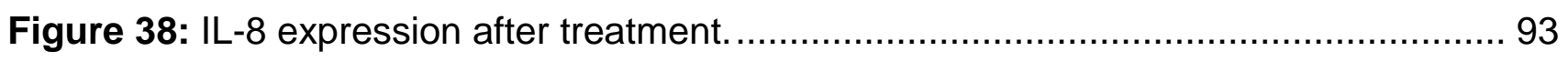

Figure 39: Capan-1 shows dependency on stellate cells to form compact spheroids........ 94

Figure 40: Increase in caspase activity in Capan-1 when co-cultured with RLT-PSC........ 95

Figure 41: Decrease in growth rate of Capan-1 GFP-shRNA when co-cultured with RLT-

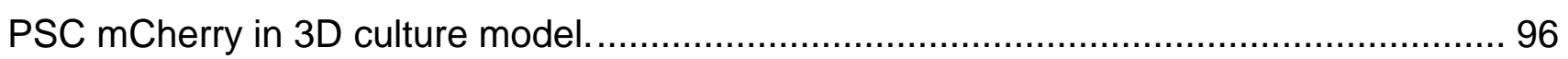

Figure 42: Arrest of the growth of stellate cells (RLT-PSC mCherry) in 3D spheroids with capan-1 cells.

Figure 43: Reduction in proliferation was observed with the treatment with Gemcitabine alone and in combination with scFv62TRAIL ${ }^{\text {Lys }}$ (3D culture) ........................................ 98 Figure 44: Reduction in proliferation was detected with the treatment with ScFv62TRAIL ${ }^{\text {Lys }}$

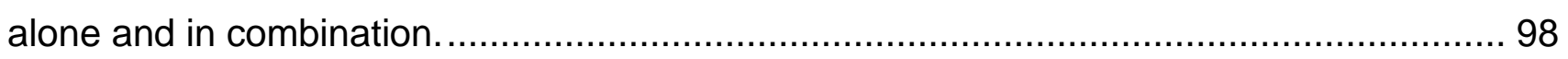

Figure 45: Conditioned medium induced growth in stellate cells in 3D culture model. ...... 99 Figure 46: In vivo testing of our combination therapy demonstrated reduction in growth rate 100 
Figure 47: Monitoring the toxicity of the therapy showed no variation in treated versus control.

\section{Tables}

Table 1: Commonly affected genes in PDAC and their frequencies ...............................2 21

Table 2: Hereditary syndromes linked to increased risk to develop PDAC ....................... 22

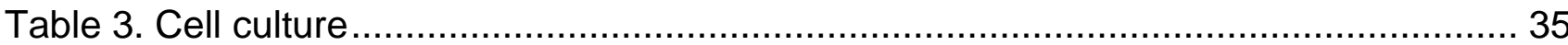

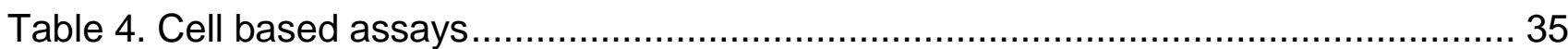

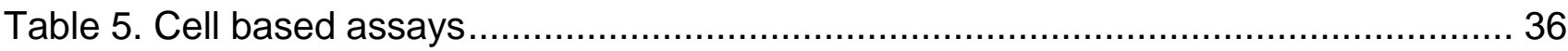

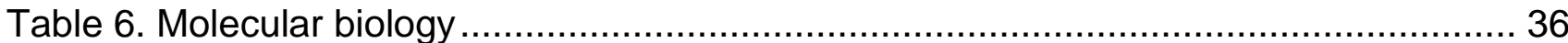

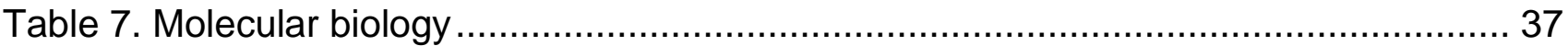

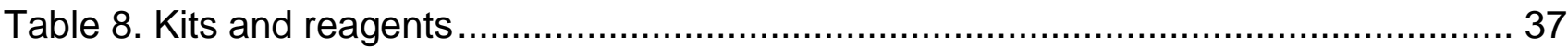

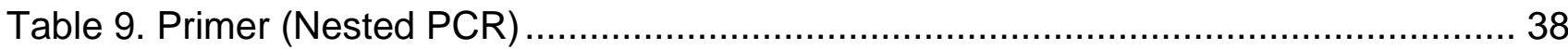

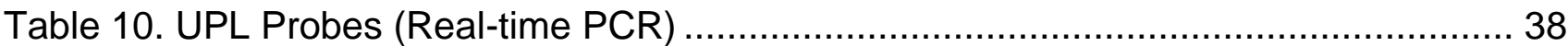

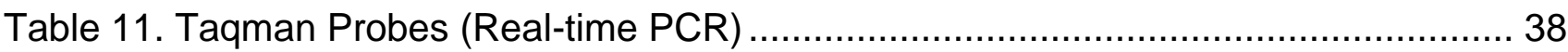

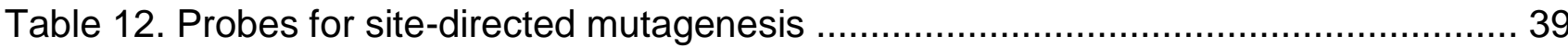

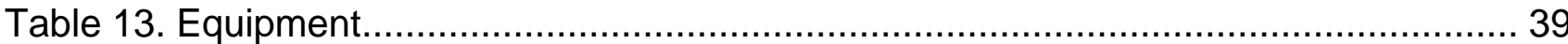




\section{ABSTRACT}

This study was conducted to explore the suitability of the voltage gated potassium channel Kv10.1 as a novel therapeutic target in pancreatic ductal adenocarcinoma (PDAC). PDAC, which is characterized by marked invasiveness, rapid progression and profound resistance to therapy, accounts for more than $85 \%$ of pancreatic cancers and ranks fourth among cancer related deaths, having a 5 -year survival rate of less than $5 \%$. Ion channels are involved in many biological and cellular functions, also in the development of malignant phenotype. In particular, Kv10.1 is specially promising, because it is relatively tumour cellspecific is aberrantly expressed in more than $70 \%$ of tumours from various origins. The two pancreatic cancer cell lines Capan-1 (high Kv10.1 expression, TRAIL insensitive) and BxPC-3 (low Kv10.1 expression, TRAIL-sensitive) were selected to test the efficacy of a bifunctional construct consisting of a single-chain antibody specific to Kv10.1 fused to a soluble TRAIL mutant designed to bind equally to the two death- inducing TRAIL receptors DR4 and DR5 (Gly131>Lys; scFv62-TRAIL ${ }^{\text {Lys }}$ ). We chose to work with the first-line chemotherapeutic agent Gemcitabine to investigate if the construct would increase the sensitivity of the cancer cells towards the agent. In cytotoxicity and apoptosis assays, in combination with flow cytometry and live-cell imaging, Gemcitabine together with scFv62TRAIL ${ }^{\text {Lys }}$ efficiently induced, apoptosis in both cell lines, outperforming both Gemcitabine alone and the combination with soluble TRAIL. After a 3 hour pre-treatment with Gemcitabine, an additional exposure of 3 hours with the construct was sufficient to trigger the maximum apoptotic effect. Evaluation of the treatment strategy on an in vivo tumour model demonstrated a significant reduction in tumour growth on treatment with the combination therapy compared to controls. In conclusion, the results suggest that Kv10.1 can be used as aim for a potential targeted therapy in pancreatic cancer both in vitro and in vivo PDAC models. 


\section{INTRODUCTION}

\section{Anatomy and physiology of the pancreas}
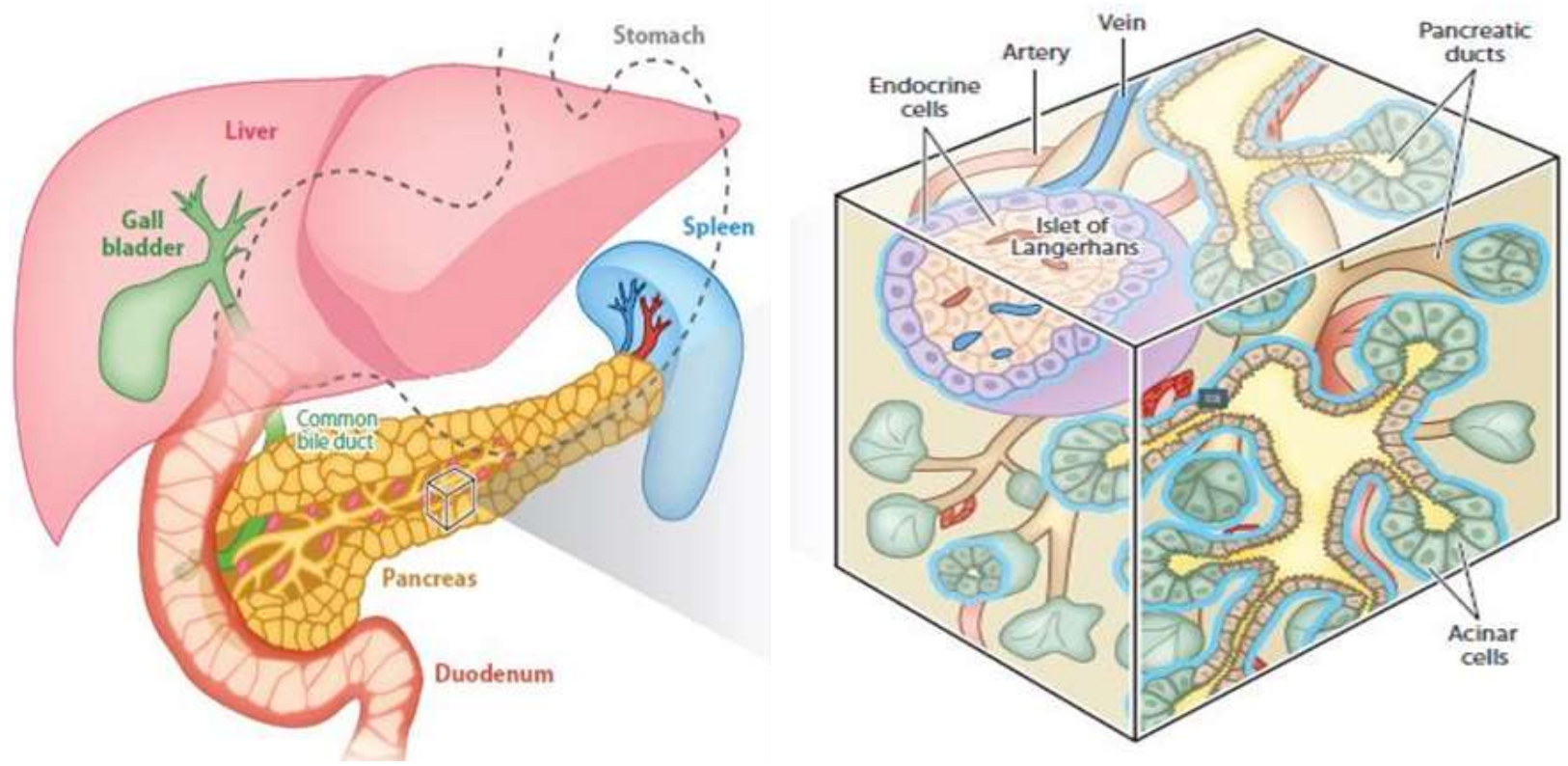

Figure 1: Anatomy of an adult pancreas (Shih et al. 2013).

The pancreas is an essential organ of endodermal derivation and is important for nutrient metabolism (protein, carbohydrate and glucose homeostasis) and has an exocrine and endocrine function.

The exocrine part of the pancreas represents $80 \%$ of the organ tissue. It is made up of a network of acinar and duct cells. The acinar cells are organized in functional units that produce pancreatic juice containing zymogens, which is transported into the duodenum through the ductal system. Inside the acinar units near the ducts are centroacinar cells. The endocrine cells are independent and responsible for controlling the homeostasis of glucose by secretion of hormones into the blood stream. The endocrine part of pancreas is made up of four specialized endocrine cell types that are clustered in so-called Islets of Langerhans (Shih et al. 2013). 
Introduction

\section{Pancreatic ductal adenocarcinoma}

Pancreatic ductal adenocarcinoma (PDAC), whose name derives from the histological similarity to ductal cells, accounts for $85 \%$ of all pancreatic cancers (Hezel et al. 2006). It is comparatively a rare disease accounting for 45,000 cases per year in the United states and the $11^{\text {th }}$ most common cancer overall (Ryan et al. 2014). Globally it is the $4^{\text {th }}$ leading cause of cancer-related deaths in both men and women (Bardeesy et al. 2002, Chu et al. 2007, Murtaugh 2014, Dunne et al. 2015). It has a 5-year survival rate of $3 \%-6 \%$ and median survival of less than 6 months that has not improved over 30 years (Murtaugh 2014, Dunne and Hezel 2015, Tanaka 2016). One of the main reasons for this lethality is the late diagnosis, by which time the disease has already infiltrated into the lymphatic system and metastasized to distant organs (Hezel et al. 2006). Complete pancreatectomy does not avoid reoccurrence (Murtaugh 2014). A recent study has estimated that the time between the first genetic 'hit' of PDAC and the invasive cancer is more than ten years and further 6 years are required before the metastatic lesions are established (Murtaugh 2014).

\section{Epidemiology and risk factors of PDAC}

PDAC is associated with only a few dominant genetic conditions, demographic and environmental factors. Over the years various studies have shown a strong link between PDAC development and age, gender, smoking, alcohol consumption, chronic pancreatitis, diabetes, blood type and obesity (Hezel et al. 2006). It is rarely diagnosed in individuals younger than 40 years of age; its average age of diagnosis is 71 years (Bardeesy and DePinho 2002, Ryan et al. 2014). It is $30 \%$ more common in men than women. This could be partly due to increased use of tobacco by men, because smokers show $75 \%$ increased risk, which persists for a minimum of 10 to 20 years after quitting (Muniraj et al. 2013). People who are obese have $20 \%$ greater risk of developing pancreatic cancer when compared to normal body weight individuals. Early age of onset of pancreatic cancer is particularly linked to abdominal obesity. A recent study showed that there is inverse correlation between the age of onset of diabetes and higher risk of developing PDAC. The relationship between alcohol and PDAC is unclear, although a recent meta-analysis linked the consumption of 3 or more drinks per day with a $20 \%-30 \%$ increased risk (Muniraj et al. 2013). 


\section{Stromal biology of PDAC}

PDAC is characterized by a histologic hallmark known as desmoplastic/fibrotic reaction or stromal reaction. The stroma plays an intricate and dynamic role by relaying signals between cancer cell and resident cells (Pandol et al. 2009). The stromal reaction is composed of both cellular and non-cellular components that provide a scaffold for the cancer cells to proliferate by providing growth factors and immune modulators (Fig. 1). The cellular components include pancreatic stellate cells (PaSCs), fibroblasts, immune cells, endothelial cells and nerve cells whereas the non-cellular components include extracellular matrix (ECM), and a variety of other proteins, enzymes and growth factors (Rucki et al. 2014).

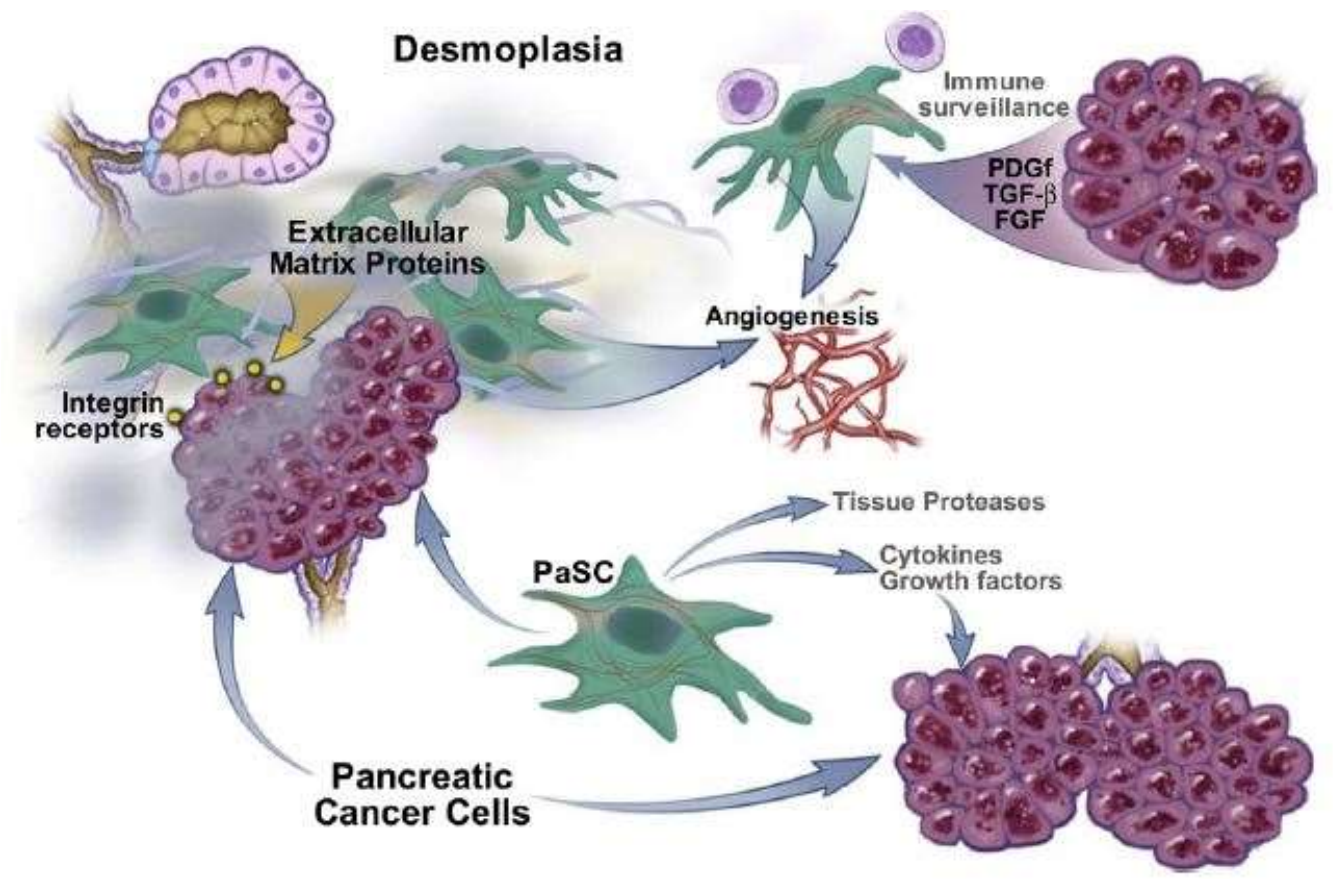

Figure 2: Desmoplasia in PDAC. Pancreatic cancer cells and duct cells boost each other's proliferation rate and regulate the accumulation of ECM deposition, angiogenesis and the immune surveillance (Pandol et al. 2009). 
Introduction

The main ECM proteins abnormally increased are type I and $V$ collagen and fibronectin (Mollenhauer et al. 1987). The amount and type of collagen in PDAC desmoplasia is similar to the one found in alcoholic chronic pancreatitis and tumour-associated chronic pancreatitis tissue (Pandol et al. 2009). The stroma has the capacity to modulate essential properties of tumour cells, including their metastatic properties. Various studies have also established that chronic inflammatory condition induces stromal activation similar to that of PDAC. Molecular events important for PDAC development, including K-Ras mutation or NFKB activation, are also deregulated in chronic pancreatitis. In the recent past, Guerra et al. have demonstrated that chronic pancreatitis in adult mice driven by the K-Ras ${ }^{G 12 V}$ mutation can lead to the formation of a PDAC-like tumour (Guerra et al. 2007). PDAC desmoplasia and chronic pancreatitis are histologically very similar and have similar gene expression profiles. All these observations point towards a possible role for inflammatory environment contributing to nurturing a change of epithelial pancreatic cells towards a neoplastic phenotype, which may result in the development of PDAC (Hernandez-Munoz et al. 2008). Inflammation and tumourigenesis are closely connected from early stages of pancreatic injury, conveying that there is an essential need for better understanding of the stroma-parenchyma association in PDAC (Gukovsky et al. 1998, Lohr et al. 2005).

Mast cells, macrophages, lymphocytes and plasma cells can be found at the edges of the tumour. It has been shown that there is an association between poor survival and high number of mast cells (Pandol et al. 2009). Interestingly, many patients with pancreatic cancer have tumour antigen-specific and functionally competent $T$ cells in both peripheral blood and bone marrow that have a cytotoxic effect upon exposure to cultured pancreatic cancer cells in-vitro (Schmitz-Winnenthal et al. 2005). This suggests that the complex cancer microenvironment within PDAC could play a role in negating beneficial effects of these T cells and thereby protecting the cancer cells (Kleeff et al. 2007). PDAC is a hypovascular solid tumour, and even the few intratumoural blood vessels present are nonfunctional. This limited number of blood vessels and dense fibrous stroma are pointed out to be among the reasons why systemic chemotherapeutic agents fail to deliver on their promise (Assifi et al. 2011, Provenzano et al. 2012). 
Introduction

\section{Pancreatic stellate cells (PaSCs)}

PaScs were discovered by Watari et al. (Watari et al. 1982) and have recently been shown to play a major role in desmoplasia of PDAC. They produce the major chunk of ECM as well as cytokines, chemokines and growth factors that play an important role in the development and progression of PDAC (Rucki and Zheng 2014).

PaSCs are predominantly located in the periacinar space of the exocrine pancreas and comprise 4 to $7 \%$ of total pancreatic parenchymal cells (Pandol et al. 2009, Wilson et al. 2014). In these periacinar spaces they are in a quiescent state, characterized by long cytoplasmic processes that encircle the base of the pancreatic acinus. They are also found in the perivascular and periductal regions of the pancreas. In an inactive form they contain a prominent endoplasmic reticulum, collagen fibrils and vitamin A-containing lipid droplets that surround the nucleus (Apte et al. 1998). They also express desmin, glial fibrillary acid protein (GFAP), vimentin and nestin as well as neuro-ectodermal markers such as nerve growth factor (NGF) and neural cell adhesion molecules; the expression of these selective markers differentiates PaSCs from fibroblasts (Wilson et al. 2014). They also have low proliferation and ECM production rates during their quiescent state. PaSCs not only produce ECM proteins but also enzymes that degrade them (Metalloproteinases (MMPs)), and inhibitors of the same MMPs thereby playing a crucial role in the maintenance of normal pancreatic architecture (Wilson et al. 2014) .

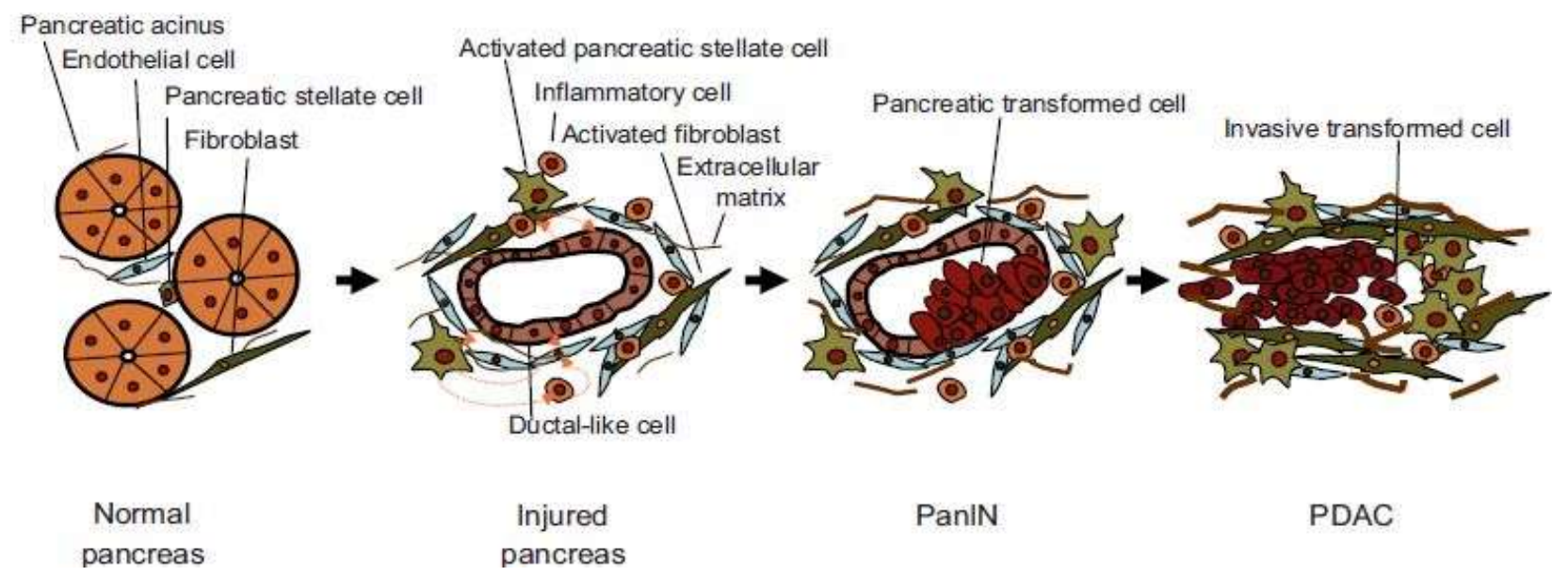

Figure 3: Schematic representation of tumour-stroma interaction during PDAC development (Hernandez-Munoz et al. 2008). 
Introduction

Acute injury of the pancreas leads to the activation of stellate cells, which secrete an excess of ECM proteins and builds a framework to regenerate epithelial cells. The activation of PaSCs at a cellular level is characterized by loss of lipid droplets and expression of alpha-smooth muscle actin (alpha-SMA) (Pandol et al. 2009). On healing, most activated PaSCs are lost through apoptosis. The few remaining active PaSCs start to secrete MMPs that degrade the excess fibrosis resulting in the return to normal pancreatic histology. However, if the injury is repeated or not healed the PaSCs retain their active form secreting cytokines and growth factors, in turn activating more PaSCs (Wilson et al. 2014). There is even a boost in the proliferation of mesenchymal cells such as interlobular fibroblasts or pericytes that contribute to the stromal composition with extensive deposition of ECM (Hernandez-Munoz et al. 2008). Additionally there is production of new blood vessels and infiltration of inflammatory cells into the stroma. This extensive deregulation can lead to the development of neoplastic lesions which further activates additional components of the stroma eventually leading to the development of PDAC (Chu et al. 2007).

Pancreatic cancer cells and PaSCs have a symbiotic relationship in PDAC that contributes to the aggressive growth of the tumour and possibly play a role in metastasis. Supernatant from human pancreatic cancer cell cultures have been shown to stimulate the proliferation and production of ECM by PaSCs. It has been reported that proliferation of PaSCs is driven by secreted platelet-derived growth factor and the ECM production by the activity of transforming growth factor-beta and fibroblast growth factor-2 (Apte et al. 2004, Bachem et al. 2005). The growth rate of tumour cells injected subcutaneously into nude mice increases in combination with PaSCs, and leads to the development of desmoplasia similar to the one seen in human PDAC patients (Bachem et al. 2005, Pandol et al. 2009). These factors are suggested to play a major role in the proliferation, migration, invasion and resistance to radiation and chemotherapy in PDAC tumours (Pandol et al. 2009).

\section{Extracellular Matrix (ECM)}

The non-cellular component of the stroma includes various fibrous proteins (collagen), polysaccharides (hyaluronan), and glycoproteins (fibronectin) and also growth factors. This stromal mesh, apart from providing support to the surrounding tissue also, plays a role in differentiation, remodeling and homeostasis in healthy organs (Frantz et al. 2010). Some of the components of ECM have tumourigenic properties; Collagen $I$ is linked to high 
Introduction

expression levels of transgelin, which is associated with the activation of PSCs (Apte et al. 2013). The expression levels of collagen have been linked to resistance towards Gemcitabine, the current first line drug for PDAC. High stromal levels of Hyaluronan, a nontypical glycosaminoglycan is able to retain water, increase intratumoural fluid pressure and thereby decrease the penetration of the drug into the tumour (Michl et al. 2012, Provenzano et al. 2012, Rucki and Zheng 2014). This, together with the hypovascular nature and the dense stroma are among the reasons for the failure of systemic chemotherapeutic agents and some newly tested antiangiogenic drugs in PDAC (Rucki and Zheng 2014).

\section{Immune cells}

Immune cells also participate in tumour progression, chemotherapy resistance and metastasis. It was first observed by Rudolf Virchow that leukocytes infiltrate tumour tissues indicating a connection between inflammation and cancer (Balkwill et al. 2001) and that chronic inflammation leads to the development of cancer. Among the inflammatory cells that infiltrate tumours and localize in the tumour stroma are tumour-associated macrophages (TAM), neutrophils and regulatory $T$ cells $\left(T_{\text {reg }}\right)$.

TAM's are the majority of immune cells infiltrating the stroma or tumour microenvironment (Solinas et al. 2009). They are recruited by chemo-attractants, get activated upon reaching the tumour and secrete growth factors and cytokines that in turn alter the stroma and enhance the desmoplasia reaction (Apte et al. 1999). Activated TAMs stimulate PDGF expression in PaSCs driving their proliferation and the synthesis of collagen type I and fibronectin (Ross 1989, Schmid-Kotsas et al. 1999, Aoyagi et al. 2004).

Neutrophils and $T_{\text {reg }}$ cells are the other types of immune cells that contribute to desmoplasia in PDAC. Neutrophils along with TAMs play a role as phagocytes at the inflammation site and release toxic granules that are the source for ROS (reactive oxygen species) production. ROS in turn contribute to genomic instability (Toyokuni et al. 1995, Vaquero et al. 2004), and in some cases lead to stimulation of the non- enzymatic activation of TGF $\beta$ in vivo which in turn leads to the activation of PaSCs (Koli et al. 2008). Infiltrating neutrophils also regulate angiogenesis and ECM remodeling via expression of MMP-9 (Nozawa et al. 2006). $T_{\text {reg }}$ cells play a major role in immune response to cancer by suppressing an effective response that the immune system may start. The increase in the frequency of $T_{\text {reg }}$ cells in PDAC patients indicates their role in suppressing an immune response (Liyanage et al. 
Introduction

2002, Liyanage et al. 2006). They also secrete TGF $\beta$, which provides an anti-inflammatory effect and contributes to suppressing auto immunity (Moore et al. 2001, Li et al. 2006, Miyara et al. 2007).

\section{Molecular genetics of PDAC}

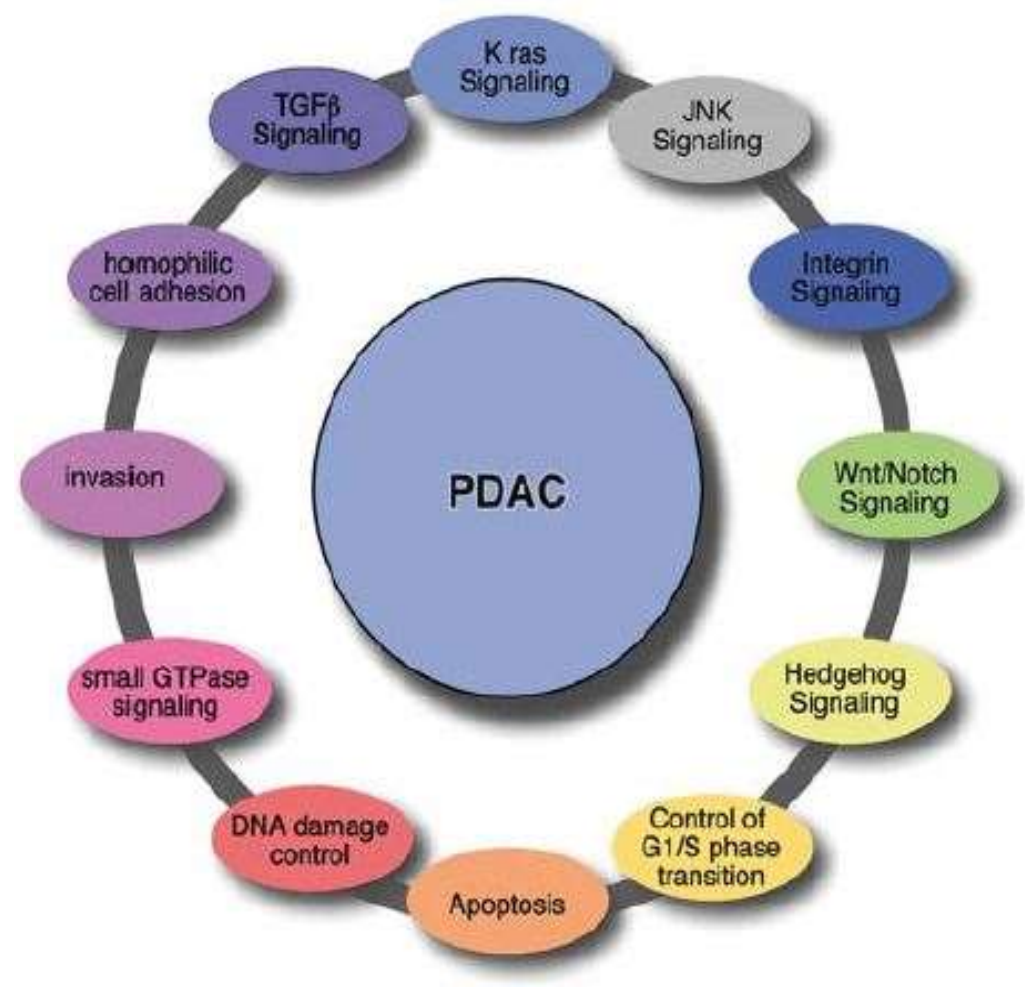

Figure 4: The core signaling pathways that are altered in PDAC (Mihaljevic et al. 2010).

Transformation from a normal cell to a tumourigenic one has been thought to involve six major steps. They do not have any specific order and can take place individually or in combination depending on the type of cancer. These steps include production of excessive growth factors, lack of response to antigrowth signals, escaping apoptosis, boundless replicative capability, continuous angiogenesis and finally metastasis or invasion (Hanahan et al. 2011). These molecular events have also been associated with PDAC development (Bardeesy and DePinho 2002, Hezel et al. 2006). 
Table 1: Commonly affected genes in PDAC and their frequencies (adapted (Ottenhof et al. 2011)

\begin{tabular}{|c|c|c|c|}
\hline Type & Genes & Function & PDAC(\%) \\
\hline \multirow{3}{*}{ Tumour suppressor genes } & CDKN2A/p16 & G1-S phase cell cycle inhibition & $95 \%$ \\
& SMAD4 & TGFB & $55 \%$ \\
& TP53 & Cell-cycle arrest & $75 \%$ \\
\hline \multirow{2}{*}{ Oncogenes } & KRAS & ERK-MAPKinase signaling & $>90 \%$ \\
& $B R A F$ & & $5 \%$ \\
& Cyclin D & Cell cycle progression & $65 \%$ \\
\hline \multirow{2}{*}{ Genome maintenance gene } & \multirow{2}{*}{ BRCA 2 } & DNA damage repair & $7 \%-10 \%$ \\
\hline
\end{tabular}

KRAS is a well-known oncogene belonging to the RAS super family of GTP binding proteins involved in cell proliferation and growth. Point mutations at codon 12, 13, and 61 (Muniraj et al. 2013, Ryan et al. 2014), near or at the catalytic site, leads to the inactivation of the GTPase activity site thereby constitutively activating KRAS signaling (Hezel et al. 2006. Mihaljevic et al. 2010). Mutant KRAS is detected only in $30 \%$ of early stage pancreatic cancers (like the PanINs), but almost $100 \%$ of PDACs (Bardeesy and DePinho 2002, Mihaljevic et al. 2010). Constitutively active KRAS results in activation of the phosphoinositide 3 kinase (PI3K) pathway, related to cell proliferation and survival (Hezel et al. 2006).

RAF/ERK is a family of serine/threonine kinases that are activated by RAS which leads to a series of phosphorylation events that ends in the activation of the mitogen activated protein kinase ERK. A histological subtype of PDAC known as the medullar subtype lacks K-RAS mutation however has mutated B-RAF pointing to the inverse correlation between the two in PDAC.

Hedgehog pathway is normally inactive in adult Pancreas however, found to be activated in PanIN lesions and increases through the progression to later stages of PDAC (Hezel et al. 2006, Mihaljevic et al. 2010, Dunne and Hezel 2015); transforming growth factor beta (TGF- $\beta$ ) pathway, whose downstream effector SMAD4 (Hezel et al. 2006) shows loss of heterozygosity ( $\mathrm{LOH}$ ) in $90 \%$ PDAC, and $50 \%$ of PDAC have either homozygous deletion or mutational inactivation of the second allele (Mihaljevic et al. 2010). 
Introduction

Wnt/ $\beta$-catenin pathway is associated with proliferation, morphogenesis and differentiation of several organs, including the pancreas (Clevers 2006). Aberrant activation of this pathway is seen in $65 \%$ of pancreatic cancers (Wormann et al. 2013).

Notch signaling pathway is involved in guiding cell fate and cell proliferation during embryonic development of the pancreas and other organs (Mihaljevic et al. 2010). Activation of Notch signaling has been associated with the development of PanIN lesions linking it to initiation, progression and maintenance of pancreatic cancer (Mullendore et al. 2009, Mazur et al. 2010, Ristorcelli et al. 2010).

\section{Tumour suppressor genes}

Table 2: Hereditary syndromes linked to increased risk to develop PDAC (Ottenhof et al. 2011)

\begin{tabular}{|c|c|c|}
\hline Syndrome & Gene(s) & Relative risk for PDAC \\
\hline $\begin{array}{c}\text { Familial atypical multiple melanoma and mole } \\
\text { syndrome }\end{array}$ & CDKN2A/p16 & $20-34$ \\
\hline Peutz-Jeghers syndrome & LKB1 & $>100$ \\
\hline Hereditary Pancreatitis & PRSS1/SPINK1 & $\sim 90$ \\
\hline Familial Breast cancer & BRCA2 & $3-10$ \\
\hline
\end{tabular}

Various tumour suppressor genes have also been linked with PDAC development. Missense mutations in the DNA binding domain of P53, a tumour suppressor gene have been detected in $>50 \%$ of PDAC cases. They are also commonly found in the later stages of PanINs that already possess a significant feature of dysplasia (Bardeesy and DePinho 2002, Hezel et al. 2006). The LOH of CDKN2A (INK4A) gene through deletions or promoter hyper methylations are seen in about $80 \%-95 \%$ of PDAC cases (Hezel et al. 2006). LKB/STK11 another tumour suppressor gene is normally involved in cell polarity, and metabolism however, also seen to be associated with PDAC (Su et al. 1999). BRCA2 gene is yet another tumour suppressor gene found to be associated with PDAC, whose loss in normal cells leads to an accumulation of pro-carcinogenic chromosomal alterations (Venkitaraman 2002). A mutation del6174T in this gene is particularly common in familial pancreatic cancer patients that have descended from the Ashkenazi Jewish population (Goggins et al. 2000, Murphy et al. 2002). 
Introduction

\section{Apoptotic signaling pathways}

Recent studies have observed that $100 \%$ of pancreatic cancers possess alteration in apoptotic pathways. Anti-apoptotic proteins like the protein tyrosine phosphatase FAP-1 and cellular FLICE-inhibitory protein (cFLIP) when overexpressed in PDAC cells protect them from apoptosis (Elnemr et al. 2001). Two other anti-apoptotic proteins that belong to the BCL2-family members; BCL $L_{X L}$ and $M C L-1$ have been observed to be over expressed, and pro-apoptotic protein BAX shows reduced expression in $\sim 50 \%$ of PDAC cases (Evans et al. 2001, Magistrelli et al. 2006). Expression of decoy receptor 3 (that either lack or have an incomplete death domain which makes it impossible to induce apoptosis upon ligand binding in tumour cells could be another reason as it competes with the binding of FASL leading to the blocking of apoptosis initiation as they do not have an intact death domain (Elnemr et al. 2001).

\section{Growth factor receptor signaling}

Epidermal growth factor (EGF) receptors and ligands are over expressed in PDAC (Barton et al. 1991, Korc et al. 1992). Insulin-like growth factor (IGF) is over expressed in both tumour and stroma (Bergmann et al. 1995, Stoeltzing et al. 2003). Met is associated with metastasis in various cancers (Hezel et al. 2006) is expressed at low levels in the exocrine pancreas, but up-regulated in PanINs and PDACs. (Ebert et al. 1994, Di Renzo et al. 1995, Paciucci et al. 1998). Fibroblast growth factor (FGF) signaling has been observed to contribute to mitogenesis and angiogenesis in PDAC. Over expression of bFGF contributes particularly to desmoplasia in primary tumours (Wagner et al. 1998, Ogawa et al. 2002, Kleeff et al. 2004). Vascular endothelial growth factor (VEGF) is also overexpressed in PDAC. Blocking of this pathway suppresses tumourigenic growth in pancreatic cancer xenografts (Itakura et al. 1997, Seo et al. 2000).

\section{Telomere shortening and dysfunction}

Telomere loss contributes to high occurrence of PDAC in conditions like advanced age or inflammatory like hereditary pancreatitis as a function of epithelial turnover. In PanIN lesions shortened telomeres and anaphase bridging have been detected as an early genetic event (van Heek et al. 2002). 


\section{Progression from normal to dysplasia and PDAC}

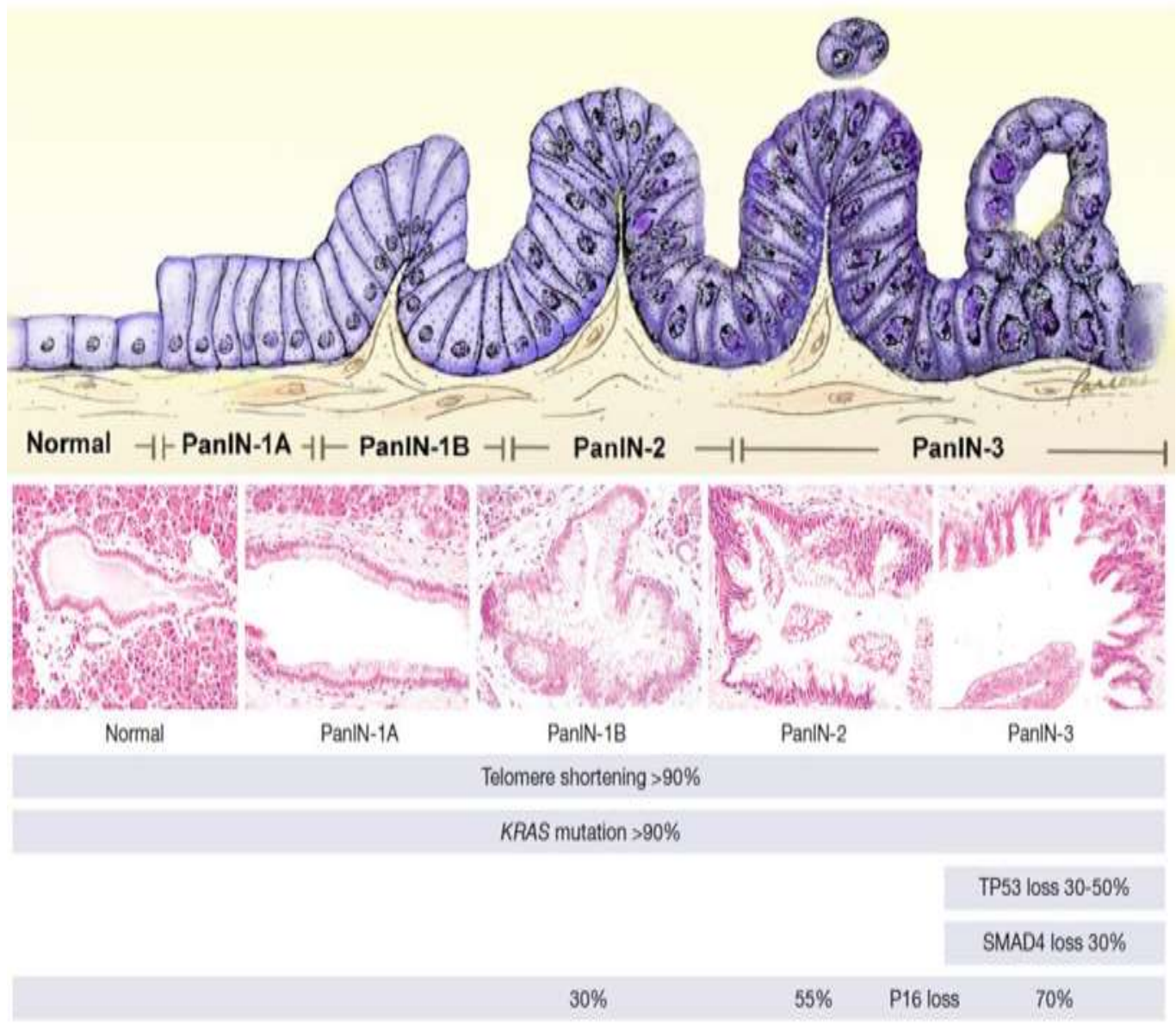

Figure 5: Progression model of PDAC: From normal epithelial to low-grade PanIN, and to High-grade PanIN accompanied by the various genetic alteration. (Adapted from (Muniraj et al. 2013, Brosens et al. 2015)

\section{Pancreatic intraepithelial neoplasias (PanIN) (carcinoma in situ)}

PanINs are important and well known precursors that are thought to be the origins of PDAC. They are characterized by small flat microscopic asymptomatic lesions measuring $<5 \mathrm{~mm}$ arising in small intralobular pancreatic ducts (Brosens et al. 2015), not invasive and not crossing the basement membrane. PanIN are grouped into three grades of dysplasia: PanIN-1A (flat epithelium); PanIN-1B (papillary or micro papillary architecture, with low grade dysplasia), PanIN-2 (papillary epithelium with intermediate grade dysplasia and mild to moderate cytological atypia), and PanIN-3 (papillary cells with high grade dysplasia and 
Introduction

severe cytological and architectural atypia). PanINs are encircled by lobular parenchymal atrophy that can be detected by endoscopy and could act as a potential biomarker in patients for high risk of PDAC (Hruban et al. 2004, Brosens et al. 2015). Early genetic alterations include telomere shortening, K-RAS activation, inactivation of various tumour suppressor genes like p53 and p16 (CDKN2A) (Distler et al. 2014).

\section{Treatment strategies in PDAC}

\section{Past and Present}

Gemcitabine has been known to be the keystone for the first-line therapy in PDAC treatment since 1997 as it showed clinical benefit. Prior to Gemcitabine, it was 5fluorouracil (5-FU) that was administered in different doses and combination regime for palliative treatment of advance PDAC. Cochrane systematic review showed that 5-FU based treatment significantly increased the 6 and 12 month survival compared to supportive care and significant clinical benefit (Yip et al. 2006). Conversely, a phase III study by Burris et al showed Gemcitabine to be better than 5-FU in regards to the clinical benefit response (CBR) and in the secondary endpoint overall survival. Additionally it also showed that the 6, 9- and 12- month survival rate was higher with Gemcitabine than with 5-FU(Burris et al. 1997). Efforts have been made to improve the efficacy of Gemcitabine in combination with a second agent for example Erlotinib (EGFR tyrosine kinase inhibitor) that ended in a statistically significant improvement in overall survival in inoperable PDAC cases (Moore et al. 2007). Louvet et al has shown that when Oxaliplatin was added to Gemcitabine there was improved response rate (ORR), progression-free survival (PFS) and CBR compared to single treatment. However, no statistical significance in OS was seen (Louvet et al. 2005). While the combination treatment with Gemcitabine and Capecitabine showed a significant improvement in ORR but no increase in OS (Cunningham et al. 2009).

FILFIRINOX treatment: Apart from Gemcitabine-based therapy, in the past few years a multi chemotherapy regimen FILFIRINOX has been employed as it was shown to have a significantly higher efficacy compared to standard single-agent Gemcitabine in a randomized multicenter phase II/III study (Conroy et al. 2011). This regimen included a combination of 4 drugs; Oxaliplatin (85 mg/m², 2 hour infusion), Leucovorin (calcium 
Introduction

folinate, $400 \mathrm{mg} / \mathrm{m}^{2}, 2$ hour infusion), irinotecan (180 mg/m², $90 \mathrm{~min}$ infusion), 5-FU (400 $\mathrm{mg} / \mathrm{m}^{2}$,bolus) followed by a 5 -FU ( $2400 \mathrm{mg} / \mathrm{m}^{2}$ infusion over 46 hours every 2 weeks). This study encompassed 342 patients with metastatic PDAC that were not treated with chemotherapy. In case of OS FOLFIRINOX group had 11.1 months as compared to Gemcitabine group with 6.8 months. And in case of median progression-free survival was 6.4 month in FOLFIRINOX group as compared to 3.3 months in Gemcitabine group. In $31 \%$ of patients there was deterioration in the quality of life at 6 months in FOLFIRINOX group when compared to $66 \%$ of patients in Gemcitabine group. Some reports have showed an increase in toxicity this included neutropenia, febrile neutropenia, thrombocytopenia, diarrhea and sensory neuropathy with this treatment regimen (Conroy et al. 2011).

Gemcitabine/NAB-Paclitaxel treatment: Nab-paclitaxel is a nanoparticle albumin-bound (nab) paclitaxel and it can be up taken by the cells that express SPARC (secreted protein acidic and rich cysteine)(Vaccaro et al. 2015). In a phase III trial that had 861 metastatic Pc patients that received randomly nab-Paclitaxel $\left(125 \mathrm{mg} / \mathrm{m}^{2}\right.$ plus Gemcitabine $\left(1000 \mathrm{mg} / \mathrm{m}^{2}\right)$ or single agent Gemcitabine $\left(1000 \mathrm{mg} / \mathrm{m}^{2}\right)$. Results indicated a significant improvement in OS with nab-Paclitaxel plus Gemcitabine when compared to Gemcitabine alone. Even the ORR was significantly higher compared to Gemcitabine alone. In spite of this having a clinical improvement in efficacy, there were adverse effects from this regimen including fatigue, alopecia, nausea, neutropenia (Vaccaro et al. 2015).

\section{Future}

The main therapeutic intervention in relation to PDAC has been limited in most cases to chemotherapy drugs. The only targeted drug being used in clinic is erlotinib but as mentioned before is also in combination with Gemcitabine. Recent clinical trials on novel therapy towards PDAC have been ongoing in various places. Many of these are maintenance therapies whose ultimate aim is to maintain the progress achieved by first line therapies such as Gemcitabine treatment and delay tumour recurrence which in turn will provide an increase in overall survival (Vaccaro et al. 2015). Reni et al documented a multicenter phase II study that encompassed 56 metastatic PDAC patients that were progression-free after 6 months from the start of first line chemotherapy, they were randomly administered with Sunitinib $(37,5 \mathrm{mg} / \mathrm{d})$ continuously, and observed a $20 \%$ 
Introduction

improvement in 6 month PFS. It was also observed that the number patients that were alive at two years tripled under the maintenance therapy with Sunitinib (Reni et al. 2013).

\section{Kv10.1 (Voltage gated potassium channel)}

Kv10.1 (Eag1, Ether-á-go-go) is a voltage-gated potassium channel first identified in Drosophila melanogaster. The mammalian homolog has three sub families; eag (Kv10.1 and $\mathrm{Kv10.2}$ ), erg (eag related gene) (Kv11.1, Kv11.2 and Kv11.3) and elk (eag-like $\mathrm{K}^{+}$ channel). Each of them has been shown to have diverse electrophysiological properties (Kaplan et al. 1969, Warmke et al. 1991).

Kv10.1 is mainly expressed in the brain among normal tissues at the transcript level. It is also expressed in myoblasts, placenta, testis and adrenal glands. Interestingly, it is aberrantly expressed in $>70 \%$ tumours from various origins. Recently, studies on the expression of Kv10.1 especially in Hela cells and mouse embryonic fibroblasts have shown that the expression is coupled to cell cycle specifically at the G2/M phase in both these cell types (Pardo et al. 1999, Urrego et al. 2016).

Molecular cloning studies suggested a structure made up of six putative transmembrane segments and a pore loop, which fits the basic frame of voltage-gated potassium channels.

Kv10.1 is encoded by the gene KCNH1 located on chromosome 1q32.1-32.3, consisting of 11 exons and large introns (Pardo et al. 1999). Various studies over the years have demonstrated the presence of alternatively spliced variants of Kv10.1, specifically in humans it is the E65 and E70 variants caused due to exon skipping (Pardo et al. 1999, Ramos Gomes et al. 2015). Kv10.1 induces malignant features including faster growth rate and loss of contact inhibition thereby promoting migration when overexpressed in cells in vitro (Pardo et al. 1998). On the contrary, antisense oligonucleotides or siRNA, or pharmacological inhibitors like imipramine, astemizole or quinidine that inhibit Kv10.1 expression or function result in a reduction in the rate of proliferation in vitro (OuadidAhidouch et al. 2001, Gavrilova-Ruch et al. 2002, Weber et al. 2006, Gomez-Varela et al. 2007, Ouadid-Ahidouch et al. 2008, Martinez et al. 2015). In vivo experiments have revealed that expression of the channel favors tumour growth in xenograft models in SCID 
Introduction

mice (Pardo et al. 1999, Downie et al. 2008). Similar to the in vitro studies, inhibiting the channel via the use of specific monoclonal antibody also demonstrate a reduction in the tumour growth in vivo (Gomez-Varela et al. 2007). Oral administration of astemizole a nonspecific blocker of the channel has also shown to have a negative effect on tumour progression and also a reduction of metastasis in lung carcinoma in vivo (Downie et al. 2008, Garcia-Quiroz et al. 2012, Martinez et al. 2015).

Kv10.1 plays an active role in tumour progression. In SHSY5Y cells, a commonly used neuroblastoma cell line, expression of Kv10.1 was shown to be indirectly controlled by p53 (Lin et al. 2011) through the E2F1 transcription factor, suggesting that p53 inactivation frequent in cancers could lead to the abundant expression of Kv10.1 seen in most tumours. Estrogen receptors (ER $\alpha$ ) and human papillomavirus (HPV) oncogenes (E6/E7) could also play a role in regulating the expression of Kv10.1. Estrogens upregulate Kv10.1 expression in a cell type dependent manner, and Kv10.1 is highly expressed in HPV oncogene expressing cells (cervical cancer cells and infected keratinocytes) when compared to normal keratinocytes (Diaz et al. 2009). HPV oncoproteins E6 and E7 have an effect on cell proliferation through $\mathrm{p} 53$ and $\mathrm{Rb}$ proteins respectively. It has been shown recently in primary keratinocytes, that targeting of the $\mathrm{p} 53$ and pRB by these oncoproteins leads to the enhanced expression of Kv10.1 at the transcript level (Urrego et al. 2016). Recent studies have also demonstrated that Kv10.1 is regulated by the pRB/E2F1 pathway in cell cycle progression specifically the $\mathrm{G} 2 / \mathrm{M}$ phase in various cells including cancer and normal proliferating cells (Urrego et al. 2016). In conclusion the voltage gated potassium channel Kv10.1 being expressed in most solid tumours including pancreatic cancer makes it not only a good tumour marker but also a potential therapeutic target. 
Introduction

\section{Apoptosis and cancer}

Programmed cell death or apoptosis occurs naturally in any multicellular organism as part of a normal physiology or as an anti-neoplastic mechanism in normal cells wherein, upon detection of alterations such as DNA damage, oncogene activation or cell cycle deregulation it induces programmed cell death so as to avoid the cell becoming tumourigenic (Hamacher et al. 2008). A major goal of cancer therapeutic research is to find a way to selectively kill cancer cells. Enormous work has been undertaken to discover a molecule that has an anti-cancer characteristic that will selectively induce apoptosis in cancer cells and not normal cells. Apoptosis is a cellular process that is characterized by distinct morphological characteristics as well as energy dependent biochemical mechanisms. The morphological features typically include cell shrinkage, chromatin condensation and cytoplasmic membrane blebbing whereas the biochemical changes include protein cleavage, protein cross linking and DNA breakdown (Hengartner 2000, Falschlehner et al. 2007, Prasad et al. 2014).

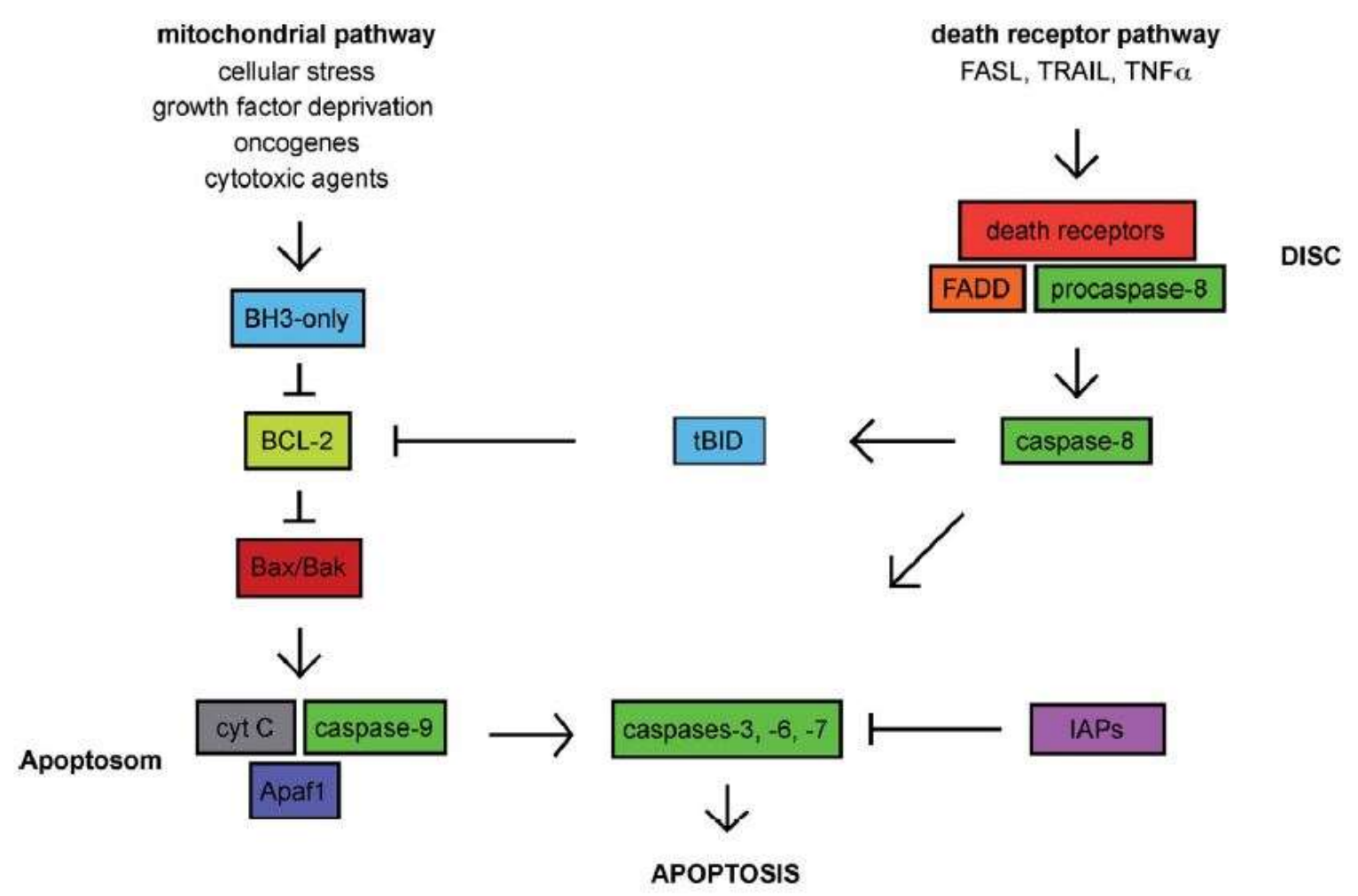

Figure 6: Apoptotic pathway: Intrinsic pathway (Mitochondrial pathway) and Extrinsic pathway (Death receptor pathway) (Adapted from (Hamacher et al. 2008). 
Introduction

Apoptosis can occur either through the extrinsic pathway, which is mediated via the tumour necrosis factor (TNF) receptor super family, or the intrinsic pathway, which involves the mitochondria and is initiated and regulated by the Bcl2-protein family. Both these pathway activate 'initiator caspases' which subsequently activate the 'effector caspases.

The extrinsic pathway is triggered by death receptors on the cell surface (DRs). They belong to the Tumour-Necrosis Factor (TNF) receptor superfamily and include TNF-, FAS (APO-1, CD-95) and TRAIL (TNF-related apoptosis inducing ligands) receptors. The caspase cascade is activated through the trimerization of death receptors that lead to formation of death-inducing signaling complex (DISC). Binding of a ligand to one of the receptors leads to the transmission of apoptotic signals via the recruitment of Fasassociated death domain protein (FADD), and activation of caspase-8 resulting in cleavage and activation of caspase-3, leading the cell to apoptosis.

The effector caspases once activated lead to the destruction of the protein scaffold and cell membrane by proteolytic cleavage. When the cleavage and inactivation of ICAD/DFF45 occurs by a caspase, it allows the caspase-activated DNase (CAD) to enter the nucleus and fragment the DNA leading to a DNA ladder characteristically seen in apoptotic cells (Widlak 2000).

\section{TRAIL}

TRAIL (TNF-related apoptosis inducing ligand) (Wiley et al. 1995, Pitti et al. 1996) is a cytokine involved in inflammation, apoptosis, proliferation, invasion, angiogenesis, metastasis and morphogenesis (Aggarwal et al. 2012). TRAIL is commonly expressed in immune cells where it plays a role in the homeostasis of T cells and in NK and T-cellmediated killing of transformed cells (Falschlehner et al. 2007). TRAIL is expressed in various tissues and cell types including thymus, lung, liver, placenta, ovary, heart, small and large intestine (Prasad et al. 2014). It is a 20kDa type II membrane glycoprotein, whose C terminus is proteolytically cleaved to give rise to soluble TRAIL. Both the full-length and soluble form of TRAIL can induce apoptosis in cancer cell lines (Trivedi et al. 2015).

TRAIL is unique in the TNF super family as it interacts with an intrinsic receptor system that consists of two agonistic or apoptosis-inducing receptors which contain an intracellular death domain (DD), DR4 (TNFRSF10a, TRAILR1) and DR5 (TNFRSF10b, TRAILR2). 
Introduction

(Falschlehner et al. 2007). Two anti-agonistic or decoy receptors DcR1 (no death domain) and DcR2 (truncated non-functional form of death domain) are also present; they not only fail to transmit apoptotic signal but also compete with the ligand-receptor binding complex thereby inhibiting TRAIL signaling. The fifth receptor is the soluble protein Osteoprotegrin (OPG) which has a low affinity towards binding to TRAIL (Trivedi and Mishra 2015).

\section{TRAIL death inducing signaling}

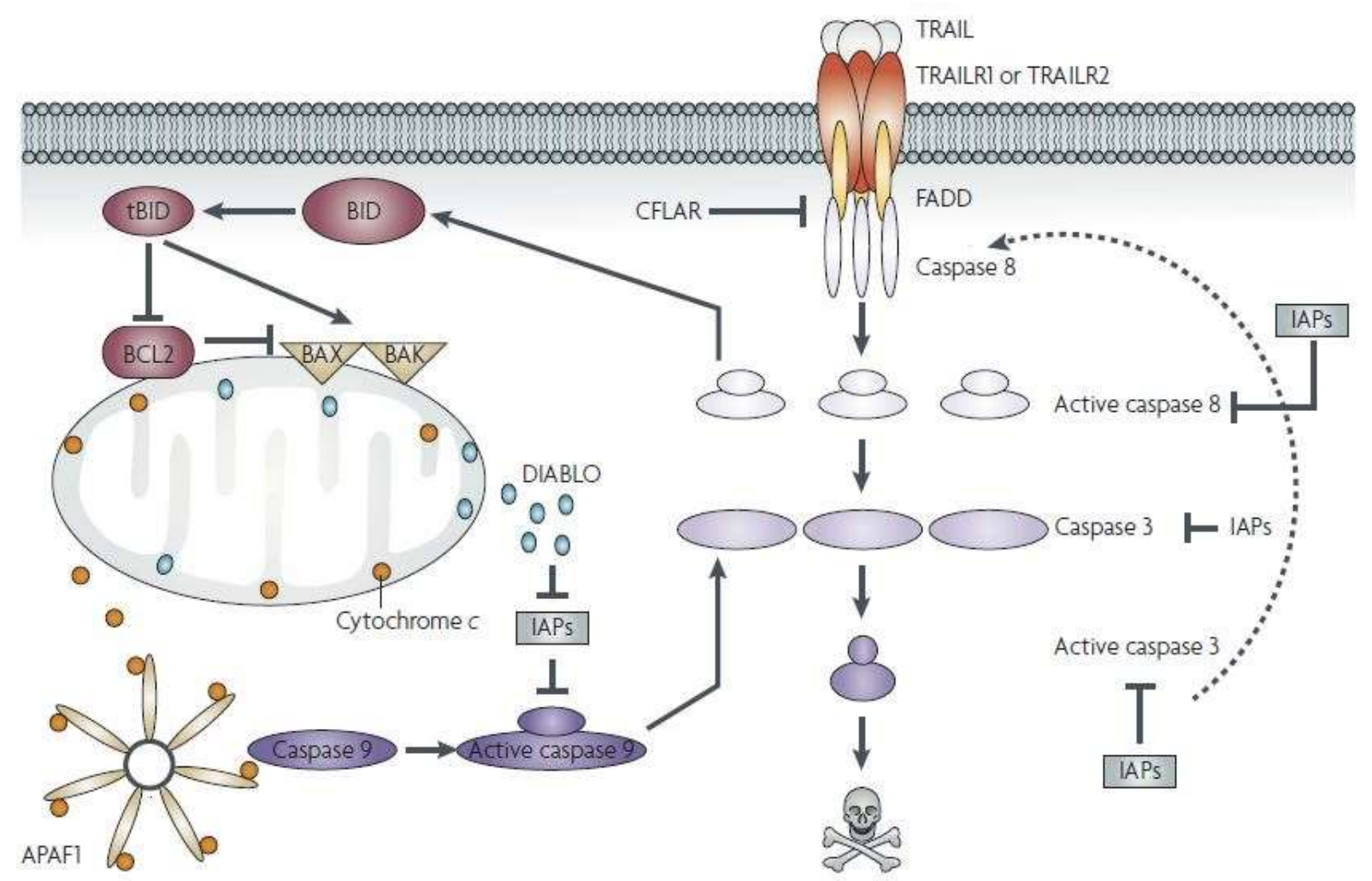

Figure 7 : Tumour Necrosis Factor (TNF) - related inducing ligand (TRAIL) apoptotic signaling pathway (Adapted from (Johnstone et al. 2008)

The activation of caspase-8 at the DISC results in the cleavage and autocatalytic activation of caspase-3 and $\mathrm{BH} 3$-only protein triggering caspase cascade and leading to apoptosis via extrinsic pathway (Jones et al. 2008). The activated and cleaved BID binds to BAX and BAK that results in mitrochondrial membrane permeabilization and releases cytochrome $\mathrm{C}$ protein and DIABLO. Cytochrome $\mathrm{c}$ and apoptotic protease-activating factor 1 (APAF1) and caspase- 9 combine with ATP to produce a functional apoptosome and cleave caspase- 9 
Introduction

which cleaves caspase-3 resulting in apoptosis. However, this activated caspase-3 also can cleave and activate caspase-8 resulting in more apoptotic signal (Jones et al. 2008).

\section{Non apoptotic TRAIL signaling}

Interestingly TRAIL signaling not only leads to the activation of initiator and effector caspases but also induces non-apoptotic pathways including activation of $\mathrm{NF}-\kappa \mathrm{B}$, and MAPKs thereby enhancing cell development and proliferation. It has been reported that both TRAIL R1 and R2 receptors can induce non-apoptotic signaling leading to survival, proliferation, invasion and metastasis (Falschlehner et al. 2007). NF-кB activation plays a role in innate and adaptive immunity, development, apoptosis and proliferation (Falschlehner et al. 2007). TRAIL activates NF-кB via TRAIL-R1 and TRAIL-R2 and TRAILR4 (Degli-Esposti et al. 1997, MacFarlane 2003). TRAIL-R1 and TRAIL-R2 has been shown to activate the protein kinase $B$ (PKB)/Akt and MAPK; when ERK is activated it leads to the suppression of TRAIL-mediated apoptosis and inhibits the activation of pro-caspase8 and Bid (Soderstrom et al. 2002, Tan et al. 2009).

\section{Bi-functional antibody specific to Kv10.1 fused to apoptosis inducing STRAIL}

It was Paul Ehrlich who depicted the future for antibodies as 'magic bullet' that would specifically kill microbes and tumour cells. Over the last 15 years several therapies involving antibodies have been established as successful strategies for treating patients with both hematological and solid tumours (Schrama et al. 2006). Single chain antibodies (scFv) have awakened interest because they are smaller in size and can penetrate faster and deeper into tumours, and are also less immunogenic compared to whole antibodies.

In a recent study a bi-functional antibody implementing Kv10.1 as a tumour marker fused to sTRAIL was designed, engineered and tested on prostate cancer models. The construct induced apoptosis in both Kv10.1-positive and neighboring Kv10.1-negative cells (bystander effect) and had no effect on surrounding normal prostate epithelial cells (Hartung et al. 2011). TRAIL signaling occurs through both DR4 and DR5, and which of the 
Introduction

two receptors is more relevant remains controversial as it appears to depend on the tumour type (Ichikawa et al. 2001, Almasan et al. 2003, Kelley et al. 2005, MacFarlane et al. 2005, Szegezdi et al. 2006). To broaden the spectrum of target tumours, it would be possible to generate a TRAIL variant capable of activating both DR4 and DR5 equally (Reis et al. 2009). Such a construct fused to a scFv against Kv10.1 has been used in this study. 


\section{AIM OF THE STUDY}

To investigate and characterize the functional role of Kv10.1 in PDAC and its possible use as therapeutic target with a bi-functional anti-Kv10.1 antibody fused to a TRAIL variant, alone or in combination with Gemcitabine. 


\section{MATERIALS}

Table 3. Cell culture

\begin{tabular}{|c|c|}
\hline Media and Reagents & Supplier \\
\hline $\begin{array}{c}\text { Dulbecco's Phosphate-Buffered } \\
\text { Saline (DPBS) }\end{array}$ & $\begin{array}{c}\text { ThermoFisher Scientific } \\
\text { Cat no 14190-094 }\end{array}$ \\
\hline Fetal bovine serum & $\begin{array}{c}\text { PAA } \\
\text { Cat no A15-151 }\end{array}$ \\
\hline Trypsin/EDTA & $\begin{array}{c}\text { Merck Biochrom } \\
\text { Cat no L2123 }\end{array}$ \\
\hline $\begin{array}{c}\text { DMEM/ F-12 (1:1) } \\
\text { GlutaMAX supplement }\end{array}$ & $\begin{array}{c}\text { ThermoFisher Scientific } \\
\text { Cat no 10565-018 }\end{array}$ \\
\hline $\begin{array}{c}\text { Iscove's Modified Dulbecco's } \\
\text { Media (IMDM) }(1 \mathrm{x}) \\
\text { GlutaMAX supplement }\end{array}$ & $\begin{array}{c}\text { ThermoFisher Scientific } \\
\text { Cat no } 31980-022\end{array}$ \\
\hline Panserin C6000 & $\begin{array}{c}\text { PAN Biotech } \\
\text { Cat no PO4-716000 }\end{array}$ \\
\hline OptiMEM & $\begin{array}{c}\text { ThermoFisher Scientific } \\
\text { Cat no 31985-070 }\end{array}$ \\
\hline Lipofectamine 2000 & $\begin{array}{c}\text { ThermoFisher Scientific } \\
\text { Cat no } 11668027\end{array}$ \\
\hline $\begin{array}{c}\text { Lipofectamine LTX and Plus } \\
\text { Reagent }\end{array}$ & $\begin{array}{c}\text { Invitrogen } \\
\text { Cat no 15338-100 }\end{array}$ \\
\hline Lenti-X P24Rapid titer kit & $\begin{array}{c}\text { Clontech } \\
\text { Cat no } 632200 \\
\end{array}$ \\
\hline Lenti-X packaging mix & $\begin{array}{c}\text { Clontech } \\
\text { Cat no } 631259\end{array}$ \\
\hline
\end{tabular}

\section{Table 4. Cell based assays I}

\begin{tabular}{|c|c|c|}
\hline kits and plates & Supplier & Purpose \\
\hline $\begin{array}{c}\text { CytoGLO Annexin V-FITC } \\
\text { Apoptosis Detection Kit }\end{array}$ & $\begin{array}{c}\text { Imgenex } \\
\text { Cat no 10085K }\end{array}$ & $\begin{array}{c}\text { Cell surface expression of } \\
\text { PS }\end{array}$ \\
\hline $\begin{array}{c}\text { Caspase 3/7 apoptosis } \\
\text { assay reagent (5mM) }\end{array}$ & $\begin{array}{c}\text { Essen Bioscience } \\
\text { Cat no 4440 }\end{array}$ & $\begin{array}{c}\text { Kinetic activation of } \\
\text { Caspase-3/7 }\end{array}$ \\
\hline $\begin{array}{c}\text { CellTox } \\
\text { TM Green Cytotoxicity Assay } \\
\text { Annexin V Green reagent }\end{array}$ & $\begin{array}{c}\text { Promega } \\
\text { Cat no G8741 }\end{array}$ & $\begin{array}{c}\text { Detrimental effect of the } \\
\text { compound }\end{array}$ \\
\hline Human IL-8 Chemiluminescent & Cat no 4642 & Cell surface expression of \\
ELISA & $\begin{array}{c}\text { Thermo scientific } \\
\text { Cat no 84774 }\end{array}$ & Secretion of IL-8 \\
\hline Assay & $\begin{array}{c}\text { Millipore } \\
\text { Cat no ECM555 }\end{array}$ & Invasion Assay \\
\hline $\begin{array}{c}\text { CytoSlect 24-well cell migration } \\
\text { assay(8 } \mu \text { m, Colorimetric Format) }\end{array}$ & $\begin{array}{c}\text { Cell biolabs } \\
\text { Cat no CBA-100-5 }\end{array}$ & Migration Assay \\
\hline $\begin{array}{c}\text { Ultra Low attachment multi well plates } \\
\text { Round bottomed plate (7007) }\end{array}$ & $\begin{array}{c}\text { Corning } \\
\text { Cat no CLS7007-24EA }\end{array}$ & 3D Cell culture \\
\hline
\end{tabular}


Table 5. Cell based assays II

\begin{tabular}{|c|c|}
\hline Agents & Supplier \\
\hline Gemcitabine & $\begin{array}{c}\text { Sigma } \\
\text { Cat no G6423-10MG }\end{array}$ \\
\hline $\begin{array}{c}\text { TRAIL, Recombinant, Human } \\
\text { (TNF-Related Apoptosis inducing ligand) }\end{array}$ & $\begin{array}{l}\text { US Biological life sciences } \\
\text { Cat no T8180-08A }\end{array}$ \\
\hline Z-VAD-FMK (General caspase Inhibitor) & $\begin{array}{c}\text { R\&D systems } \\
\text { Cat no FMK001 } \\
\end{array}$ \\
\hline Astemizole & $\begin{array}{c}\text { Tocris } \\
\text { Cat no } 3489 \\
\end{array}$ \\
\hline G418 & $\begin{array}{c}\text { Gibco } \\
\text { Cat no 11811-031 }\end{array}$ \\
\hline Puromycin & $\begin{array}{c}\text { ThermoFisher Scientific } \\
\text { Cat no A11138-03 }\end{array}$ \\
\hline Zeocin & $\begin{array}{c}\text { InvivoGen } \\
\text { Cat no ant-zn }\end{array}$ \\
\hline Matrigel basement membrane mix & $\begin{array}{c}\text { Corning } \\
\text { Cat no } 4272006\end{array}$ \\
\hline
\end{tabular}

Table 6. Molecular biology I

\begin{tabular}{|c|c|}
\hline Kits and Reagents & Supplier \\
\hline Pierce BCA Protein Assay Kit & $\begin{array}{l}\text { ThermoFisher Scientific } \\
\text { Cat no } 23225\end{array}$ \\
\hline BSA & $\begin{array}{c}\text { Sigma } \\
\text { Cat no A9418-100MG }\end{array}$ \\
\hline Non Fat Dry Milk & $\begin{array}{c}\text { BIO RAD } \\
\text { Cat no 170-6404 }\end{array}$ \\
\hline $\begin{array}{l}\text { cOmplete, ULTRA, Mini, EDTA free, EASYpack } \\
\text { Protease inhibitor cocktail tablets }\end{array}$ & $\begin{array}{c}\text { Roche } \\
\text { Cat no } 05892791001\end{array}$ \\
\hline $\begin{array}{c}\text { Prestained Protein Ladder, Broad Range } \\
(10-230 \mathrm{KDa})\end{array}$ & $\begin{array}{l}\text { New England BioLabs } \\
\text { Cat no P7710S }\end{array}$ \\
\hline $\begin{array}{c}\text { NuPAGE Novex } 4 \%-12 \% \text { Bis-Tris Protein Gel } \\
1.5 \mathrm{~mm}, 10 \text { well }\end{array}$ & $\begin{array}{l}\text { ThermoFisher Scientific } \\
\text { Cat no NP0335BOX }\end{array}$ \\
\hline NuPAGE Sample reducing agent (10x) & $\begin{array}{l}\text { Novex by Life technologies } \\
\text { Cat no NP0009 }\end{array}$ \\
\hline NuPAGE LDS sample buffer (4x) & $\begin{array}{l}\text { Novex by Life technologies } \\
\text { Cat no NP0007 }\end{array}$ \\
\hline NuPAGE MOPS SDS running buffer (20x) & $\begin{array}{l}\text { Novex by Life technologies } \\
\text { Cat no NP0001 }\end{array}$ \\
\hline $\begin{array}{c}\text { Nitrocellulose Pre-Cut blotting Membrane } \\
0.2 \mu \mathrm{m} \text { pore size }\end{array}$ & $\begin{array}{l}\text { ThermoFisher Scientific } \\
\text { Cat no LC2000 }\end{array}$ \\
\hline $\begin{array}{c}\text { Amersham Protran supported } \\
0.45 \mathrm{~mm} \mathrm{NC}\end{array}$ & $\begin{array}{l}\text { GE Healthcare life science } \\
\text { Cat no } 10600016\end{array}$ \\
\hline Quentix Western Blot Signal Enhancer Kit & $\begin{array}{l}\text { ThermoFisher Scientific } \\
\text { cat no } 21050\end{array}$ \\
\hline Western blocking reagent & $\begin{array}{c}\text { Roche } \\
\text { cat no } 11921681001\end{array}$ \\
\hline Pierce ECL Western blotting substrate & $\begin{array}{c}\text { ThermoFisher Scientific } \\
\text { cat no } 32106 \\
\end{array}$ \\
\hline
\end{tabular}


Table 7. Molecular biology II

\begin{tabular}{|c|c|c|}
\hline Antibody & Dilution & Supplier \\
\hline Cleaved caspase-3 (Asp175) & $1: 1000$ & $\begin{array}{l}\text { Cell signaling } \\
\text { Cat no } 9661\end{array}$ \\
\hline $\operatorname{Actin}(\mathrm{C}-11)$ & $1: 1000$ & $\begin{array}{l}\text { Santa Cruz } \\
\text { Cat no1615 }\end{array}$ \\
\hline $\begin{array}{l}\text { Rabbit Anti Goat IgG } \\
(\mathrm{H}+\mathrm{L})+\mathrm{HRP} \text { Conjugate }\end{array}$ & $1: 1000$ & $\begin{array}{c}\text { BioRad } \\
\text { Cat no 172-1034 }\end{array}$ \\
\hline 9391 (polyclonal antibody Kv10.1) & $\begin{array}{l}1: 1500 \\
1: 2000\end{array}$ & $\begin{array}{l}\text { L.A. Pardo; (Napp et al., } \\
\text { 2005) }\end{array}$ \\
\hline $\begin{array}{l}\text { Anti-Glyceraldehyde-3-Phosphate } \\
\text { Dehydrogenase, Clone 6C5 }\end{array}$ & $1: 100$ & $\begin{array}{c}\text { Millipore } \\
\text { cat no MAB374 }\end{array}$ \\
\hline $\begin{array}{l}\text { Amersham ECL Anti-rabbit IgG, } \\
\text { Horseradish peroxidase-linked species- } \\
\text { specific whole antibody (from Donkey) }\end{array}$ & $\begin{array}{l}1: 1000 \\
1: 2000\end{array}$ & $\begin{array}{c}\text { GE Healthcare life science } \\
\text { Cat no NA934 }\end{array}$ \\
\hline $\begin{array}{l}\text { Amersham ECL Anti-mouse lgG, } \\
\text { Horseradish peroxidase-linked species- } \\
\text { specific whole antibody (from Sheep) }\end{array}$ & $1: 10000$ & $\begin{array}{l}\text { GE Healthcare life science } \\
\text { Cat no NA931 }\end{array}$ \\
\hline $\begin{array}{l}\text { Monoclonal anti-alpha Tubulin } \\
\text { clone DM1Av }\end{array}$ & $1: 1000$ & $\begin{array}{l}\text { Sigma Aldrich } \\
\text { cat no T9026 }\end{array}$ \\
\hline $\begin{array}{l}\text { Goat anti-Mouse lgG1 Secondary } \\
\text { Antibody, Alexa Fluor } 488 \text { conjugate }\end{array}$ & $1: 1000$ & $\begin{array}{l}\text { Thermo scientific } \\
\text { Cat no A-21121 }\end{array}$ \\
\hline
\end{tabular}

Table 8. Kits and reagents

\begin{tabular}{|c|c|}
\hline Reagents & Supplier \\
\hline NucleoBond Xtra Midi EF & $\begin{array}{l}\text { Macherey Nagel } \\
\text { Cat no } 740420.50\end{array}$ \\
\hline Taq DNA polymerase with ThermoPol Buffer & $\begin{array}{c}\text { New England Biolabs } \\
\text { Cat no M0267S }\end{array}$ \\
\hline RNeasy Mini Kit & $\begin{array}{c}\text { Qiagen } \\
\text { Cat no 74106 }\end{array}$ \\
\hline RNase-Free DNase set & $\begin{array}{c}\text { Qiagen } \\
\text { Cat no } 79254\end{array}$ \\
\hline SuperScript First-Strand Synthesis System & $\begin{array}{c}\text { Invitrogen } \\
\text { Cat no 18080-051 }\end{array}$ \\
\hline Ribonuclease $\mathrm{H}$ & $\begin{array}{c}\text { Invitrogen } \\
\text { Cat no 18021-071 }\end{array}$ \\
\hline Deoxynucleotide (dNTP) Solution mix & $\begin{array}{c}\text { BioLabs } \\
\text { Cat no N0447S }\end{array}$ \\
\hline SuperScript II Reverse Transcriptase & $\begin{array}{c}\text { Invitrogen } \\
\text { Cat no 18064-022 }\end{array}$ \\
\hline $1 \mathrm{~kb}$ DNA Ladder & $\begin{array}{c}\text { BioLabs } \\
\text { Cat no N3232S }\end{array}$ \\
\hline TaqMan PCR Reagent Kit & Applied Biosystems \\
\hline QuikChange Site-Directed Mutagenesis Kit & $\begin{array}{c}\text { Stratagene } \\
\text { Cat no } 200518\end{array}$ \\
\hline Human TRAIL/TNFSF10 Immunoassay & $\begin{array}{c}\text { Quantikine ELISA } \\
\text { Cat no DTRL00 }\end{array}$ \\
\hline
\end{tabular}


Table 9. Primer (Nested PCR)

\begin{tabular}{|l|l|}
\hline \multicolumn{1}{|c|}{ Primer name } & \multicolumn{1}{c|}{ Sequence (5'-3') } \\
\hline $\mathrm{K}_{\mathrm{v}} 10.1$ External Forward & TGT TCG GCG GTC CAA TGA TAC TAA \\
\hline $\mathrm{K}_{\mathrm{v}} 10.1$ External Reverse & TCC CGG CCC CCT CTC TCA \\
\hline $\mathrm{K}_{\mathrm{v}} 10.1$ Internal Forward & TTG GGG AAT GCT CAG ATA GTG G \\
\hline $\mathrm{K}_{\mathrm{v}} 10.1$ Internal Reverse & GGC CTC ATT CTT TCG TTT CAT \\
\hline
\end{tabular}

Table 10. UPL Probes (Real-time PCR)

\begin{tabular}{|c|c|c|}
\hline ID & $5^{\prime}$-Sequence-3' & Gene \\
\hline $\mathrm{F}$ & $5^{\prime}$-TTG AGA AAA CAA TGC AAA ATG TG-3' & \multirow{3}{*}{$\begin{array}{l}\text { Human transferrin receptor } \\
\text { (TFRC) }\end{array}$} \\
\hline $\mathrm{R}$ & 5'- CCC AGT TGC TGT CCT GAT ATA GA-3' & \\
\hline UPL & 5'-FAM- CTG GGC AA -Dark Quencher Dye-3' & \\
\hline $\mathrm{F}$ & 5'-TGA GGT GGT GGC CAT TCT A -3' & \multirow{3}{*}{ Human Kv10.1 (KCNH1) } \\
\hline $\bar{R}$ & $5^{\prime}$ - GGC CCT AAC ATT GGC ACA -3' & \\
\hline UPL & 5'-FAM- TTG CCC AG -Dark Quencher Dye-3' & \\
\hline $\mathrm{F}$ & 5'-GGG TCC ACA AGA CCT TCA AGT-3' & \multirow{3}{*}{$\begin{array}{c}\text { Human TRAIL receptor } 1 \\
\text { (TNFRSF10A) }\end{array}$} \\
\hline $\mathrm{R}$ & $5^{\prime}$ - TGC AGC TGA GCT AGG TAC GA-3 & \\
\hline UPL & 5'-FAM- TCC TGC TG -Dark Quencher Dye-3' & \\
\hline $\mathrm{F}$ & 5'-AGA CCC TTG TGC TCG TTG TC -3' & \multirow{3}{*}{$\begin{array}{c}\text { Human TRAIL receptor } 2 \\
\text { (TNFRSF1OB) }\end{array}$} \\
\hline $\mathrm{R}$ & 5'- TTG TTG GGT GAT CAG AGC AG -3' & \\
\hline UPL & 5'-FAM- TCC TGC TG -Dark Quencher Dye-3' & \\
\hline $\mathrm{F}$ & $5^{\prime}$-TTG AGA AAA CAA TGC AAA ATG TG-3' & \multirow{3}{*}{ Human TRAIL 3 (TNFRSF10C) } \\
\hline $\mathrm{R}$ & 5'- CCC AGT TGC TGT CCT GAT ATA GA-3' & \\
\hline UPL & 5'-FAM- CTG GGC AA -Dark Quencher Dye-3' & \\
\hline $\mathrm{F}$ & 5'-TGA GGT GGT GGC CAT TCT A -3' & \multirow{3}{*}{ Human TRAIL 4 (TNFRSF10D) } \\
\hline $\mathrm{R}$ & $5^{\prime}-$ GGC CCT AAC ATT GGC ACA -3' & \\
\hline$\overline{\mathrm{UPL}}$ & $5^{\prime}$-FAM- TTG CCC AG -Dark Quencher Dye-3' & \\
\hline
\end{tabular}

Table 11. Taqman Probes (Real-time PCR)

\begin{tabular}{|c|c|c|}
\hline & 5'-Sequence-3' & Gene \\
\hline $\mathrm{F}$ & $5^{\prime}$-TCT GTC CTG TTT GCC ATA TGA TGT-3' & \multirow{3}{*}{ Human Kv10.1 $(\mathrm{KCNH} 1)$} \\
\hline $\mathrm{R}$ & $5^{\prime}-$ CGG AGC AGC CGG ACA -3' & \\
\hline Taq & $\begin{array}{c}\text { 5'-FAM AAC GTG GAT GAG GGC ATC AGC } \\
\text { AGC CT- Tamra-3' }\end{array}$ & \\
\hline $\mathrm{F}$ & 5'-GAC TTT GGA TCG GTT GGT GC-'3 & \multirow{3}{*}{$\begin{array}{l}\text { Human transferrin receptor } \\
\text { (TFRC) }\end{array}$} \\
\hline $\mathrm{R}$ & 5'-CCA AGA ACC GCT TTA TCC AGA T-'3 & \\
\hline Taq & $\begin{array}{l}\text { 5'-JOE-TGA ATG GCT AGA GGG A-Tamra dT- } \\
\text { ACC TT CGT CCC-'3 }\end{array}$ & \\
\hline
\end{tabular}


Table 12. Probes for site-directed mutagenesis

\begin{tabular}{|c|c|}
\hline Primer & Sequence \\
\hline Forward & CATAACTGGGACCAGAAAGAGAAGCAACACATTGTC \\
\hline Reverse & GACAATGTGTTGCTTCTCTTTCTGGTCCCAGTTATG \\
\hline
\end{tabular}

Table 13. Equipment

\begin{tabular}{|c|c|}
\hline Equipment & Supplier \\
\hline Microscope Axiovert 100 & Carl Zeiss \\
\hline Megafuge 1.0 & Heraeus Sepatech \\
\hline Centrifuge 5415D (Table-centrifuge) & Eppendorf \\
\hline Centrifuge 5402 (Cooling-centrifuge) & Eppendorf \\
\hline${\text { Victor }{ }^{2} \text { 1420 Multilabel counter }}^{\text {Mastercycler gradient }}$ & Wallac \\
\hline Thermomixer comfort & Eppendorf \\
\hline NuPAGE Bis-Tris Electrophoresis System & Eppendorf \\
\hline Incubator & Invitrogen \\
\hline FACSaria cytometer & Heraeus instruments \\
\hline Spectrophotometer & BD Bioscience \\
\hline pH meter & Implen \\
\hline ChemiDoc XRS system & Knick, pH-Meter 766 Calimatic \\
\hline GelDoc & BioRAD \\
\hline LightCycler 480 Real-Time PCR System & Roche \\
\hline Water Purification System & Sartorius \\
\hline IncuCyte ZOOM system & Essen Biosciences \\
\hline
\end{tabular}




\section{METHODS}

\subsection{Cell culture}

\subsection{Cell lines}

PDAC cell lines were obtained from ATCC. Capan-1(HTB-79) cells were grown in $\operatorname{IMDM}(1 \mathrm{x})+$ GlutaMAX (GIBCO/Invitrogen) medium supplemented with $20 \%$ FCS (PAA Gold). AsPC-1(CRL 1682) and BxPC-3 (CRL-1687) in RPMl-1640 (GIBCO/Invitrogen) medium supplemented with 10\% FCS (PAA Gold). MIA PaCa-2 (CRL 1420) in DMEM/F12 (1:1)(1x) GlutaMAX medium supplemented with 10\% FCS (PAA Gold) and 2.5\% horse serum: PANC-1(CRL1469) in GlutaMAX medium supplemented with 10\% FCS (PAA Gold).

Immortalized pancreatic stellate cells RLT-PSC were generously provided by Dr. Ralf Jesnowski. These cells were grown in DMEM/F12 (1:1)(1x) GlutaMAX medium supplemented with 10\% FCS (PAA Gold).

CHO-K1 (Chinese hamster ovary) cells (ACC 110) were obtained from DSMZ and grown in Ham's F-12 (GIBCO/Invitrogen) medium supplemented with 10\% FCS (PAA Gold).

Cells were cultured in $5 \% \mathrm{CO}_{2}$ and a humidified atmosphere at $37{ }^{\circ} \mathrm{C}$. For sub culturing the cells were washed with Dulbecco's phosphate buffered saline (DPBS, GIBCO/Invitrogen), after which they were incubated with Trypsin/EDTA (0.05\%/0.02\% $\mathrm{W} / \mathrm{V}$, Biochrom) in PBS for $4 \mathrm{~min}$ at $37^{\circ} \mathrm{C}$. Once the cells were detached the enzymatic reaction was stopped by addition of culture medium supplemented with FCS. The detached cells were collected in a $15 \mathrm{ml}$ falcon tube with fresh pre-warmed medium and washed at $235 \times \mathrm{g}$ for $2 \mathrm{~min}$. The pellet of cells was further re-suspended in fresh prewarmed complete medium. 
Materials and Methods

\subsection{Cell counting}

This was performed using a mixture of cell suspension and trypan blue ( $0.4 \%$ solution). The cells were counted on a Neubauer counting chamber under light microscope.

\subsection{Cryopreservation and storage of cell lines}

The freezing medium contained $40 \%$ medium, 50\% FCS, and 10\% DMSO. Cells were pelleted, re-suspended in freezing medium and frozen in $1 \mathrm{ml}$ aliquots containing $1 \times 10^{6}$ $-2 \times 10^{6}$ cells per cryotube. Cryotubes were then placed at $-80^{\circ} \mathrm{C}$ in a container filled with isopropanol to ensure a constant decrease in the temperature at a rate of $1{ }^{\circ} \mathrm{C}$ per minute. The cryotubes were stored in liquid nitrogen.

\subsection{Thawing of cell lines}

As the frozen cells were in DMSO, which is toxic to the cell, thawing was done as quickly as possible. The frozen vials of cells were thawed in a water bath at $37{ }^{\circ} \mathrm{C}$ for approximately one min. The suspension of cells was pipetted into a $30 \mathrm{ml}$ tube containing $10 \mathrm{ml}$ pre-warmed medium and centrifuged at $235 \times \mathrm{g}$ for $2 \mathrm{~min}$. The supernatant was aspirated and the pellet was re-suspended in fresh medium supplemented with FCS and plated into a culture flask. The flask was then placed in the incubator for 24 hours after which the medium was changed.

\subsection{RNA isolation}

RNeasy Mini Kit (Qiagen) was used to isolate RNA. Briefly, cells were lysed in the presence of guanidine thiocyanate-containing buffer, which inactivates RNases and thus assures the integrity of the purified RNA. The lysate was transferred into QIAshredder spin column (Qiagen) and centrifuged at $16100 \mathrm{xg}$ for 2 minutes to shear genomic DNA and reduce viscosity. The homogenized lysate was mixed in a 1:1 proportion with $70 \%$ ethanol and then transferred into the RNeasy mini column (Qiagen), followed by centrifugation at $8000 \mathrm{xg}$ for $50 \mathrm{~s}$. DNase digestion was 
performed using the RNase-free DNase Set (Qiagen) to remove the DNA in the ratio of $20 \mu \mathrm{L}$ of DNase and $140 \mu \mathrm{L}$ of RDD buffer (undisclosed composition; used to optimize on column DNase digestion) per column and incubated for 30 minutes at room temperature. It was then washed twice (500 $\mu \mathrm{L} /$ wash) with buffer RPE (proprietary composition; a mild wash buffer) and centrifuged at $8000 \times g$ for $50 \mathrm{~s}$ to remove contaminants. Finally, the RNA was eluted from the silica membrane by adding RNase free water followed by centrifugation. The purified RNA samples were stored at $-80^{\circ} \mathrm{C}$ until use.

\section{1 cDNA Preparation}

The reverse transcription of total mRNA was performed using SuperScript III Firststrand synthesis system (Invitrogen). Retro transcription was carried out by mixing 2.5 $\mu \mathrm{g}$ of total mRNA, $12 \mu \mathrm{L}$ of RNase-free water, and $1 \mu \mathrm{L}$ of $50 \mu \mathrm{M}$ oligo (dT), and incubating at $70^{\circ} \mathrm{C}$ for $10 \mathrm{~min}$. The mixture was placed on ice for $1 \mathrm{~min}$ to allow primer annealing, and the RNA-primer mix was adjusted to $20 \mu \mathrm{L}$ final volume for the cDNA synthesis, containing 1x RT (reverse transcriptase) buffer, $2.5 \mathrm{mM} \mathrm{MgCl}_{2}, 10 \mathrm{mM}$ DTT, $0.5 \mathrm{mM}$ dNTP mix and $10 \mathrm{U} / \mu \mathrm{L}$ SuperScript III RT. The mixture was incubated at $42^{\circ} \mathrm{C}$ for $50 \mathrm{~min}$, followed by $15 \mathrm{~min}$ incubation at $70^{\circ} \mathrm{C}$ to stop the reaction. Afterwards, $1 \mu \mathrm{L}$ RNase $\mathrm{H}(2 \mathrm{U} / \mu \mathrm{L})$ was added to the mixture and incubated at $37^{\circ} \mathrm{C}$ for 20 min to eliminate any trace amounts of RNA. Finally, the cDNA volume was made up to $25 \mu \mathrm{L}$ with water to get a final concentration of $0.1 \mu \mathrm{g} / \mu \mathrm{L}$.

\subsection{Polymerase chain reaction}

PCR reactions were performed using $10 \mathrm{ng}$ template plasmidic DNA (or $100 \mathrm{ng}$ first strand cDNA), $2.5 \mu \mathrm{L} 10 \mathrm{X}$ reaction buffer (containing $20 \mathrm{mM}$ Tris- $\mathrm{HCl}, 10 \mathrm{mM}$ $\left(\mathrm{NH}_{4}\right)_{2} \mathrm{SO}_{4}, 10 \mathrm{mM} \mathrm{KCl}, 2 \mathrm{mM} \mathrm{MgSO}{ }_{4}, 0.1 \%$ Triton $\mathrm{X}-100, \mathrm{pH}$ 8.8; from New England Biolabs), $200 \mu \mathrm{M}$ dNTP mix (New England Biolabs), $0.2 \mu \mathrm{M}$ of specific primers (synthesized by Sigma), 1.2 U of Taq DNA polymerase (New England Biolabs) and sterile $\mathrm{H}_{2} \mathrm{O}$ to make a final volume of $25 \mu \mathrm{L}$. The thermocycler (Mastercycler, Eppendorf) was set up using the following amplification program: 


\begin{tabular}{|l|l|l|l|}
\hline Segments & Cycles & Temperature & Time \\
\hline 1 & 20 & $95^{\circ} \mathrm{C}$ & $3 \mathrm{~min}$ \\
\hline & & $95^{\circ} \mathrm{C}$ & $30 \mathrm{sec}$ \\
\hline & & $69^{\circ} \mathrm{C}$ & $1 \mathrm{~min}$ \\
\hline & & $72^{\circ} \mathrm{C}$ & $3 \mathrm{~min}$ \\
\hline
\end{tabular}

Nested PCR reactions were performed using $150 \mathrm{ng}$ first strand CDNA, $2.5 \mu \mathrm{L} 10 \mathrm{X}$ reaction buffer (containing $20 \mathrm{mM}$ Tris- $\mathrm{HCl}, 10 \mathrm{mM}\left(\mathrm{NH}_{4}\right)_{2} \mathrm{SO}_{4}, 10 \mathrm{mM} \mathrm{KCl}, 2 \mathrm{mM} \mathrm{MgSO}_{4}$, $0.1 \%$ Triton X-100, pH 8.8), 200 $\mu \mathrm{M}$ dNTP mix, $0.2 \mu \mathrm{M}$ of each specific primer (Ref Table 6), $1.2 \mathrm{U}$ of Taq DNA polymerase and sterile $\mathrm{H}_{2} \mathrm{O}$, up to $25 \mu \mathrm{L}$ final volume. $1 \mu \mathrm{L}$ of the first PCR product as template for the second round of PCR was used. The second PCR was carried out using the following amplification program:

\begin{tabular}{|l|l|l|l|}
\hline Segments & Cycles & Temperature & Time \\
\hline 1 & 35 & $95^{\circ} \mathrm{C}$ & $3 \mathrm{~min}$ \\
\hline & & $95^{\circ} \mathrm{C}$ & $30 \mathrm{sec}$ \\
\hline & & $65^{\circ} \mathrm{C}$ & $2 \mathrm{~min}$ \\
\hline & & $72^{\circ} \mathrm{C}$ & $3 \mathrm{~min}$ \\
\hline
\end{tabular}

The amplification products were loaded on a $1.2 \%$ agarose gel containing $5 \mu \mathrm{L}$ (for each $100 \mathrm{ml}$ gel volume) Serva DNA stain G (SERVA). Electrophoresis was performed at $100 \mathrm{~V}$ for $\sim 40 \mathrm{~min}$; the electrophoretic mobility was visualized with UV light.

\subsection{Quantitative real time PCR}

TaqMan assay (fluorescent donor: quencher hybridization)

Gene expression in Capan-1, BxPC-3 and RLT-PSC were assessed by quantitative real-time PCR (qRT-PCR). qRT-PCR was performed using specific TaqMan sets in a Light Cycler 480 (Roche Applied Science) detection system. For the qRT-PCR reaction, $2 \mu \mathrm{L}$ of cDNA was mixed with $1 \mu \mathrm{L}$ of $100 \mu \mathrm{M}$ primer mix, $0.1 \mu \mathrm{L}$ of $10 \mu \mathrm{M}$ Universal Probe Library probe (Roche), and $0.1 \mu \mathrm{L}$ Uracil-DNA-glycosylase $2 \mathrm{U} / \mu \mathrm{L}$ (New England BioLabs). Afterwards, $5 \mu \mathrm{L}$ of ready-to-use hot-start PCR mix (Roche) containing FastStart Taq DNA Polymerase reaction buffer, and dNTPmix were added.

LightCycler 480 (Roche Applied Science) detection system was programmed 
Taqman probes

\begin{tabular}{|l|l|l|l|}
\hline Segments & Cycles & Temperature & Time \\
\hline 1 & & $50^{\circ} \mathrm{C}$ & $2 \mathrm{~min}$ \\
\hline \multirow{3}{*}{50} & $95^{\circ} \mathrm{C}$ & $10 \mathrm{~min}$ \\
\hline \multirow{3}{*}{50} & $95^{\circ} \mathrm{C}$ & $10 \mathrm{seC}$ \\
\cline { 3 - 4 } & & $56^{\circ} \mathrm{C}$ & $1 \mathrm{~min}$ \\
\cline { 3 - 4 } & & $60^{\circ} \mathrm{C}$ & $1 \mathrm{~min}$ \\
\hline \multirow{2}{*}{} & & $40^{\circ} \mathrm{C}$ & $30 \mathrm{sec}$ \\
\hline & & \multicolumn{2}{|l}{} \\
\hline
\end{tabular}

UPL probes

\begin{tabular}{|l|l|l|l|}
\hline Segments & Cycles & Temperature & Time \\
\hline 1 & & $50^{\circ} \mathrm{C}$ & $2 \mathrm{~min}$ \\
\hline & & $95^{\circ} \mathrm{C}$ & $10 \mathrm{~min}$ \\
\hline \multirow{2}{*}{4} & $95^{\circ} \mathrm{C}$ & $10 \mathrm{seC}$ \\
\cline { 1 - 1 } & & $60^{\circ} \mathrm{C}$ & $30 \mathrm{seC}$ \\
\hline \multirow{2}{*}{4} & & $40^{\circ} \mathrm{C}$ & $10 \mathrm{sec}$ \\
\hline
\end{tabular}

Relative quantification of the samples and human calibrator was done using the $\Delta \Delta \mathrm{Ct}$ method (Livak \& Schmittgen, 2001); the human housekeeping gene transferrin receptor was used for normalization.

\subsection{Site-directed mutagenesis}

The Quick-change site-directed Mutagenesis Kit (Stratagene) was used to create point mutations in pSecTagscFv62-TRAIL plasmid (provided by Dr. Franziska Hartung) with the primer set (refer Table 12). The site-directed mutagenesis method was performed with complementary primers containing the mutation and the PfuTurbo polymerase. During temperature cycling the oligonucleotides generate the mutated plasmid. Dpnl is used to digest the methylated parental DNA template and to select for mutationcontaining synthesized plasmid. The digested DNA was then transformed into E.coli XL1-Blue cells (see below).

QuikChange mutagenesis PCR $(50 \mu \mathrm{L})$ reaction consisted of $5 \mu \mathrm{L} 10 \mathrm{x}$ reaction buffer, 100ng DNA, $125 \mathrm{ng}$ forward primer, $125 \mathrm{ng}$ reverse primer, $1 \mu \mathrm{L}$ of dNTP mix and $\mathrm{H}_{2} \mathrm{O}$ 


\begin{tabular}{|l|l|l|l|}
\hline Segments & Cycles & Temperature & Time \\
\hline 1 & 1 & $95^{\circ} \mathrm{C}$ & $30 \mathrm{sec}$ \\
\hline 2 & 18 & $95^{\circ} \mathrm{C}$ & $30 \mathrm{sec}$ \\
\hline & & $55^{\circ} \mathrm{C}$ & $1 \mathrm{~min}$ \\
\hline & & $68^{\circ} \mathrm{C}$ & $1 \mathrm{~min} / 1 \mathrm{~kb}$ plasmid \\
\hline
\end{tabular}

\subsection{Transformation of bacteria}

An aliquot of competent bacteria was thawed on ice and incubated with $100 \mathrm{ng}$ plasmid DNA. Following the incubation on ice for $30 \mathrm{~min}$, a heat shock at $42^{\circ} \mathrm{C}$ for $45 \mathrm{sec}$ was performed for the purpose of the plasmid to be taken up by the cells chemically. After which a 2 min incubation on ice is performed and $500 \mu \mathrm{L}$ LB-medium was added and further incubated for $1 \mathrm{~h}$ at $37^{\circ} \mathrm{C}$ with gentle agitation. Finally, cells were plated on LBagar plates containing appropriate antibiotics and grown overnight at $37^{\circ} \mathrm{C}$.

\subsection{Plasmid DNA purification}

pBRY-nuclear mCherry-IRES-PURO (plasmid \# 52409 from Addgene)

pSecTagscFv62-TRAIL ${ }^{\text {Lys }}$ (Backbone from Invitrogen and cloned in the laboratory)

Non-Silencing-GIPZ lentiviral shRNAmir control (Glycerol stock) (ThermoScientific cat no RHS4346)

To isolate single colonies from a stab culture, the bacteria were spread over one third of an LB-agar plate (with $100 \mu \mathrm{g} / \mathrm{ml}$ Ampicillin) using an inoculating loop, which was then sterilized and used to spread the bacteria onto the next one-third section of the plate and so on. The plate was incubated at $37^{\circ} \mathrm{C}$ overnight (12 hours). Next day single colonies were spotted. With the help of a sterile pipette tip, a single colony was picked and dropped into $5 \mathrm{ml}$ of liquid LB with $100 \mu \mathrm{g} / \mathrm{ml}$ Ampicillin in a $15 \mathrm{ml}$ loose-capped conical bottom tube. This was incubated at $37^{\circ} \mathrm{C}$ for 12 hours in a shaking incubator. Next day it was checked for bacterial growth that was characterized by a cloudy haze in the medium. 


\subsection{Endotoxin-free (EF) plasmid DNA purification}

The bacterial cells were harvested by centrifugation at $4500 \mathrm{xg}$ for 15 minutes at $4{ }^{\circ} \mathrm{C}$. The cell lysis was done by re-suspending the bacterial cell pellet in $8 \mathrm{ml}$ of RES-EF (Resuspension buffer) buffer and allowed to sit at room temperature for $5 \mathrm{~min}$. To equilibrate the NucleoBond Xtra column filter, $15 \mathrm{ml}$ of buffer EQU-EF (Equilibration) was pipetted along the side of the column. The cell lysis reaction was neutralized after 15 minutes by adding $8 \mathrm{ml}$ of buffer NEU-EF (Neutralization buffer) and mixed gently by inverting 10-15 times. Next the lysate was loaded on to the NucleoBond Xtra column filter. The lysate was allowed to pass through the column, after which it was washed with $5 \mathrm{ml}$ of FIL-EF (Filter Wash) buffer and allowed to pass through. Once that was done the NucleoBond Xtra column filter was discarded. The column was washed a second time with $35 \mathrm{ml}$ of ENDO-EF and followed by a third time with $15 \mathrm{ml}$ of WASHEF. Once this was allowed to completely flow through, the elution was performed with 5 $\mathrm{ml}$ of ELU-EF (Elution) buffer. The next step was to precipitate the flow through with 3.5 $\mathrm{ml}$ of Isopropanol which was centrifuged at $5-15000 \times \mathrm{g}$ for $30 \mathrm{~min}$ at $4{ }^{\circ} \mathrm{C}$. The DNA pellet was washed with $2 \mathrm{ml}$ of $70 \%$ ethanol, centrifuged at $15000 \times \mathrm{g}$ for 5 minutes and dried. The DNA pellet was reconstituted with appropriate volume of $\mathrm{H}_{2} \mathrm{O}-\mathrm{EF}$.

\subsection{Concentration of DNA and RNA}

The concentration of both RNA and DNA as well as the purity of the DNA was measured spectrometrically using a NanoDrop instrument at $260 \mathrm{~nm}$. Any sample that had a $260 \mathrm{~nm} / 280 \mathrm{~nm}$ readout less than 1.8 or more than 2 were discarded.

$\mathrm{cDNA}(\mu \mathrm{g} / \mathrm{ml})=\mathrm{A} 260 \times 50$

$\operatorname{cRNA}(\mu \mathrm{g} / \mathrm{ml})=\mathrm{A} 260 \times 40$

\subsection{Transfection}

DNA transfection was performed using Lipofectamine LTX and Plus Reagent (Invitrogen) (according to the user manual) with $2 \mu \mathrm{g}$ of DNA for the two plasmids for respective cell lines was used along with the reagent in opti-MEM medium. It was incubated for 4 hours and replaced with normal medium containing $10 \%$ FCS. 


\begin{tabular}{|l|l|l|l|}
\hline Tube 1 & $2 \mu \mathrm{g}$ DNA & $7,5 \mu \mathrm{L}$ Plus Reagent & $500 \mu \mathrm{L}$ OptiMEM \\
\hline Tube 2 & $30 \mu \mathrm{L}$ Lipofectamine & $1 \mathrm{ml}$ OptiMEM & \\
\hline
\end{tabular}

It was allowed to stand for $5 \mathrm{~min}$ at room temperature, meanwhile replacing the complete medium from the T25 flask to $3 \mathrm{ml}$ of OptiMEM medium. The mixtures from the two tubes were added to the cells followed by further incubation for 4 hours in the incubator. Change the medium to the complete medium and for stably transfected cell lines appropriate antibiotics were used after 24 of transfection.

- CHO-K1 (pSecTagscFv62-TRAIL Lys $)$ - zeocin $(500 \mu \mathrm{g} / \mathrm{ml})$

- RLT-PSC (pBRY-nuclear mCherry-IRES-PURO) - Puromycin $(0.5 \mu \mathrm{g} / \mathrm{ml})$

SiRNA transfection was performed using Lipofectamine 2000 (Invitrogen) (according to the user manual) with $30 \mathrm{nM}$ SiRNA control and SiRNA Kv10.1 along with Lipofectamine 2000 in opti-MEM medium. It was incubated for 4 hours and replaced with normal medium containing $10 \%$ FCS.

\begin{tabular}{|l|l|l|}
\hline Tube 1 & 30nM SiRNA & $500 \mu \mathrm{L}$ OptiMEM \\
\hline Tube 2 & $15 \mu \mathrm{L}$ Lipofectamine 2000 & $500 \mu \mathrm{L}$ OptiMEM \\
\hline
\end{tabular}

The two tubes were allowed to stand at room temperature for $5 \mathrm{~min}$ and followed by mixing them together and incubated for $15 \mathrm{~min}$. Meanwhile, the medium from T25 flask is replaced with $3 \mathrm{ml}$ of OptiMEM medium and the transfection mixture was added to the cells. The cells in the flask were incubated with the transfection mixture for 4 hours. After 24 hours of transfection the cells were used for experimental purpose or collection for RNA or proteins.

\subsection{Expression of ScFv62 TRAIL $^{\text {Lys }}$ agent}

The fusion proteins were expressed in stably transfected $\mathrm{CHO}$ K1 cells. The vector pSecTag2A has murine kappa leader sequences, which allow secretory protein expression. One week of selection was performed to achieve stably transfected cells. For protein expressions stably expressing monoclones were seeded at $80 \%$ confluency in T175 flasks. The medium was changed into serum-free medium Panserin C6000 (PAN Biotech) for expression. This was incubated for 3-5 days and then the medium 
Materials and Methods

supernatant was collected, concentrated with Centricon YM-100, sterile filtered and stored at $4^{\circ} \mathrm{C}$.

\subsection{Lent-X Lentiviral Expression System (Clontech)}

\section{Production of lentiviral particles.}

The packaging mix VSV-G envelope (cat no. 631259) and Lenti-X 293T cell line (cat no. 632180 ) were used. The medium used for culturing Lenti-X 293T cell line was DMEM with high glucose (4.5g/L), 4 mM L-glutamine, and $3.7 \mathrm{~g} / \mathrm{L}$ sodium bicarbonate (SigmaAldrich cat no.D5796) $1 \mathrm{mM}$ sodium pyruvate and 10\% tetracycline-free fetal bovine serum.

Polybrene (Hexadimethrine bromide; Sigma-Aldrich, Cat no. H9268) was needed for standard transfection to facilitate lentiviral gene transfer. It is a polycation that reduces the charge repulsion between the virus and cellular membrane. The concentration that was optimized and used was $4 \mu \mathrm{g} / \mathrm{ml}$. RetroNectin reagent (Takara Bio, Inc., cat. No T100B) is a recombinant fragment fibronectin $(\mathrm{CH}-296)$ that was used to improve the lentiviral transduction efficiency. It was coated onto the tissue culture plate to provide a substratum for the virus and cells to bind.

The vial of Lenti-X 293T cell line was thawed rapidly on a $37^{\circ} \mathrm{C}$ water bath, immediately after which the cells were transferred to a $15 \mathrm{ml}$ centrifuge tube containing $1 \mathrm{ml}$ prewarmed medium and gently mixed. Additional $4 \mathrm{ml}$ of pre warmed medium was added to the tube. Then it was centrifuged at $100 \times g$ for $5 \mathrm{~min}$, the supernatant was aspirated and the pellet of cells was re-suspended with complete medium and plated in culture flask. This was placed in a $37{ }^{\circ} \mathrm{C}$ humidified incubator with $5 \% \mathrm{CO}_{2}$ for 24 hours. Once attached and confluent the cells were passaged and plated for transfection. For transfection purposes, $5 \times 10^{6}$ Lenti-X 293T cells/ $100 \mathrm{~mm}$ plate in $10 \mathrm{ml}$ of complete medium were incubated at $37{ }^{\circ} \mathrm{C}, 5 \% \mathrm{CO}_{2}$ overnight. Once the cells reach a confluency of $80 \%$ it was ready to be transfected.

For transfection, two different tubes containing the plasmid DNA (Non-silencing-GIPZ lentiviral shRNAmir control vector or shRNA pGIPZ-hEag1(III) lentiviral particles vsv-g 
envelope) were mixed with the viral packaging mix in one tube, and the Xfect polymer in another one were prepared as follows:

\begin{tabular}{|l|l|l|l|}
\hline Tube 1 & Plasmid DNA & Tube 2 & Polymer \\
\hline $557 \mu \mathrm{L}$ & Xfect reaction buffer & $592,5 \mu \mathrm{L}$ & Xfect reaction buffer \\
\hline $36 \mu \mathrm{L}$ & Lenti-X HTX Packaging Mix & $7,5 \mu \mathrm{L}$ & Xfect Polymer \\
\hline $7 \mu \mathrm{L}$ & Lenti-X Vector DNA $(1 \mu \mathrm{g} / \mathrm{ml})$ & & \\
\hline $600 \mu \mathrm{L}$ & Total volume & $600 \mu \mathrm{L}$ & Total Volume \\
\hline
\end{tabular}

( ${ }^{*} X=$ Non-silencing-GIPZ lentiviral shRNAmir control vector / shRNA pGIPZ-hEag1(III) lentiviral particles vsv-g envelope)

The two tubes were vortexed (medium speed for $10 \mathrm{~s}$ ) and mixed together. This mixture was incubated at room temperature for $10 \mathrm{~min}$ to permit nanoparticle complexes to form, and then added dropwise on to the cells. After gentle mixing, the plate was placed at $37^{\circ} \mathrm{C}, 5 \% \mathrm{CO}_{2}$ for 4 hours, and then the transfection mixture was replaced with fresh complete medium and placed back into the incubator for additional 48 hours, when viral titers are expected to be highest. The lentiviral supernatants were harvested and centrifuged at $500 \mathrm{xg}$ to remove cellular debris. The viral stocks were verified with the help of Lenti-X GoStix, aliquoted and stored at $-80^{\circ} \mathrm{C}$.

Transducing target cells with the viral particles was performed in Retronectin-coated 6well plates, which were prepared by incubating the plate for 2 hours at room temperature with a $50 \mu \mathrm{g} / \mathrm{ml}$ solution of retronectin in PBS. Then, retronectin was removed and replaced with $2 \mathrm{ml}$ of $2 \%$ Bovine serum albumin in PBS. This was allowed to stand at room temperature for 30 min and then was washed once with PBS.

$200 \mu \mathrm{L}$ of the appropriate Lenti-X virus supernatant was added onto to the coated plates. The plate was then centrifuged at $1000 \times g$ for 2 hours to help in binding the virus particles to the retronectin reagent, and then washed with PBS, making sure not to dry the plate. The target cells were then added at $1 \times 10^{6}$ cells/ well and incubated overnight. 
For generating stably transfected cells, the medium was changed after 24 hours to medium containing Puromycin $(0.5 \mu \mathrm{g} / \mathrm{ml})$.

\subsection{Characterization of stably transfected cell lines}

Stably transfected cell lines were generated for co-culture experiments involving cancer cell lines and stellate cells for the purpose of investigating their symbiotic relationship as per literature (Pandol et al. 2009).
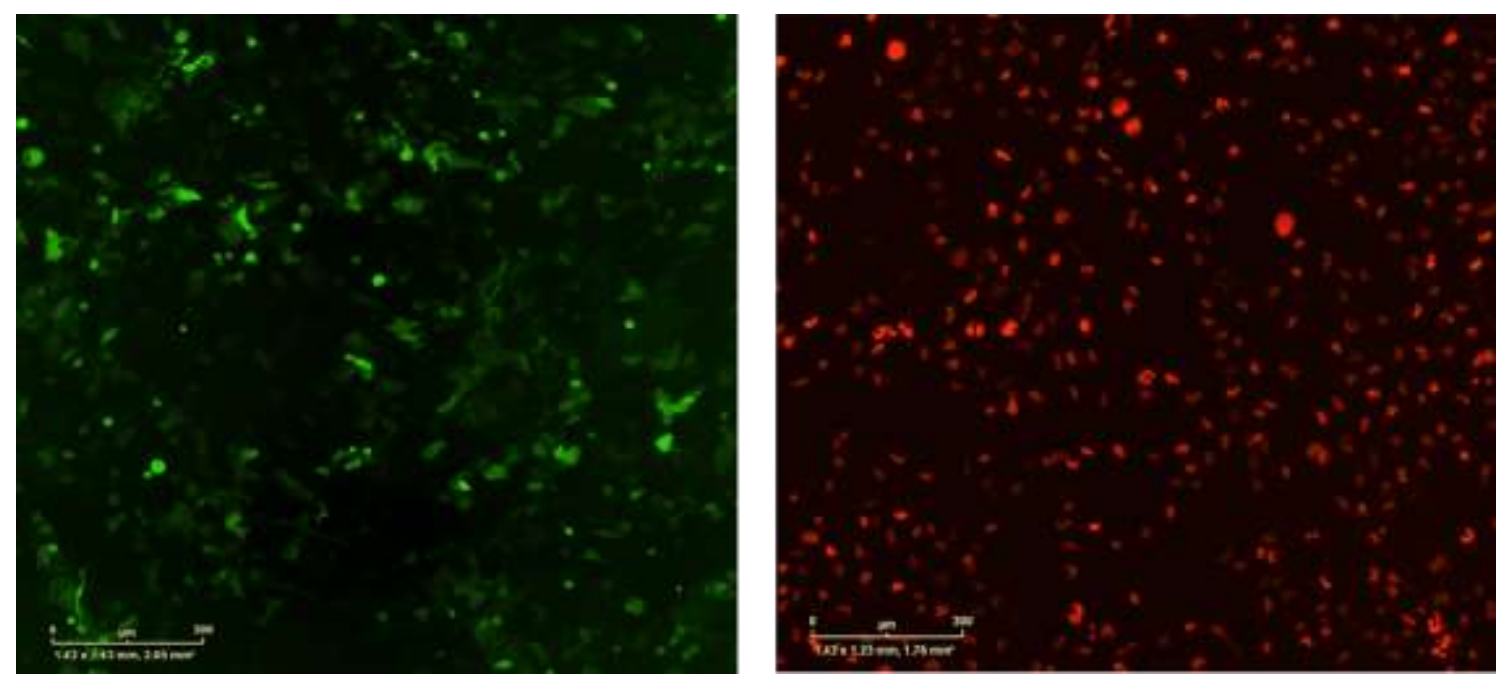

Figure 8 : Labeling of stellate cells and cancer cells for co-culture experiments.

RLT-PSC cell's nuclei labeled with pBRY-nuclear mCherry-IRES-PURO (left) and Capan-1 labeled with (shRNA pGIPZ-hEag1 vsvg envelope) and/or Capan-1 (Nonsilencing pGIPZ lentiviral control vector) (right).

RLT-PSC cell lines were labelled with $p B R Y$ - nuclear mCherry-IRES-PURO as described above. Among the five PDAC cell lines we were successful in transducing Capan-1 cell lines shRNA pGIPZ-hEag1 vsvg envelope and Non-silencing pGIPZ lentiviral control vector as described in the materials and methods section. 


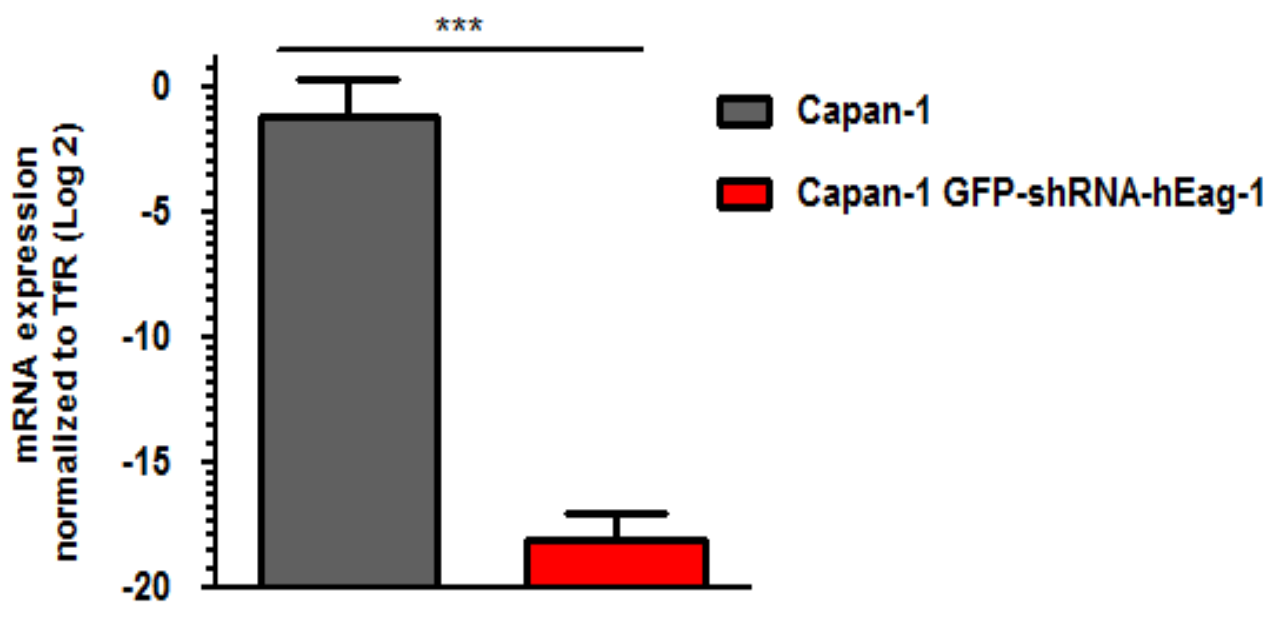

Figure 9: Real-time PCR confirming knock down of Kv10.1 in Capan-1. RNA was isolated from Capan-1 GFP-shRNA-hEag-1 stably transfected cells and Capan-1 (Wildtype). $5 \mu \mathrm{g}$ total RNA was used to synthesize cDNA and quantitative real-time PCR was performed with human transferrin receptor a reference gene.
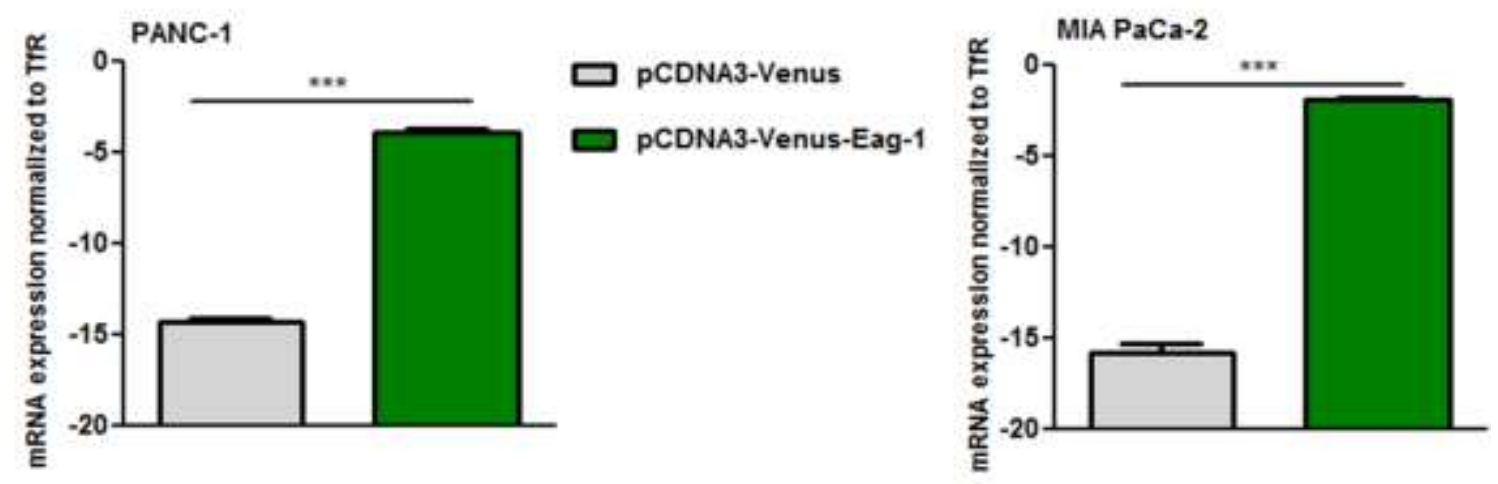

Figure 10: Real-time PCR confirming over expression of Kv10.1 in cancer cell lines. RNA was isolated from PANC-1, MIA PaCa-2 (wild-type, pCDNA3-Venus and pCDNA3-Venus-Eag-1) cells. $5 \mu \mathrm{g}$ total RNA was used to synthesize cDNA (as described in the materials and methods) and quantitative real-time PCR was

We were only successful in over expression of Kv10.1 in PANC-1 and MIA PaCa-2 cell lines, which was confirmed through real-time PCR. We achieved a high stable over expression compared to the control. 


\subsection{Protein extraction}

For detection of Cleaved Caspase-3, cells were collected by trypsinization and washed with PBS. After centrifugation, the cell pellet was re-suspended in non-denaturing lysis buffer and incubated for 30 minutes at room temperature. The lysis buffer contained $1 \%$ Triton $\mathrm{X}-100,50 \mathrm{mM}$ Tris $-\mathrm{HCl}, 300 \mathrm{mM} \mathrm{NaCl}, 5 \mathrm{mM}$ EDTA and protease Inhibitor cocktail (Roche). After incubation, the cell lysates were centrifuged at $11400 \mathrm{xg}$ for 15 min. The supernatant was collected into new $1.5 \mathrm{ml}$ microcentrifuge tubes.

For detection of Kv10.1, cells were collected by trypsinization and washed with PBS. After centrifugation, the cell pellet was re-suspended in $70 \mu \mathrm{L}$ lysis buffer (8M Urea, $65 \mathrm{mM}$ DTT, $4 \%$ CHAPS, $1 \%$ NP-40) by constant vortexing. Thermal shock was performed by placing the suspension of cells in the lysis buffer first in liquid nitrogen until frozen, then at $37^{\circ} \mathrm{C}$ degree (water bath) until thawed and vortexing for $30 \mathrm{~s}$. This cycle was done 5 times. After which it was centrifuged at $2708 \mathrm{xg}$ for 10 minutes (at 4 $\left.{ }^{\circ} \mathrm{C}\right)$. The supernatant was collected into a new $1.5 \mathrm{ml}$ micro centrifuge tube.

\subsection{Protein quantification with BCA Protein Assay}

Protein concentration was determined using Pierce BCA Protein Assay Kit. The protein lysates were diluted 1:5 with water and loaded in triplicates on a 96 well plate, together with triplicates of diluted BSA (bovine serum albumin) standard $(0-2000 \mu \mathrm{g})$. Reagent B ( $4 \%$ cupric sulfate) was diluted $1 / 50$ in Reagent A (sodium carbonate, sodium bicarbonate, bicinchoninic acid and sodium tartrate in $0.1 \mathrm{M}$ sodium hydroxide) and mixed thoroughly. $200 \mu \mathrm{L}$ of this mixture was added to each sample in the 96-well plate and incubated for $30 \mathrm{~min}$ at $37^{\circ} \mathrm{C}$. The absorbance of the samples at $562 \mathrm{~nm}$ was measured using a Wallac VICTOR ${ }^{2}$ plate reader (Perkin Elmer). With these data we could draw a titration curve, which allowed us to estimate the protein amount relative to our samples. 


\subsection{SDS-PAGE}

The proteins were allowed to migrate depending on the mass to charge ratio during sodium dodecyl sulphate polyacrylamide gel electrophoresis (SDS-PAGE). NuPAGE reducing agent (Invitrogen) and NuPAGE LDS sample buffer (Invitrogen) pH 8.4 were added to the samples (to provide optimal conditions for reduction of disulfide bonds) (50 $\mu \mathrm{g}$ of total protein for caspase-3, $200 \mu \mathrm{g}$ for $\mathrm{Kv10.1}$ ) in a 1:10 and 1:4 ratio to the final volume, respectively. The reducing agent removes any remaining tertiary and quaternary structures by reducing their disulfide bonds. These samples were heated at $70{ }^{\circ} \mathrm{C}$ for 10 minutes.

The denatured samples were then resolved in a 4-12\% NuPAGE Novex Bis-Tris Mini Gels (Invitrogen) at $200 \mathrm{~V}$ using NuPAGE MOPS SDS Running Buffer (for caspase) or NuPAGE MES SDS Running Buffer (for Kv10.1), both with NuPAGE antioxidant. Along with the protein samples a ColorPlus prestain protein ladder (BioLabs) was run, to mark the molecular weights across the gel.

\section{Immunoblotting}

After the protein samples were separated by SDS-PAGE, they were transferred onto a nitrocellulose membrane (NC) (GE Healthcare, $0.2 \mu \mathrm{m}$ for caspase, $0.45 \mu \mathrm{m}$ for Kv10.1) using the electro-transfer protocol. For caspase 3, the transfer buffer used was composed of $10 \mathrm{mM} \mathrm{NaHCO}$, $3 \mathrm{mM} \mathrm{Na}_{2} \mathrm{CO}_{3}, 0.01 \%$ SDS and $20 \%$ methanol, for Kv10.1 the transfer buffer used contained 8 M Urea, 25 mM Tris Base, 192mM Glycine and $20 \%$ methanol. The gel was removed from the cast and incubated for 30 minutes with the transfer buffer in order to equilibrate it before the transfer.

For caspase immunoblotting, transfer was performed using a voltage-gradient protocol from $10 \mathrm{~V}$ and increased every $10 \mathrm{~min}$ by $10 \mathrm{~V}$ until $50 \mathrm{~V}$, then maintained for $40 \mathrm{~min}$. The NC membranes were subsequently rinsed with deionized water and incubated with Blot signal enhancer (Thermo Scientific) according to the manufacturer's instructions. The membrane was incubated with Quentix enhancer Solution A for 2 minutes on a shaker and washed with deionized water 5 times, then incubated with Quentix enhancer solution B for $10 \mathrm{~min}$, which was then washed with deionized water 5 times. The 
Materials and Methods

membrane was then blocked with $0.1 \%$ Casein (Roche) in TBS-T $(0,1 \%$ Tween 20$)$ for 1 hour. This was followed by incubating the membrane with the primary antibody of interest (Ref table 7) diluted in blocking buffer overnight at $4{ }^{\circ} \mathrm{C}$ on a shaker. The next day, the membrane was washed 5 times with deionized water and incubated with TBS$T$ for 5 minutes, after which it was incubated with horseradish peroxidase (HRP)conjugated secondary antibody (Refer table 7) diluted in blocking buffer for 45 minutes. The membrane was washed 7 times with deionized water and incubated for 5 minutes in TBS-T.

In the case of $\mathrm{Kv10.1}$, the transfer was performed at 20 volts at $4^{\circ}$ overnight on a magnetic stirrer. Next day, blocking was performed to prevent non-specific binding, $5 \%$ non-fat dry milk (Bio Rad) in PBS for 1 hour, followed by incubating the membrane with the primary antibody of interest (Ref table 7) diluted in blocking buffer on an orbital shaker for 2 hours. Next ECL peroxidase labeled anti rabbit antibody (Refer table 7) diluted in PBS for 1 hour. The membrane was washed 3 times with PBS-T (10 $\min /$ wash).

Finally, the membrane was incubated for 5 minutes with chemiluminescent HRP substrate (Millipore) in order to initiate the chemiluminescence reaction catalyzed by the peroxidase conjugated to the secondary antibody. This reaction was detected with a ChemiDoc XRS system (Bio-Rad); the image acquisition was done using Quantity One 1-D Analysis software v4.6.9 (Bio-Rad).

\subsection{Immunofluorescence: Immunohistochemistry}

Tumour tissue sections were first de-paraffined by washing in Xylene twice followed by ethanol series from $100 \%, 90 \%, 70 \%$ and distilled water. A water bath was heated to $90^{\circ}$ and antigen retrieval was performed in $10 \mathrm{mM}$ citrate buffer $(\mathrm{pH} \mathrm{6.0)}$ ) for 30 minutes, after which the slides were allowed to cool down to room temperature for approximately an hour. The slides were then washed in TBS-T once for 5 minutes. Now to avoid nonspecific binding, blocking was performed with 10\% BSA (Globulin free) in TBS-T for 1 hour at room temperature. The slides were then washed twice in TBS-T. 
Primary antibody mAb62 in 1:100 dilution in blocking solution was prepared and the tissue sections were incubated overnight at $4^{\circ} \mathrm{C}$. Next day, the slides were washed in thrice in TBS-T (5 min/wash). This was followed by 1 hour incubation with secondary antibody, goat anti-mouse IgG1 secondary antibody, Alexa Fluor 488 conjugate. The slides were then washed 1x in TBS-T (5 min/wash). For staining nuclei, DRAQ5 was used at 1:1000 dilution in blocking solution for 15 minutes. The slides were then washed $1 \mathrm{x}$ in TBS-T ( $5 \mathrm{~min} /$ wash). Finally the sections were mounted with Prolong Gold antifade reagent with DAPI.

After 24 hours, when the mounting medium was completely dry, the slides were visualized under LSM 510 Meta laser scanning confocal microscope (Zeiss). The ZEN (Zeiss) software was used for image acquisition and processing was done with the help of FIJI image anaylsis software.

\subsection{Live cell imaging}

The incuCyte Zoom is a live-cell imaging system that can be placed within an incubator. It is essentially a motorized microscope that can take images from cells growing in cell culture vessels of varying formats. The system used, equipped with three different objectives (4x,10x and 20x) can produce phase contrast, green and red fluorescence images. Cell behavior and function can be monitored and quantified in real time. We employed the incuCyte system to perform proliferation assays by analyzing the increase in area occupied by cells (\%) as the cells proliferate. Scratch assay was quantified by generating a scratch wound mask (width of the wound) and a confluence mask (cell confluence of the wound region) at the beginning of the assay. 


\subsection{Caspase activity determination}

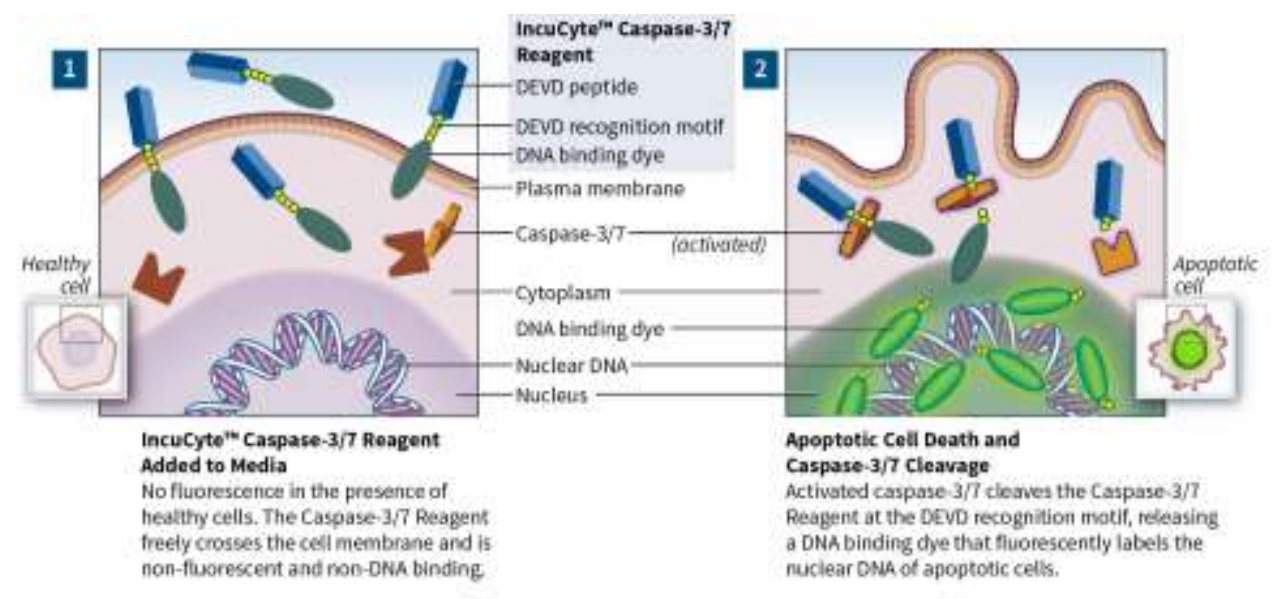

Apoptosis was monitored through activation of Caspase-3 (and -7), one of the main effector caspases involved in apoptosis in mammalian cells. This is achieved through cleavage of a caspase substrate that consists of a caspase-3/7 recognition motif (DEVD) coupled to a DNA intercalating dye. This non-fluorescent substrate crosses the cell membrane and is cleaved by activated caspases-3/7. This results in the release of the DNA dye, leading to green fluorescent staining of the DNA. 6000 cells/well were plated in a 96-well flat bottom plate. After 24 hours, once the cells were attached, the specific treatment was added (6 wells/treatment), along with $5 \mu \mathrm{M}$ caspase-3/7 substrate reagent. The plate was placed in the imaging system with both phase contrast and fluorescence green channels capturing images every hour. The images were used to quantify the green spots which represent stained DNA of an apoptotic cell.

The treatments used were:

1. ScFv62TRAIL Lys $0,48 \mu \mathrm{g}$ per $\mathrm{ml}$

2. Gemcitabine $25 \mu \mathrm{M}$

3. Soluble TRAIL $0,48 \mu \mathrm{g}$ per $\mathrm{ml}$

4. scFv62TRAIL Lys + Gemcitabine

5. Soluble TRAIL + Gemcitabine 
Pan Caspase Inhibitor Z-VAD-FMK was used along with the treatment at a concentration from $50 \mu \mathrm{M}, 100 \mu \mathrm{M}, 150 \mu \mathrm{M}$ and $200 \mu \mathrm{M}$.

\subsection{Kinetic measurement of cytotoxicity}

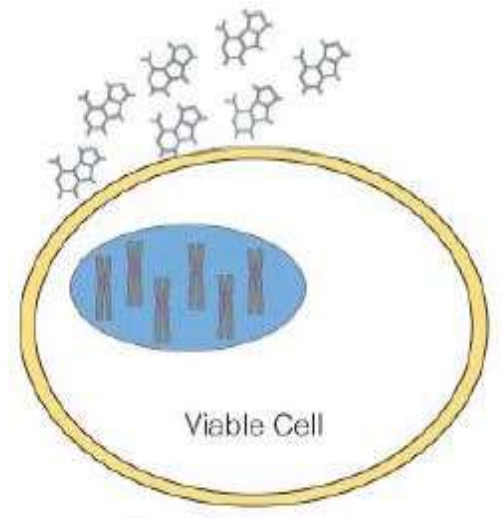

Low Fluorescence

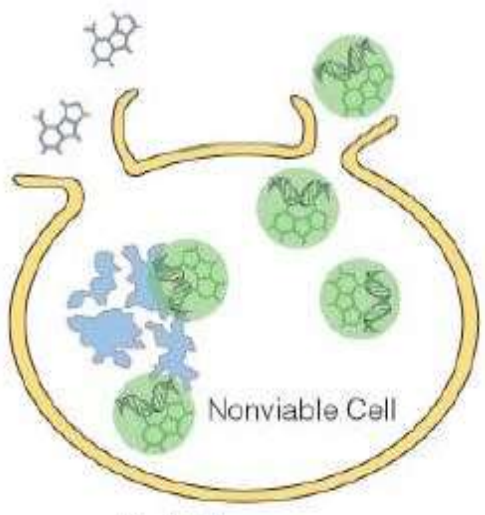

High Fluorescence

CellTox Green is a cell impermeant cyanine dye that stains DNA only when it can access the cell due to loss of membrane integrity as a result of the death of a cell. The dye is virtually non-fluorescent when not bound to DNA, and live cells do not produce any fluorescence. The fluorescent signal produced is proportional to the cytotoxicity. 6000 cells per well were plated in a 96-well plates and allowed to attach for $24 \mathrm{~h}$. Then, the specific treatment was added ( 6 wells/treatment) together with the cytotoxicity dye (1:1000). The plate was placed in the incuCyte and images were captured every hour in phase contrast and green fluorescence channels. 


\subsection{Spheroid assay: 3D spheroid culture}

This protocol employs a round bottomed, hydrogel (hydrophilic and neutrally charged) coated 96-well plate, termed ultra-low attachment plate (ULA; corning 7007). The hydrogel inhibits specific and non-specific immobilization, thereby forcing the cells to be in suspension and enabling 3D spheroid formation. The IncuCyte automatically measures the size of spheroid using fluorescently labeled cells.

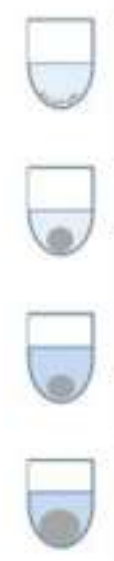

\section{Day 0 : Seed 5000 cells/well/100ul complete medium $+2 \%$ Matrigel. Centrifuge at $1000 \mathrm{rpm}$ for 10 minutes}

\section{Day 3 : Formation of spheroids Spheroid : 400-500um in size Addition of treatments}

\section{Day 7 : Replenish treatment} (Remove 100ul and add treatment) Observation and quantifying shrinkage

The cells $(100 \mu \mathrm{L})$ were seeded at 5000 cells/well in combination with $2 \%$ matrigel. The plate was centrifuged at $163 \mathrm{xg}$ for 10 minutes and then placed in the imaging system. Images were collected every hour. After 72 to 96 hours, firm spheroids of 400 to $500 \mu \mathrm{m}$ in size were formed. An equal amount (100 $\mu \mathrm{L} /$ well) of medium containing the treatments ( $2 x$ concentrated) was then added to the wells. The treatment was replenished after 4 days by replacing $100 \mu \mathrm{L}$ of the medium from the well to freshly prepared medium containing the drug. 


\subsection{Annexin V-FITC/PI apoptosis Assay using Flow cytometry}

This assay is based on the detection of phosphatidylserine (PS) at the outer surface of the cell membrane and can be measured using flow cytometry. When a cell undergoes apoptosis, PS that is normally in the inner leaflet of the cell membrane flips to the outer surface of the membrane. This flip of PS occurs in the early stages of apoptosis and remains this way for the rest of the dying process. Annexin V-FITC staining is used in conjugation with Propidium lodide (PI) to differentiate between early apoptotic, late apoptotic and necrotic cells.

In a 12 well plate 100,000 cells were plated per well. When cells were attached after 24 hours, medium was exchanged with new medium containing treatment in duplicates. The treatment (ref to caspase assay) proceeded for $12 \mathrm{~h}$. The cells were then washed with PBS, trypsinized, collected in tubes and centrifuged at $275 \times \mathrm{g}$ for 4 minutes. The cell pellet was washed with PB and re-suspended in $100 \mu \mathrm{L} 1 \mathrm{x}$ annexin binding buffer (containing enough calcium to assist with the annexin $\mathrm{V}$ binding to PS on the cell surface), $4 \mu \mathrm{L}$ annexin V-FITC and $4 \mu \mathrm{L}$ propidium iodide (PI). This was incubated for 20 minutes at room temperature in the dark. After the incubation period, $400 \mu \mathrm{L}$ of $1 \mathrm{x}$ annexin binding buffer was added and the samples were analyzed by flow cytometry. The FACSaria cytometer (BD sciences) was used to analyze the stained cells ( $E x=488$ $\mathrm{nm}$ and $\mathrm{Em}=530 \mathrm{~nm}$ ) using FL1 channel for detecting Annexin V FITC staining and the $(E x=561 \mathrm{~nm}$ and $E m=>575 \mathrm{~nm})$ FL2 channel for detecting PI staining. 


\subsection{Live cell fluorescent imaging of Annexin V staining of PS}

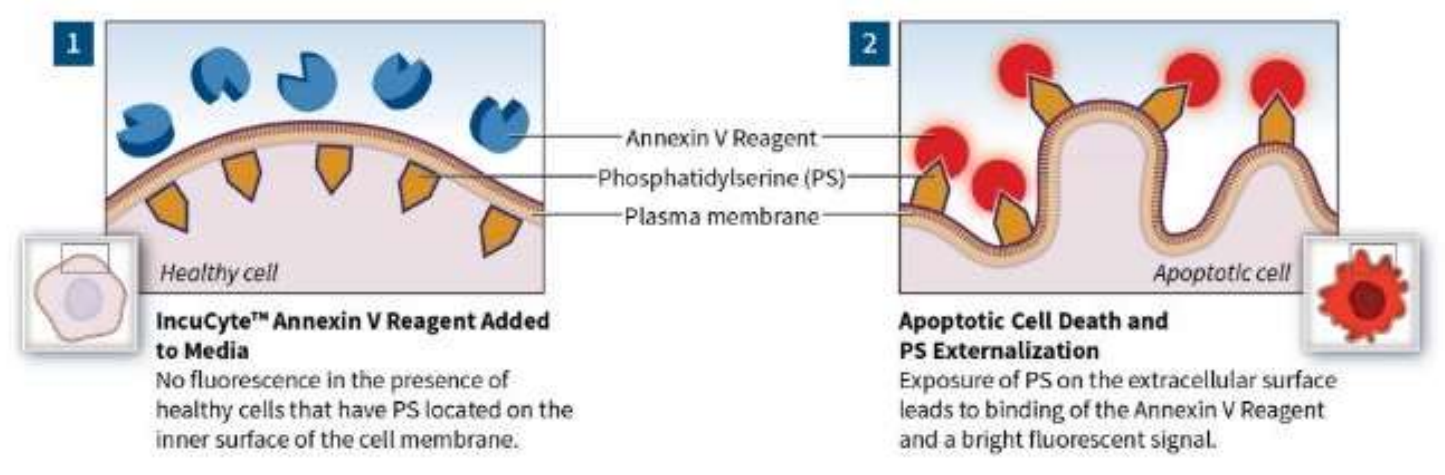

The annexin $V$ reagent from Essen Bioscience is a cyanine-based fluorescent dye, bases on the same principle as the flow cytometric assay described above. The reagent is non-fluorescent in solution, but gives rise to a bright and photo stable fluorescent signal when bound to PS. 6000 cells per well were plated in a 96-well plate, and after 24 $\mathrm{hr}$ the specific agents were added together with annexin $\mathrm{V}$ reagent (1:200 dilution). The wells were imaged every hour using the IncuCyte system. The fluorescent intensity is directly proportional to the amount of annexin V-positive cells. 


\subsection{TRAIL and IL-8 concentrations were determined by Enzyme- linked Immunosorbent Assay (ELISA).}

The Quantikine Human TRAIL/TNFSF10 Immunoassay was used to measure human TRAIL in cell culture supernatants. We employed a microplate pre-coated with monoclonal antibody specific for human TRAIL. The standards and samples to be measured were pipetted into the wells, sealed and incubated for 2 hours in an orbital shaker. Unbound material was washed out with a Wash buffer (four times with buffered surfactant), and an enzyme-linked polyclonal antibody specific for human TRAIL was added to the wells. The plates were again sealed and incubated for further 2 hours in an orbital shaker. The wells were washed four times to remove unbound antibody-enzyme reagent, and substrate solution (a mixture of hydrogen peroxide and tetramethylbenzidine in equal volumes) was added to the wells and incubated at room temperature in the dark for $30 \mathrm{~min}$.

The reaction was stopped using $2 \mathrm{~N}$ sulfuric acid, and the color developed was measured in a Wallac Victor 2 photometer at $570 \mathrm{~nm}$. The unknown concentrations were interpolated from a log-log standard curve generated using 1000, 500, 250, 125, $62.5,31.2,15.6$, and $0 \mathrm{pg} / \mathrm{ml}$ human TRAIL).

IL-8 levels were measured in a similar manner, using a luminescent substrate. Culture supernatants were diluted (1:5). Samples were pipetted in the wells of a plate precoated with an anti-human IL-8 capture antibody and incubated for 1 hour at room temperature. After washing thrice with the wash buffer, $50 \mu \mathrm{L}$ of biotinylated antibody reagent binding to a second site on the IL-8 protein was added, and the plate was sealed and incubated for $30 \mathrm{~min}$ at room temperature. Excess detecting antibody was removed with three washes and streptavidin-HRP reagent was added and incubated for $30 \mathrm{~min}$ at room temperature. The plate was washed thrice and pat dried. $50 \mu \mathrm{L}$ Supersignal working solution was added which was prepared with one part stable peroxide to one part of luminol enhancer.

The plate was read in luminometer within $15 \mathrm{~min}$ of addition. The luminescence was read for $1 \mathrm{~s}$ per well and is proportional to the amount of human IL-8 in standard or 
sample. The average relative light (RLU) obtained from each standard (500, 50, 5, 0.5 and $0 \mathrm{pg} / \mathrm{ml} \mathrm{IL8)}$ was used to interpolate the concentration in the unknown samples.

\subsection{Cell Migration Assay}

Migration was determined by trans-well assay, by determining the amount of cells that move between two chambers through a membrane with $8 \mu \mathrm{m}$ pores, following a nutrient gradient. Prior to performing this assay the cells were starved overnight. The next day the cells were harvested and counted and a cell suspension of $5 \times 10^{5}$ cells $/ \mathrm{ml}$ in serum free medium was prepared. The 24-well migration plate was allowed to warm up at room temperature for 10 minutes under sterile conditions. $500 \mu \mathrm{L}$ of medium containing $10 \%$ fetal bovine serum was added to the lower well of the migration plate and $300 \mu \mathrm{L}$ of the cell suspension solution was added into each insert. The plate was incubated for 24 hours.

Next day, the medium from the inserts was carefully aspirated, and the inner part was gently scraped with a wet, flattened cotton-tipped swab, thereby removing the nonmigrating cells without puncturing the polycarbonate membrane. Then the inserts were transferred to a clean well containing $400 \mu \mathrm{L}$ of Cell Stain Solution (crystal violet) and incubated for 10 minutes at room temperature. After staining, the inserts were gently washed several times in a beaker of water to remove excess staining. Each insert was transferred to a well containing $200 \mu \mathrm{L}$ of extraction solution per well and incubated for 10 minutes on an orbital shaker. From the cell suspension $100 \mu \mathrm{L}$ was pipetted into a 96-well microtiter plate and the OD at $560 \mathrm{~nm}$ was measured in a plate reader. 


\subsection{Animal experiments}

The animal study was conducted in accordance to German law and approval by the local ethical LAVES committee (no. 33.19-42502-04-15/1845). A total of 32 mice which

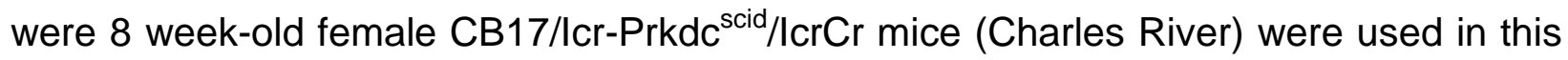
study. They were housed in individually ventilated cages (two mice per cage), with free access to food (autoclaved pellets) and water.

Implantation:

The medium from the T175 flask was aspirated and washed once with PBS. $5 \mathrm{ml}$ of trypsin was added onto the cells in the flask and incubated for 4 min until the cells detached. Cells were harvested and counted as described earlier and $5 \times 10^{6}$ cells/200 $\mu \mathrm{L}$ of PBS of Capan-1 was injected with $1 \mathrm{ml}$ syringe (BD Plastipak Ref no. 300013) and Needle (BD Microlance 3 27Gx 3/4" Nr 20 Ref no 302200) subcutaneously into the flank of the animal. The mice were monitored once every two days. One week after implantation the first tumour volume measurement was done, and thereafter by the same person throughout the experiment. The length and width of tumour were measured with which the tumour volume was calculated.

Tumour volume $\left(\mathrm{mm}^{3}\right)=$ Length $(\mathrm{mm})^{*}$ width $(\mathrm{mm})^{*}$ width $(\mathrm{mm})^{*} 0.5$

Treatment: We had four groups (8 mice/group);

1. Control

2. ScFv62TRAIL ${ }^{\text {Lys }}$

3. Gemcitabine and

4. Combination. 
Treatement Schedule 1

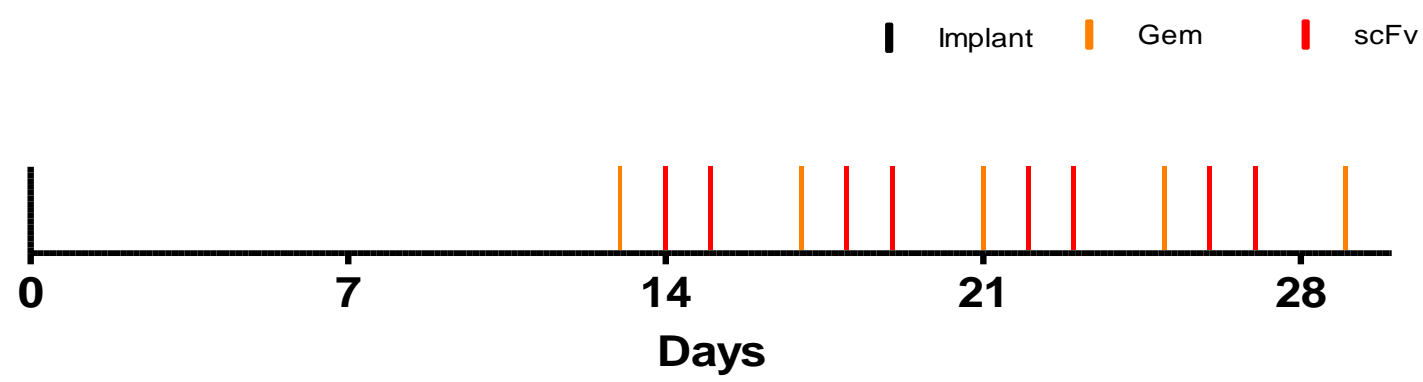

First dose of treatment started 2 weeks after the implantation, intra-peritoneal with 80 $\mathrm{mg} / \mathrm{kg}$ of Gemcitabine $(200 \mu \mathrm{L})$ followed by the scFv62TRAIL ${ }^{\text {Lys }}(200 \mu \mathrm{L})$ next two days as shown in the diagram above. This treatment cycle lasted for two weeks and simultaneously the tumour volume was monitored. 


\section{RESULTS}

\section{Kv10.1 is expressed in PDAC cell lines}

\subsection{Expression of Kv10.1 in PDAC cell lines at the transcript level}

The voltage-gated potassium channel Kv10.1 is normally expressed in the CNS of humans and rodents (Martin et al. 2008). Recently, it was demonstrated that all cells express Kv10.1 in a cell cycle phase-specific manner, in a short time window during G2/M. Channel expression contributes towards progression through G2/M. This could explain the aberrant expression of Kv10.1 observed in tumours of diverse origins (Urrego et al. 2016). To determine if -and if so, which one- of the studied PDAC cell lines belong to the Kv10.1-positive group, we isolated total RNA from each of the cell lines and reverse transcribed it to obtain cDNA using oligo-dT as primer. On this material, we performed nested PCR as described in materials and methods (Ramos Gomes et al. 2015), which also allows distinguishing between alternatively spliced variants.

a
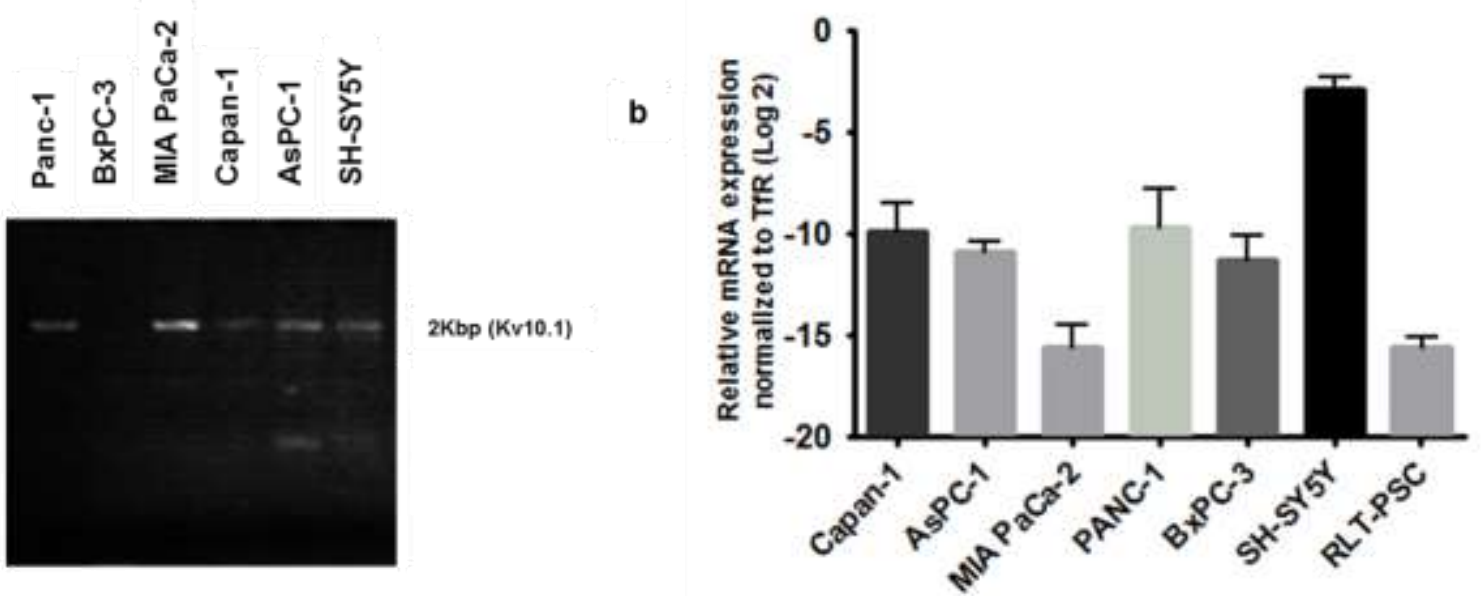

Figure 11: Analysis of the expression of Kv10.1. RNA was isolated from the five PDAC, SH-SY5Y and RLT-PCS cell lines. cDNA was synthesized from $5 \mu \mathrm{g}$ of total RNA as described in Materials and Methods and PCR was performed on the samples. a. Nested PCR detected expression of Kv10.1 in the cell lines. b. Real-time PCR confirmed expression in all five PDAC cell lines and the stellate cells (RLT-PSC). 
Results

Capan-1, PANC-1, AsPC-1, and MIA PaCa-2 cDNA gave rise to bands of the same size as to those from the positive control (SH-SY5Y neuroblastoma cells (Ramos Gomes et al. 2015) (Fig. 11). Only AsPC-1 showed a band compatible with known Kv10.1 splice variants.

Quantitative real-time PCR (RT-PCR) using TaqMan probes (see Methods) confirmed the expression of Kv10.1 in those cell lines (Fig. 11). Expression levels were normalized to the reference housekeeping gene transferrin receptor. The positive control SH-SY5Y had the highest expression levels, while MIA PaCa-2 had the lowest. Immortalized human pancreatic stellate cells (RLT-PSC) were tested in the same experiments, and showed also low expression of Kv10.1

The intensities of the bands from nested PCR were not parallel to RT-PCR values. Besides the intrinsic qualitative nature of conventional PCR, could reflect differences in cell cycle distribution between experiments. From these experiments, we conclude that all cell lines, and also PSCs, express Kv10.1 at modest levels,

\subsection{Expression of Kv10.1 in PDAC cell lines at the protein level}

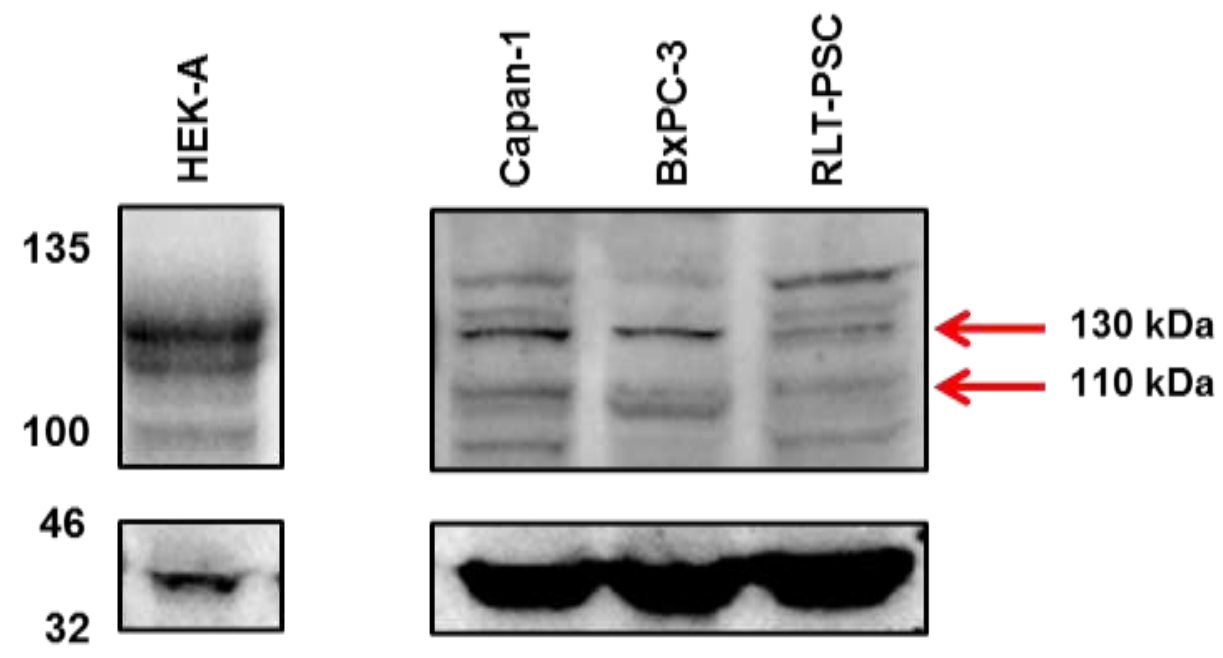

Figure 12: Protein expression of Kv10.1. Lysates were extracted from Capan-1, BXPC-3, RLT-PSC cell lines and HEK-A cell line (positive control). $100 \mu \mathrm{g}$ total protein was loaded and immunoblot was performed as described in the Materials and Methods section. Expression of Kv10.1 was detected in all cell lines. 
To confirm expression of Kv10.1 also at the protein level, we collected extracts of the cell lines relevant for further experiments (see below), both PDAC and stellate cells. A polyclonal antibody against the C-terminus of the channel detected $\sim 110$ and $\sim 130 \mathrm{kDa}$ bands, compatible with Kv10.1 and similar to those present in HEK-A cells (a stably transfected HEK-derived clone). The highest expression level was detected in Capan-1, followed by BxPC-3 and was lowest in RLT-PSC (Fig. 12). 


\subsection{Expression of Kv10.1 in tumour tissues}
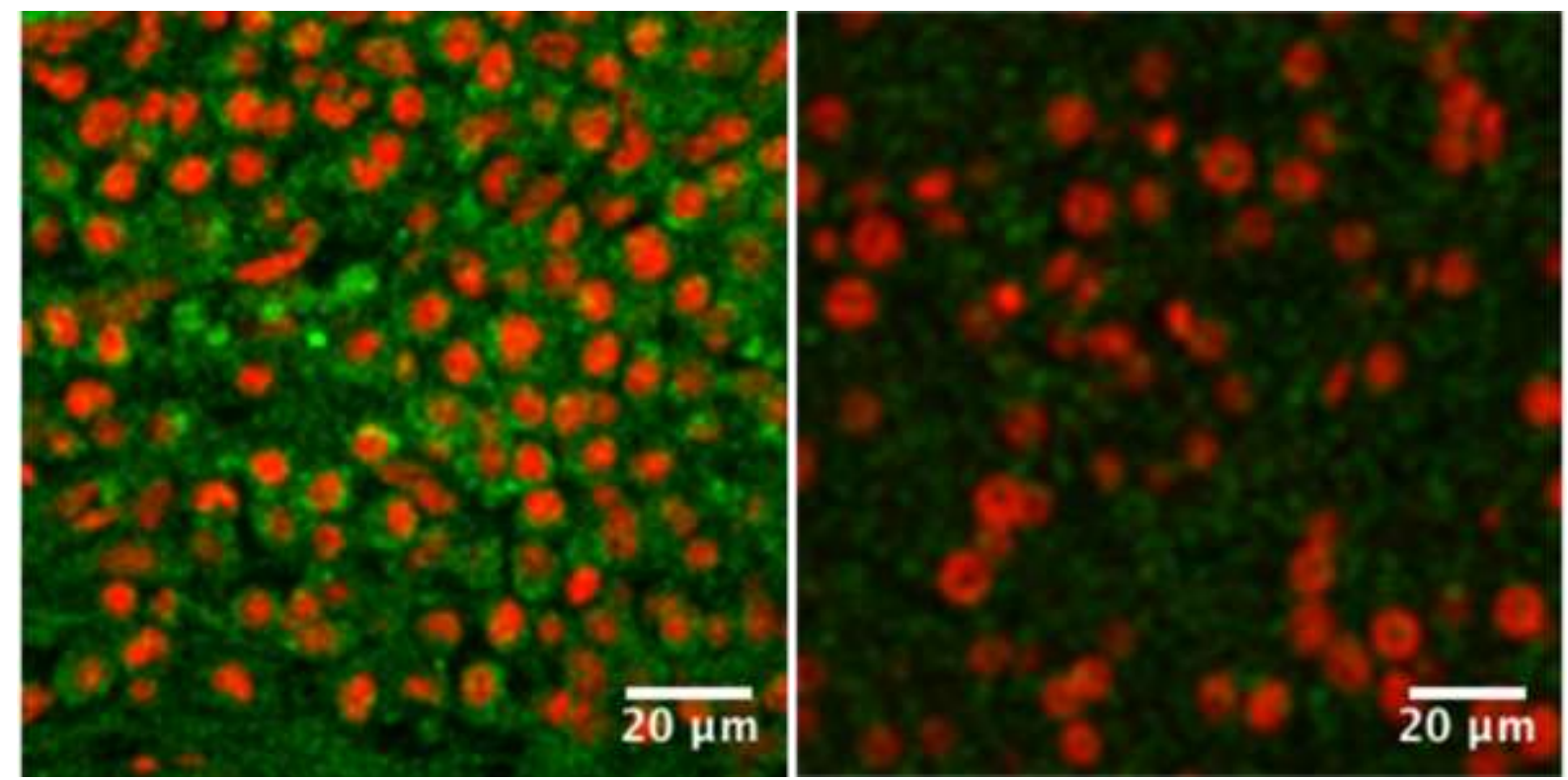

Figure 13: Expression of Kv10.1 in tumour tissue. Confocal image of immunofluorescence staining of Kv10.1 in orthotropic tumour model of Capan-1 (left) and BxPC-3 (right). DRAQ5 (red) stained the nuclei and AlexaFluor448 (green)

Expression of Kv10.1 in cultured cells does not necessarily mean that the protein is expressed in the tumours. To confirm expression in vivo, we stained slices from tumours obtained through orthotopic implantation of Capan-1 and BxPC-3 cells.

Slices cut from paraffin blocks from tumours were stained using the monoclonal antiKv10.1 mAb62 (Hemmerlein et al, 2006) and a secondary antibody labeled with Alexa Fluor 488. DRAQ5 was used for counterstaining the nuclei. The slices were imaged by confocal microscopy. The green fluorescence indicating the presence of Kv10.1 was not homogeneously distributed in the tissue, rather there were restricted areas of positivity (also in haematoxylin-eosin staining; not shown). Within those positive areas (Fig 13), the staining was more intense in Capan-1 tumours. 
Results

\section{Functional analysis of Kv10.1 in PDAC cell lines}

Earlier studies investigating the functional role of Kv10.1 have demonstrated that in vitro knock down in several cell lines leads to a reduction in the rate of proliferation and in migration (Ouadid-Ahidouch et al. 2016). We wanted to investigate if the functional role of Kv10.1 in PDAC cells is similar to the ones described in the literature.
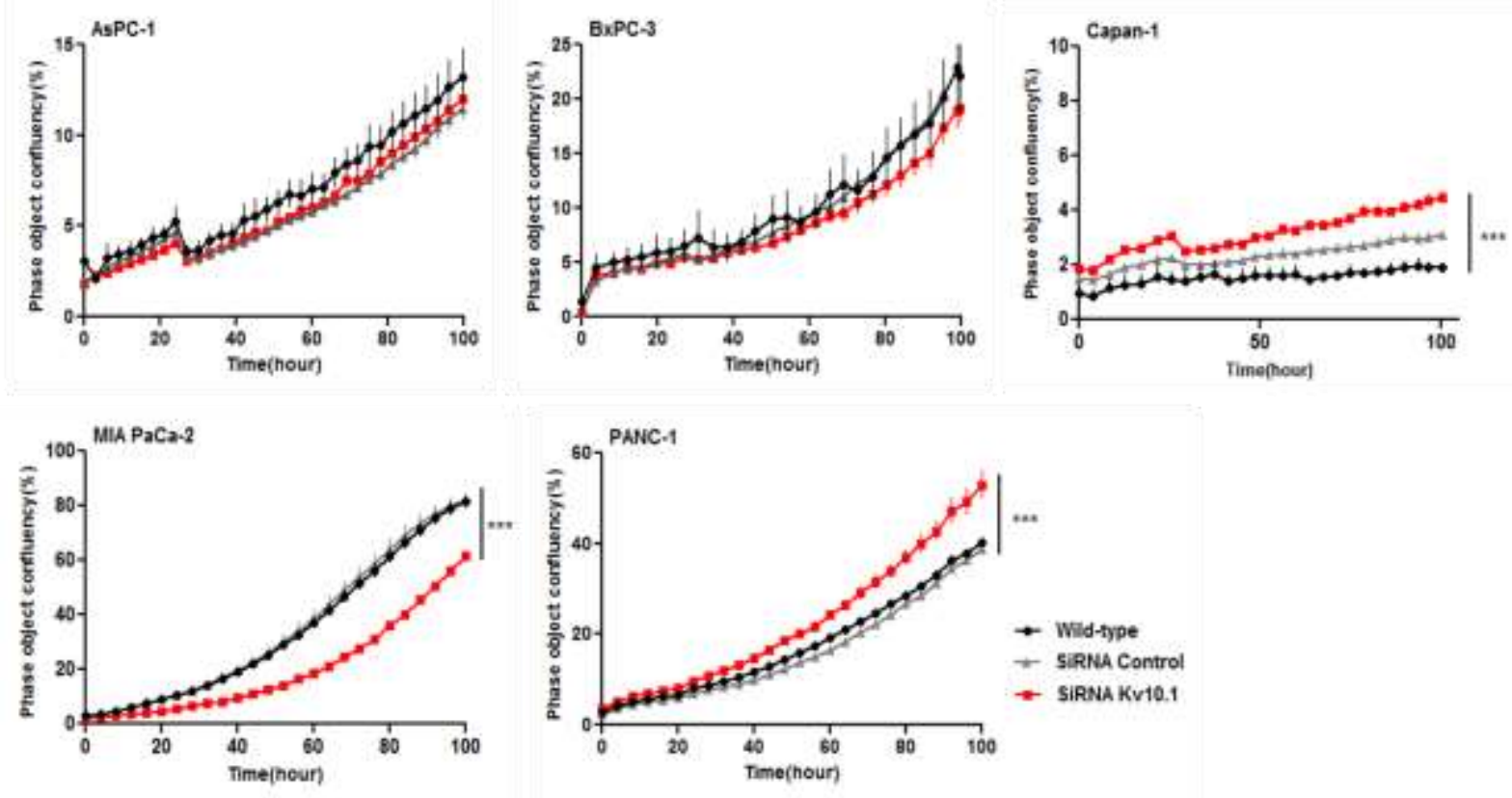

Figure 14: Effect of knock down of Kv10.1 on proliferation. The effect of the knock down of Kv10.1 was cell line specific. Confluence mask indicated an increase in proliferation in Capan-1 and PANC-1 however a decrease in MIA PaCa-2.

To do this, we first tested the effects of short-term RNAi-mediated knockdown of Kv10.1. Transient knockdown was carried out by already characterized siRNA (Weber et al. 2006) in all five PDAC cell lines, and confirmed by real-time PCR. We then determined proliferation by live cell imaging using the IncuCyte system. Using phase contrast images and with the help of IncuCyte zoom software, we determined the area of the culture surface covered by cells (confluence) and used it as a measure of proliferation. 
Results

The effect of transient knock-down of Kv10.1 was cell-type dependent. While in Capan1 and PANC-1 cells we observed a modest but a significant increase in the rate of proliferation, against the pattern described in the literature with other cell lines, in MIA $\mathrm{PaCa}-2$ cells there was a significant decrease in proliferation. In AsPC-1 and BxPC-3 no difference was observed.
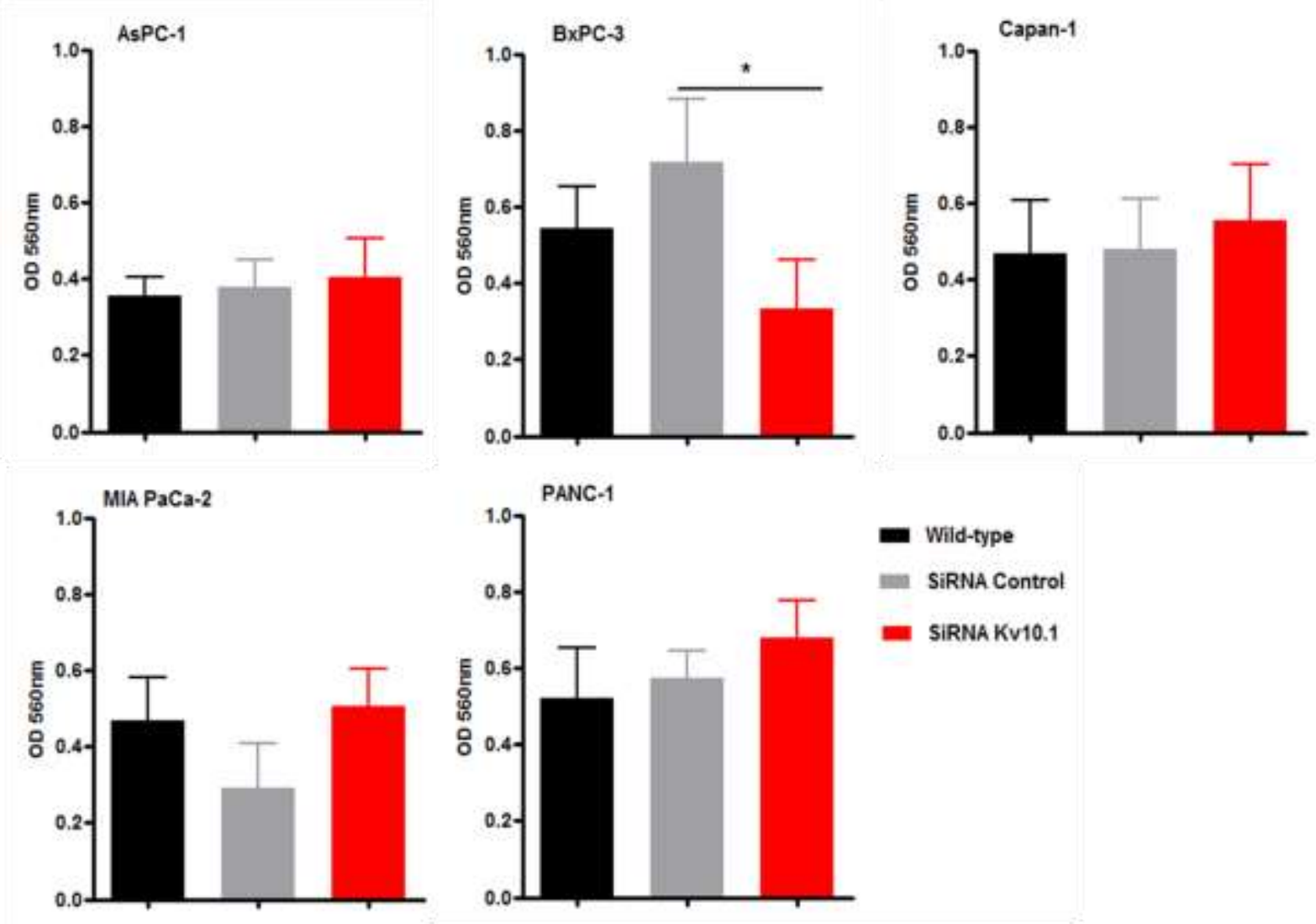

Figure 15: Effect of knock down of Kv10.1 on migration. No significant effect of knock down of Kv10.1 in four of the PDAC cells, however there is reduction in the rate of migration in only BxPC-3 cells in 24 hours migration assay.

We also studied migration, using trans-well assays with the five PDAC cell lines. Knockdown of Kv10.1 had a significant effect only in BxPC-3 cells, whose migration was reduced by approximately 50\% upon knockdown compared to the control cells (Fig 15). There was no significant effect in any of the other cell lines tested. 
Results

We then attempted to generate long-term knockdown PDAC cells lines for Kv10.1 via a shRNA-mediated strategy. However, we were only successful in generating stable Kv10.1 knock down in Capan-1 cells. These cells were assessed for proliferation and migration.

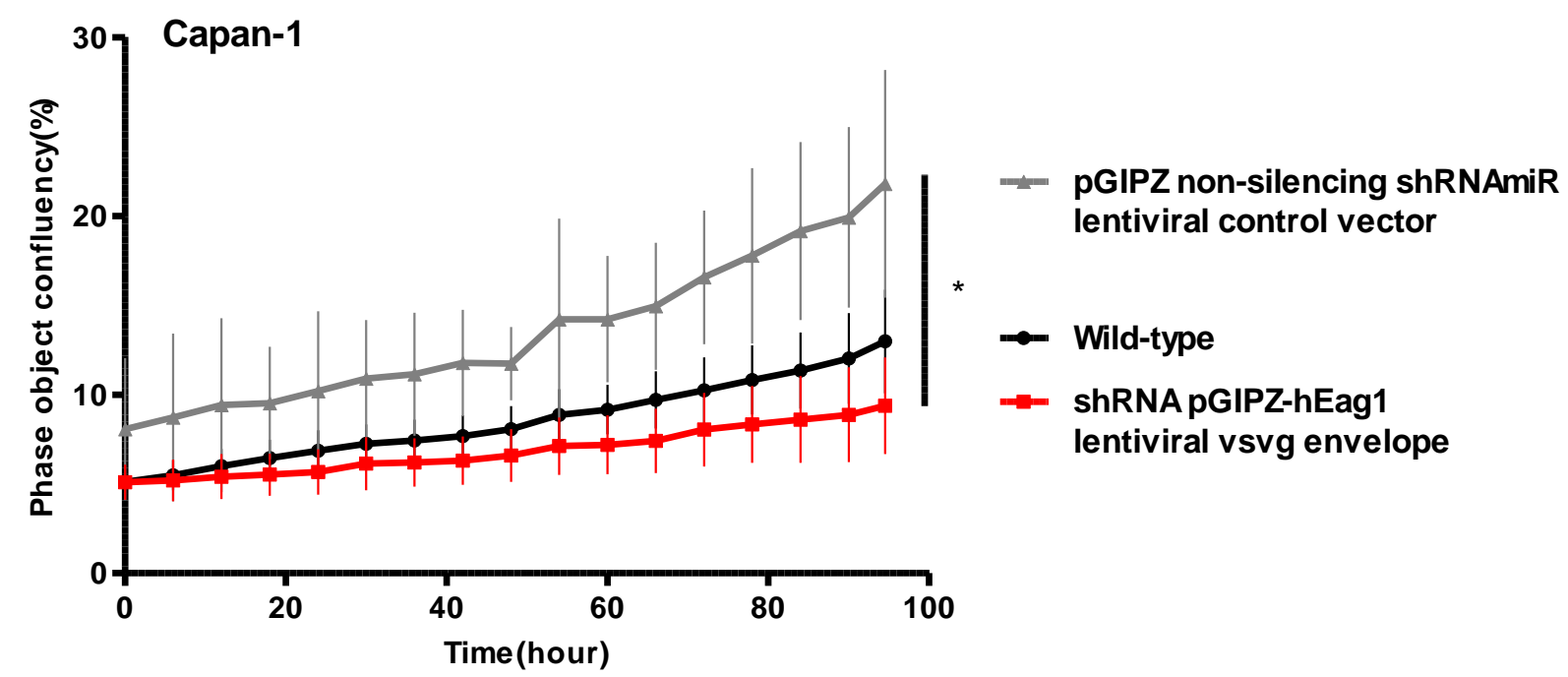

Figure 16: Reduction of rate of proliferation in Kv10.1 knock-out Capan-1 cells. Confluence mask indicated a decrease in the proliferation in Kv10.1 knock down Canan- 1 cells comnared to the control.

The rate of proliferation was significantly reduced in Kv10.1 knock down cells compared to the controls Figure 16, in contrast to the results obtained with transient knockdown. However, in trans-well assays, we observed no significant difference in the rate of migration in knockdown cells compared to the controls.

Therefore, we conclude that knock down of Kv10.1 in vitro leads to a decrease in the rate of proliferation of -at least- Capan-1 and MIA PaCa-2 cells, but does not affect migration of any of the cell lines. 


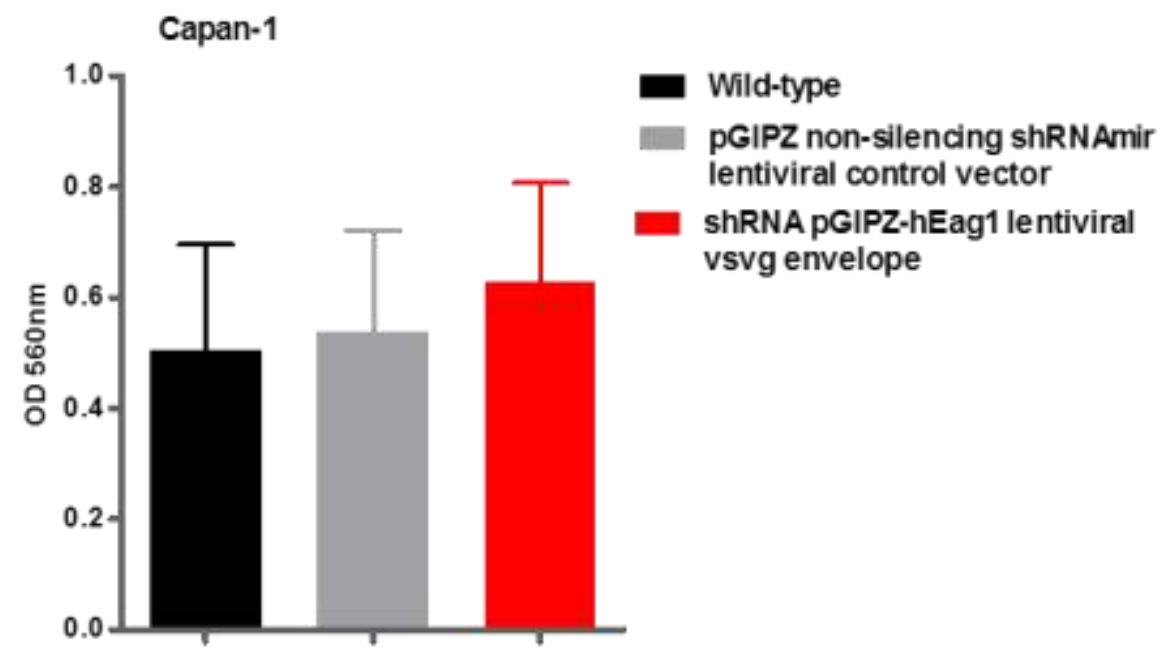

Figure 17: The rate of migration of Capan-1 cells was not affected by stable Kv10.1 knockdown.

We also performed overexpression experiments, using a vector that contains Kv10.1 fused to the yellow fluorescent protein mVenus under the control of the CMV promoter. All five PDAC cell lines were transfected with pCDNA3-Venus and pCDNA3-VenusKv10.1, but we could successfully generate stably transfected cell lines of only PANC-1 and MIA PaCa-2 cells.
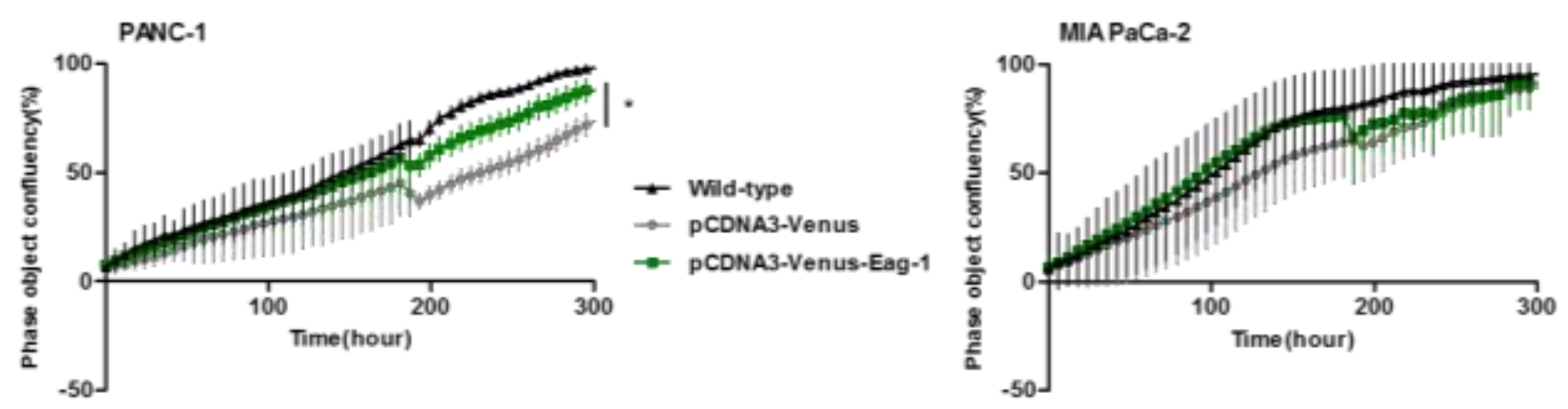

Figure 18: Kv10.1 over expressing cells show a cell line specific effect. Confluence mask indicated an increase in rate of proliferation in Panc-1 cells over expressing Kv10.1 and no difference in MiaPaCa-2. 
In live cell imaging experiments, a significant increase in the rate of proliferation in Panc-1 (pCDNA3-Venus-Eag-1) compared to PANC-1 (pCDNA3-Venus) was observed, while in MIA PaCa-2 we detected no effect (Fig 18).
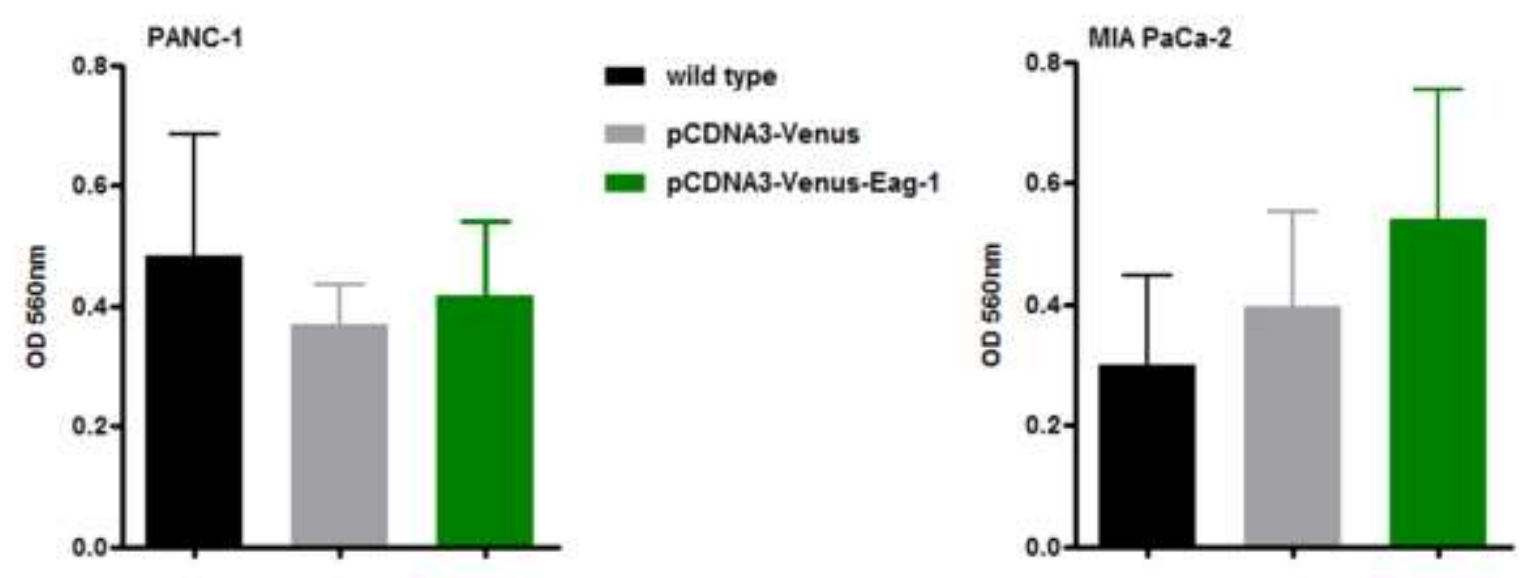

Figure 19: No significant effect of Kv10.1 on the rate of migration. Both cells lines showed no significant difference in rate of migration upon over expression of Kv10.1.

We further went on to investigate the effect on migration using the trans-well assay as described before. We observed there was no significant difference in the rate of migration between the wild-type, pCDNA3-Venus and pCDNA3-Venus-Eag-1 in both PANC-1 and MIA PaCa-2 Fig 19.

\section{Effects of scFv62TRAIL ${ }^{\text {Lys }}$ and Gemcitabine on PDAC cell lines in single 2D culture.}

The results described up to now showed a limited relevance of Kv10.1 expression in the proliferation of PDAC cell lines, and would argue against the use of Kv10.1 blockers/modulators in therapy. Nevertheless, Kv10.1, due to its enrichment in tumour tissue, can still be used as a label to target other agents to the tumour site. Over the last 15 years several therapies involving antibodies have been established as successful 
Results

strategies for treating patients with both haematological and solid tumours. We set out to investigate the potential of Kv10.1 as a target in PDAC cell lines. We achieved this with an in-house constructed bi-functional antibody which has a Kv10.1-specific (scFv62) antibody fused to TRAIL ${ }^{\text {Lys }}$ (optimized TRAIL mutant).

For our study we have used Capan-1, which is positive for Kv10.1 and also known to be resistant to TRAIL-induced apoptosis, and the BxPC-3 cell line, which is known to be sensitive to TRAIL-induced apoptosis (Wang et al. 2007, Wicker et al. 2010).

\subsection{Effect of ScFv62TRAIL ${ }^{\text {Lys }}$ on PDAC cell viability}

This assay was performed to test the concentration and the degree of cytotoxicity of scFv62TRAIL ${ }^{\text {Lys }}(0.48 \mu \mathrm{g} / \mathrm{mL})$ alone and in combination with Gemcitabine $(25 \mu \mathrm{M})$ on the PDAC cells. These experiments detect cell death, irrespective of the mechanism of cytotoxicity.

Capan-1 cells were treated with scFv62TRAIL ${ }^{\text {Lys }}$ alone or in combination with Gemcitabine along with the CellTox dye (1:2000 dilution) as described in the Methods section. Gemcitabine $(25 \mu \mathrm{M})$ or sTRAIL $(0.48 \mu \mathrm{g} / \mathrm{mL})$ alone induced virtually no cytotoxicity, and very few green fluorescent cells could be observed Fig. 20. 
Results

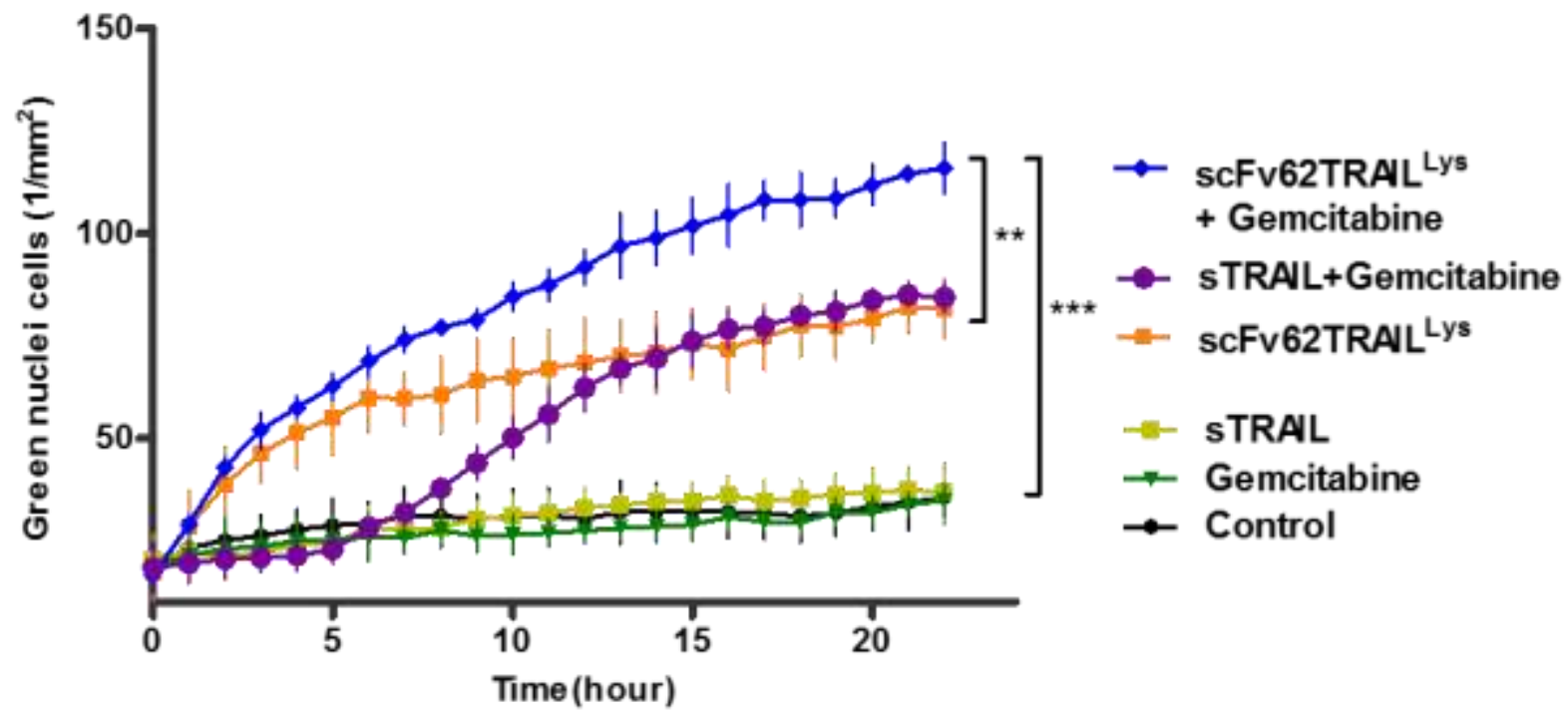

Figure 20: Cytotoxicity induced in Capan-1 cells. High level of toxicity observed in cells that were treated with scFv62TRAILLys in combination with Gemcitabine.

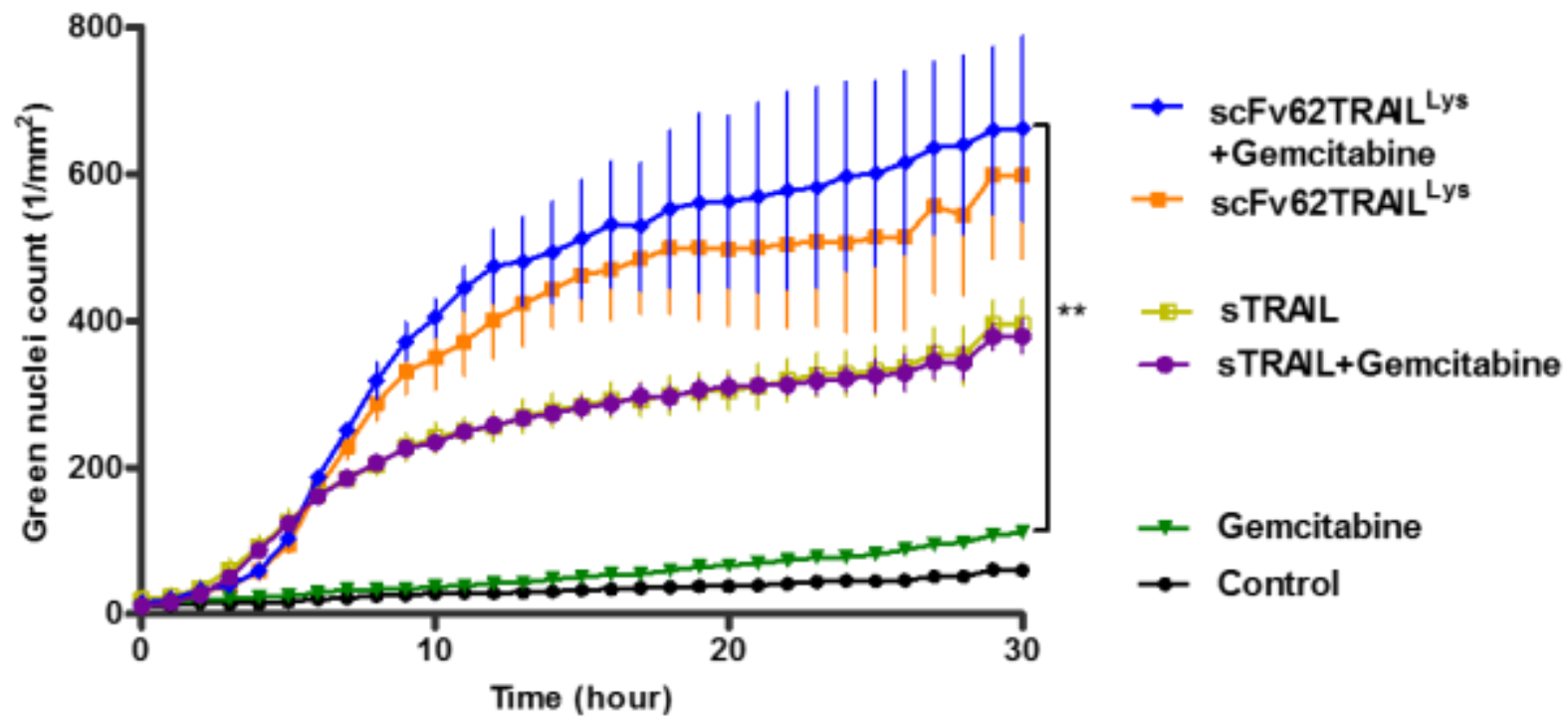

Figure 21: Cytotoxicity induced in BxPC-3 cells. High level of toxicity observed in these cells that were treated with both combination therapy 
In contrast, both agents combined produced an increase in green fluorescent (dead) cells after approximately 6 hours of treatment. scFv62TAIL ${ }^{\text {Lys }}(0.48 \mu \mathrm{g} / \mathrm{mL})$ alone already induced cytotoxicity from the first hours. Combination of Gemcitabine and scFv62TRAIL ${ }^{\text {Lys }}$ induced the death of a significantly larger fraction of cells, representing approximately 3.4 fold the extent of cytotoxicity induced by Gemcitabine alone and 1.4 fold compared to scFv62TAIL Lys alone.

When the equivalent experiment was performed on BxPC-3 cells Fig. 21, Gemcitabine alone again failed to induce cell death. In contrast, sTRAIL, both alone or in combination induced a clear increase in the fraction of non-viable cells. This was expected, because BxPC-3 cells are known to be sensitive to TRAIL (Wang et al. 2007). scFv62TRAIL ${ }^{\text {Lys }}$ again induced the strongest effect, but in this case there was no difference between the construct alone or in combination with Gemcitabine. Still, the treatment with the construct in combination with Gemcitabine showed an 8.6 fold increase in cytotoxicity when compared to Gemcitabine alone. 


\subsection{Cell death induced by combination treatment is largely due to apoptosis}

To investigate the mechanism of cytotoxicity induced by the different treatments, we measured activation of Caspase-3/7 as indicator of apoptotic cell death. During apoptosis, caspase- 3 is one of the main effector caspases that are activated. The assay we used consists on the addition of a cell-permeant caspase-3/7 substrate to the medium. When cleaved, the reagent releases a DNA intercalating dye. The activated caspase-3/7 results in green fluorescent nuclei.

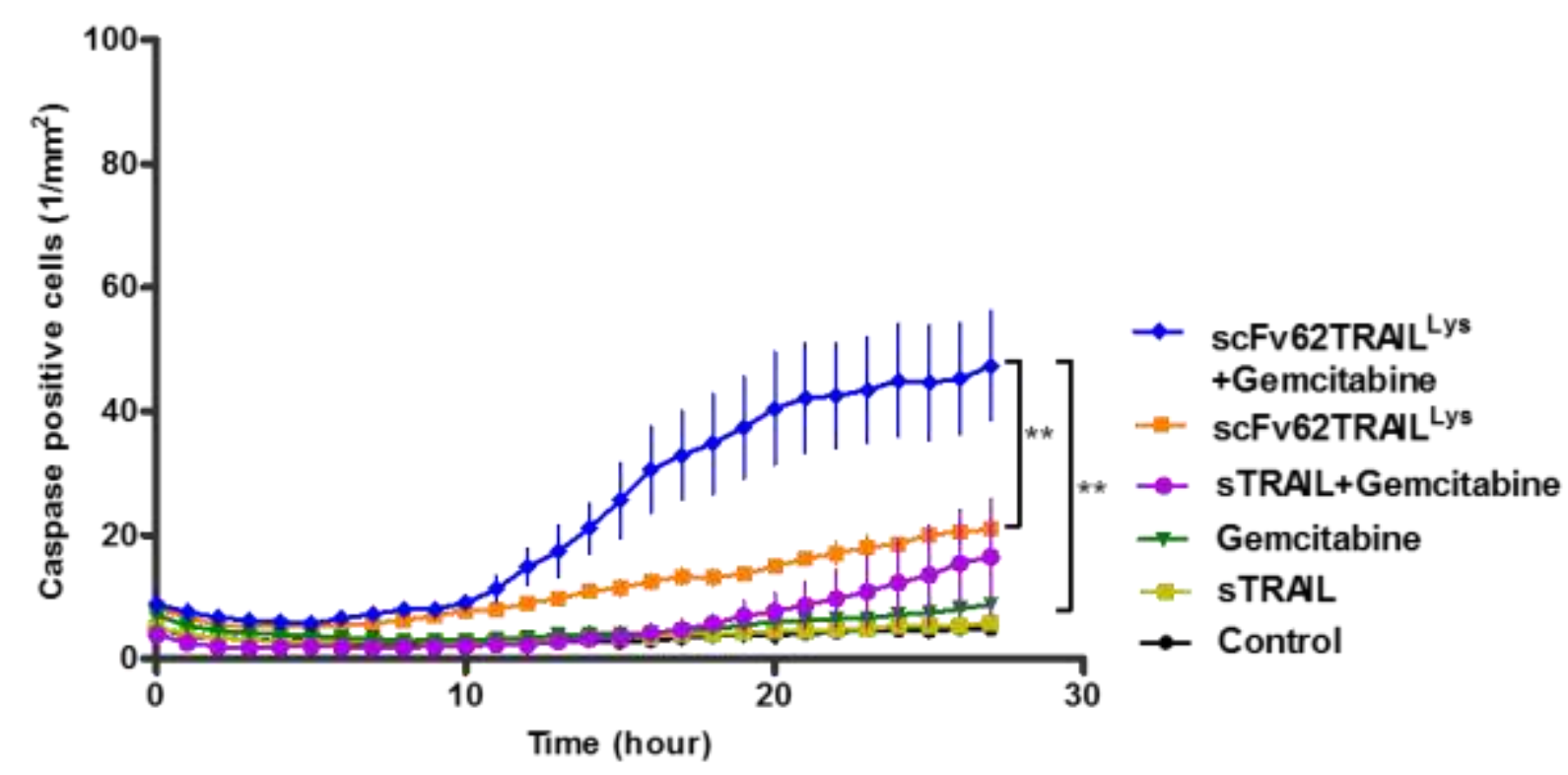

Figure 22: Increase in Caspase-3/7 activity observed in Capan-1 cells when treated with scFv62TRAILLys in combination with Gemcitabine.

The live-cell imaging was performed in the IncuCyte Zoom. The zoom software was used to generate a process definition that created a mask for the green fluorescent staining and thereby quantified the number of apoptotic (caspase-positive) cells.

In Capan-1 cells, no or very little apoptosis was detected over a $24 \mathrm{~h}$ period in the control, or when $25 \mu \mathrm{M}$ Gemcitabine, sTRAIL $(0.48 \mu \mathrm{g} / \mathrm{mL})$ or the scFv62TRAIL ${ }^{\text {Lys }}(0.48$ $\mu \mathrm{g} / \mathrm{mL}$ ) construct alone were added to the medium Fig. 22. There was a significant 
Results

increase in apoptotic cells on treatment with ScFv62TRAIL ${ }^{\text {Lys }}$ in combination with Gemcitabine compared to Gemcitabine alone (5.2 fold). There was also a significant increase in apoptosis in cells treated with scFv62TRAIL Lys in combination with Gemcitabine compared to scFv62TRAIL Lys.

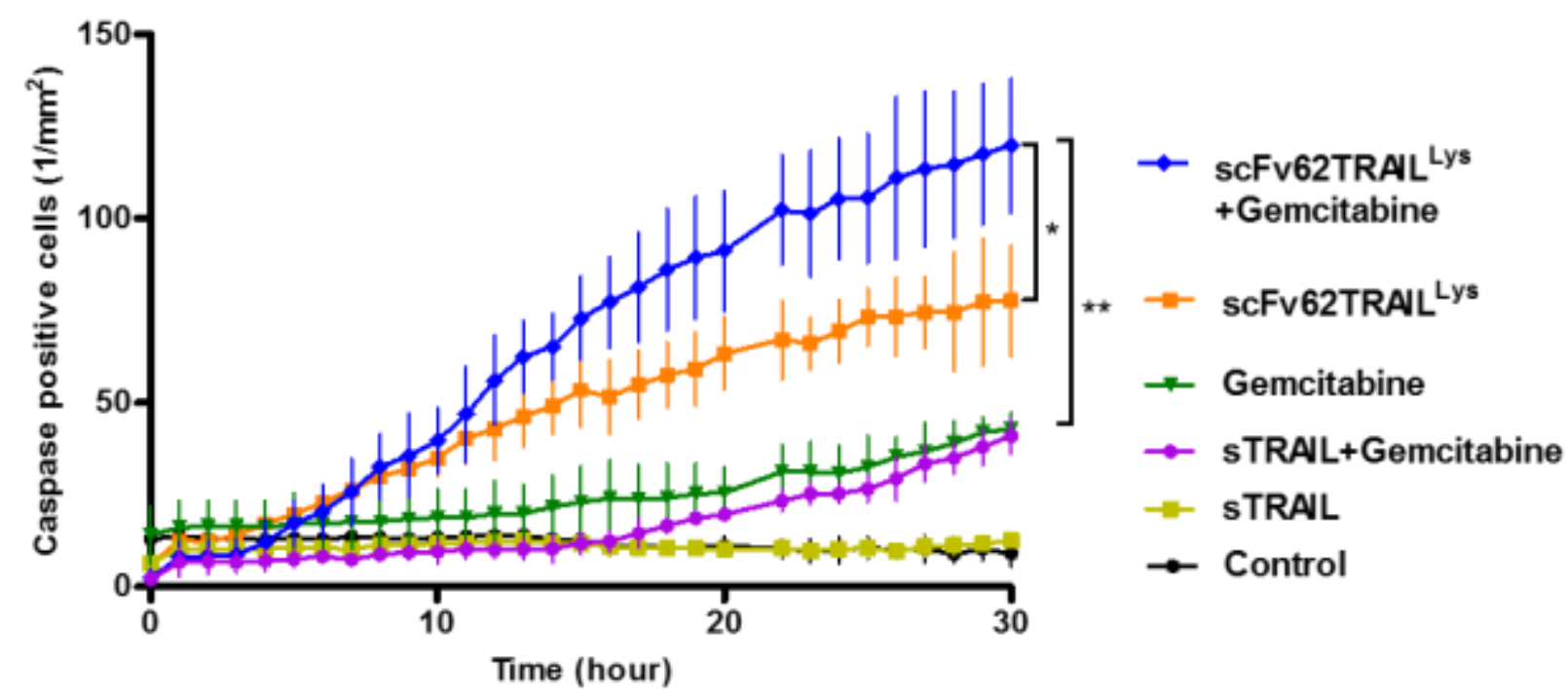

Figure 23: High Caspase-3/7 activity induced in BxPC-3 cells when treated with scFv62TRAILLys alone or in combination with Gemcitabine.

In BxPC3, caspase activity was low in the control over a $30 \mathrm{~h}$ period Fig. 23 . We did not observe a consistent increase in caspase activity in the presence of sTRAIL alone, although as mentioned previously, BxPC-3 cell line is reportedly sensitive to TRAILinduced apoptosis (Wang et al. 2007). In contrast, scFv62TRAIL ${ }^{\text {Lys }}$ alone induced apoptosis in a relevant fraction of cells. ScFv62TRAIL Lys in combination with Gemcitabine showed an additive effect, and the induction of apoptosis was significantly larger than with Gemcitabine or ScFv62TRAIL ${ }^{\text {Lys }}$ alone. The treatment with ScFv62TRAIL ${ }^{\text {Lys }}$ in combination with Gemcitabine had a significant 2.7 fold increase in caspase activity compared to Gemcitabine alone. Interestingly, we also observed that addition of Gemcitabine to STRAIL slowed down the activation of caspase Fig. 23. Despite the absence of caspase activation in cells treated with STRAIL alone, the 
Results

viability of cells treated with sTRAIL alone and in combination with Gemcitabine was reduced (see Fig. 21).

To confirm that the increase of fluorescence that we used as indicator of apoptosis is indeed due to caspase activation, we performed similar experiments to those described above in the presence of the general caspase inhibitor Z-VAD-FMK, which binds to the active site of the activated proteases thereby inhibiting apoptosis (Zhang et al. 2015).

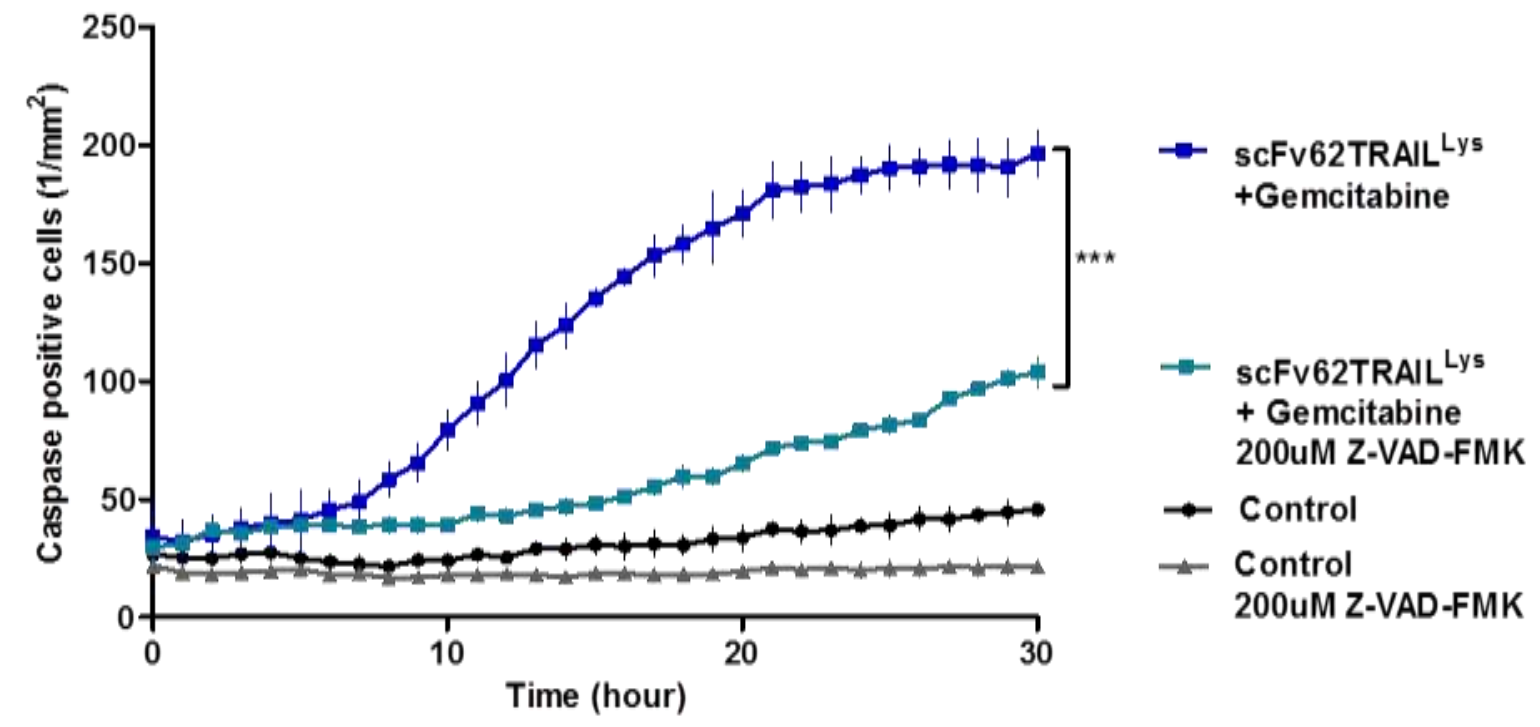

Figure 24: Fluorescence is significantly reduced in the presence of Caspase-3/7 inhibitors. When treated with combination therapy in the presence of Z-VAD-FMK reduction in induction of apoptosis in Capan-1 cells.

Capan- 1 cells were treated with scFv62TRAIL ${ }^{\text {Lys }}(0.48 \mu \mathrm{g} / \mathrm{ml})$ and Gemcitabine $(25 \mu \mathrm{M})$ along with caspase-3/7 substrate, with or without Z-VAD-FMK $(200 \mu \mathrm{M})$. Live-cell imaging revealed a significant reduction of the caspase reporter signal in the cells in the presence of caspase inhibitor. Therefore, the green fluorescent signal is likely due to activation of caspase.

As a more direct test for caspase activation, we performed western blot detection of cleaved caspase- 3 in cells treated as in the previous experiments. This test 
distinguishes additionally between Caspase-3 and Caspase-7 (through both antibody specificity and band size).

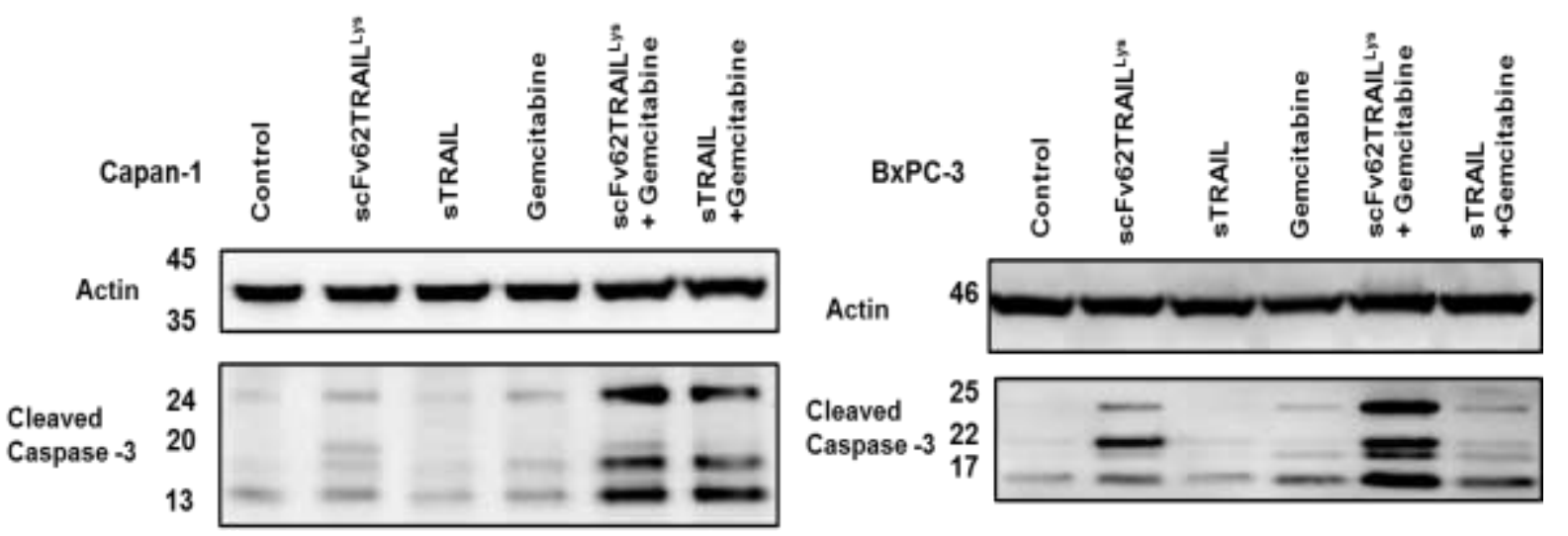

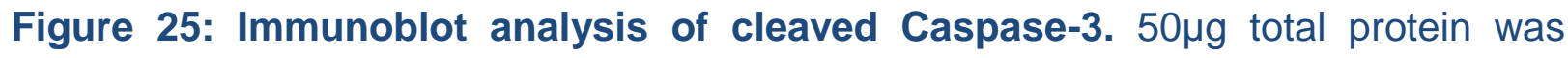
loaded and Immunoblot was performed as described in the Materials and Methods section. Protein expression of cleaved caspase-3 (17kDa, 19kDa and $26 \mathrm{kDa}$ ) was detected in lysates from cells treated with combination treatment.

Capan-1 and BxPC-3 cells were treated with ScFv62TRAIL ${ }^{\text {Lys }}$ alone or in combination with Gemcitabine for 12 hours. Cells were then harvested and lysed for western blotting using anti-cleaved caspase- 3 antibody as described in the Methods section. Capan-1 cells treated with scFv62TRAIL ${ }^{\text {Lys }}$ and Gemcitabine, or with TRAIL and Gemcitabine, showed intense bands corresponding to active (cleaved) caspase (17kDa and 19kDa) (Chandler et al. 1998). The $\sim 26 \mathrm{kDa}$ band could correspond to an additional cleavage product previously reported by others (Nakajima et al. 2011), and not to Pro-caspase-3, which is expected to be significantly larger. These experiments confirmed the activation of caspase-3 when both Gemcitabine and TRAIL were present.

BxPC-3 cells treated with scFv62TAIL ${ }^{\text {Lys }}$ or scFv62TAIL ${ }^{\text {Lys }}$ in combination with Gemcitabine showed strong bands corresponding to cleaved caspase-3, while Gemcitabine and sTRAIL produced only very faint bands. 
Results

These results correlate well with to the caspase- $3 / 7$ activity observed in live cell imaging lines in Figure. 21 and 23.
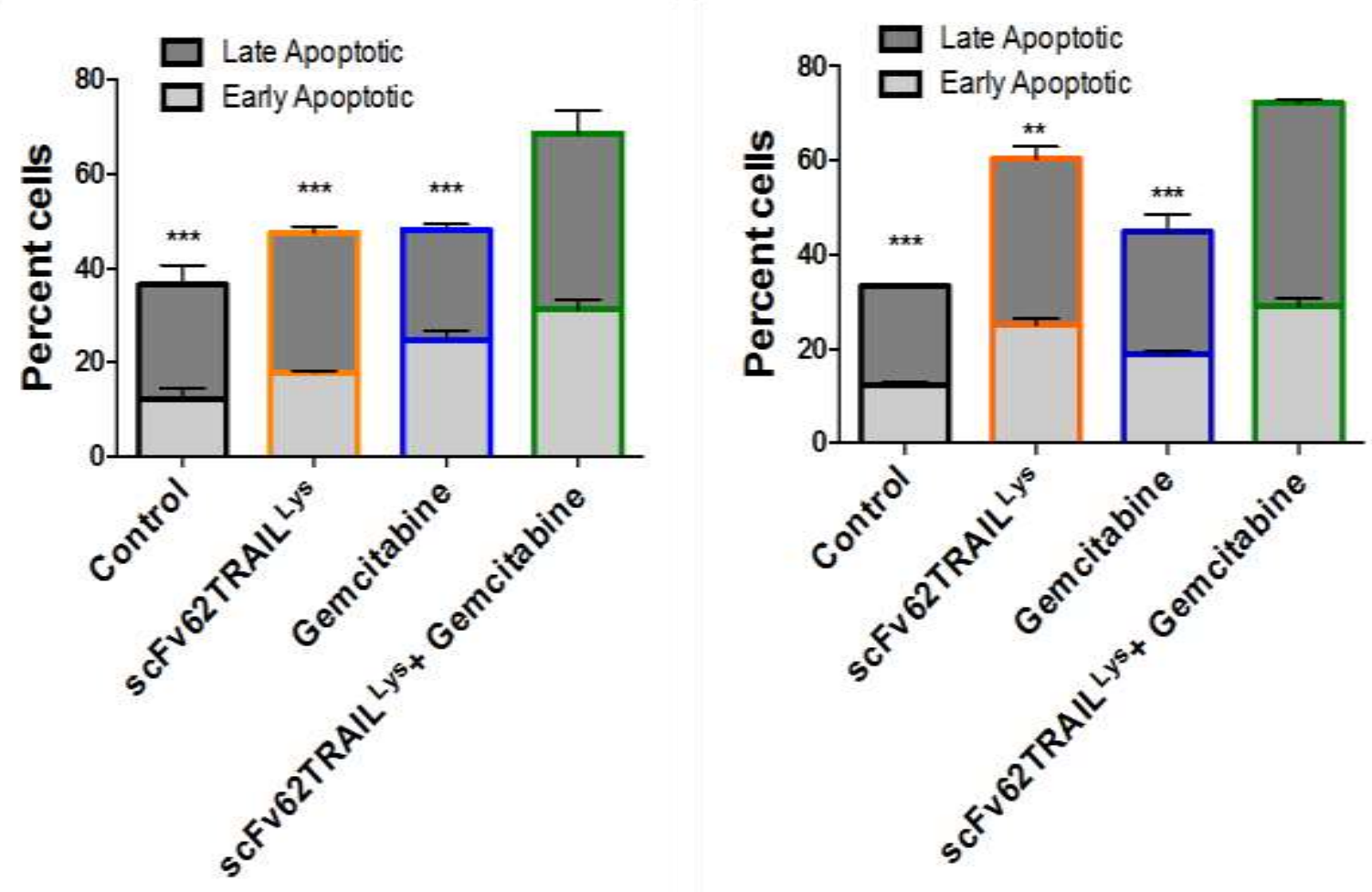

Figure 26: Increase apoptotic cells determined by flow cytometry. On treatment with ScFv62TRAIL Lys in combination with Gemcitabine led to a significant increase in apoptosis compared to Gemcitabine alone in both Capan-1 (left) and BxPC-3 (right) (Two way ANOVA; ${ }^{* *}: P<0.01 ;{ }^{* * *}: P<0.001$ )

One of the first events when a cell undergoes apoptosis is the loss of asymmetry of the plasma membrane; thus, phosphatidylserine (PS), a phospholipid normally present in the inner leaflet of the cell membrane, flips to the outer surface and is exposed to the medium and accessible to Annexin $\mathrm{V}$ binding. Flow cytometry experiments were performed using fluorescently labeled Annexin $\mathrm{V}$ to stain PS together with propidium iodide $(\mathrm{PI})$, which enters only dead cells because of the incompetence of the membrane. Early apoptotic cells will be annexin $\mathrm{V}$ positive and PI negative, while late apoptotic cells are double positive. Necrotic cells are only positive for PI. 
Capan-1 and BxPC-3 cells were treated with scFv62TRAIL ${ }^{\text {Lys }}$ in combination with Gemcitabine for 15 hours. Annexin V/PI staining was performed as described in the Methods section and analysed by FACS. In Capan-1 cells, the amount of viable cells decreased substantially with combination treatment with ScFv62TRAIL Lys and Gemcitabine as compared to the controls; this was accompanied by an increase in early and late apoptotic cells. Both agents used alone induced less reduction in viability. BxPC-3 cells are more sensitive to ScFv62TRAIL ${ }^{\text {Lys }}$, and the combination also induced a clear significant increase in apoptotic cells (Fig. $21 \& 23$ ).

Annexin $\mathrm{V}$ assay was also performed on Capan-1 and BxPC-3 cells during treatment and live cell imaging in the IncuCyte as described in the Methods section.

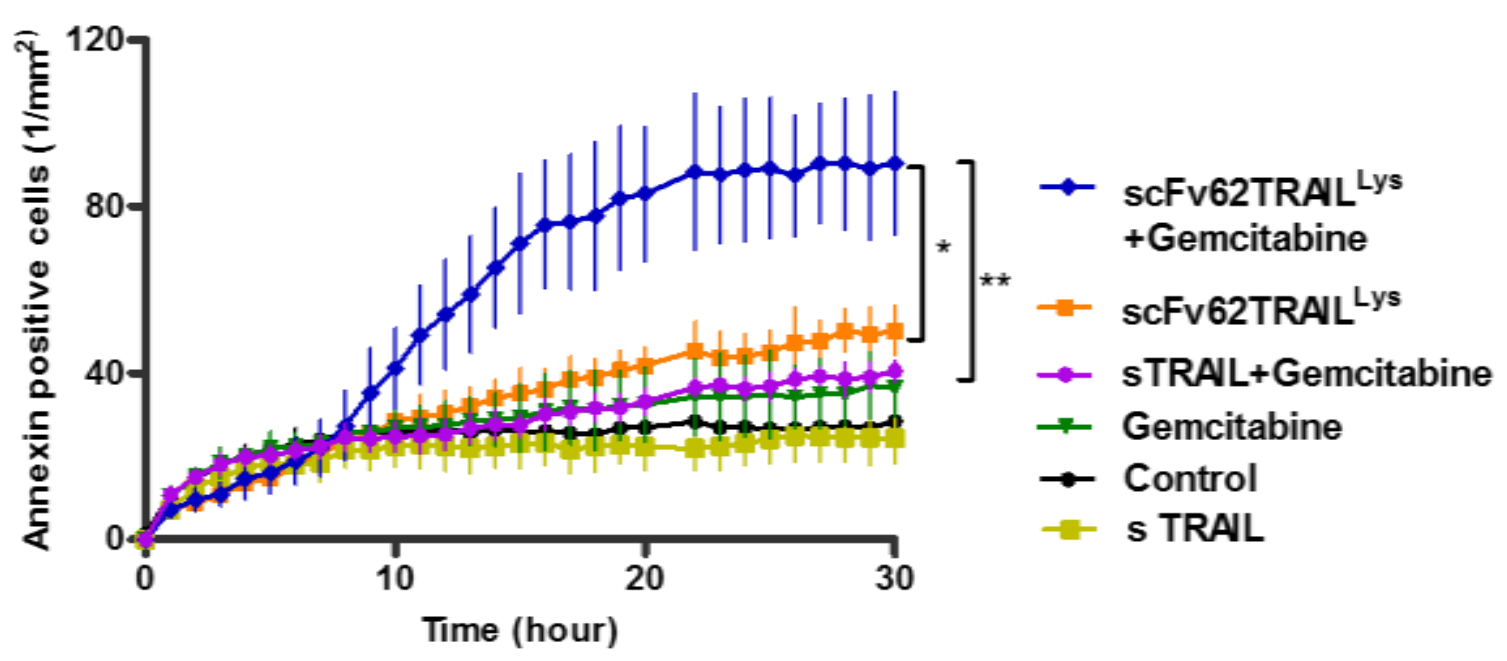

Figure 27: Annexin V binding in Capan-1 measured in live cell imaging. Treatment with scFv62TRAIL ${ }^{\text {Lys }}$ in combination with Gemcitabine induced apoptosis.

In Capan-1 cells treated with scFv62TRAIL ${ }^{\text {Lys }}$ in combination with Gemcitabine, there was a significant increase in Annexin $\mathrm{V}$ binding when compared to Gemcitabine. The difference was also significant between ScFv62TRAIL ${ }^{\text {Lys }}$ alone and in combination with Gemcitabine (Fig. 27). 


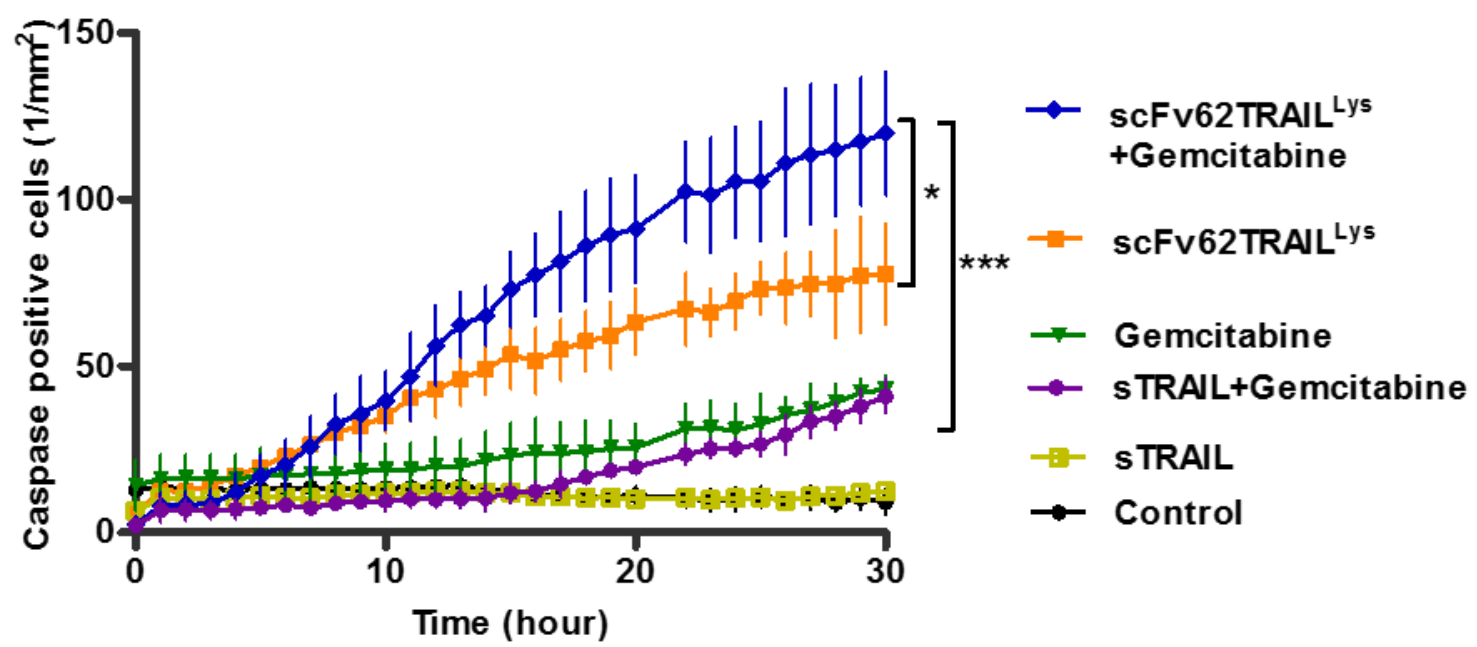

Figure 28: Annexin V binding in BxPC-3 in live cell imaging. Treatment with scFv62TRAILLys alone and in combination with Gemcitabine induced apoptosis.

The same experiment was performed on BxPC-3 cell line. In contrast to Capan-1, both ScFv62TRAIL ${ }^{\text {Lys }}$ alone and in combination with Gemcitabine produced a significant increase in apoptosis when compared to Gemcitabine alone (Fig. 28). There increase in apoptotic cells in ScFv62TRAIL ${ }^{\text {Lys }}$ in combination with Gemcitabine when compared to scFv62TRAIL ${ }^{\text {Lys }}$ alone was also significant. Therefore, the outcome of this experiment confirms the results observed in flow cytometry (Fig. 26).

\subsection{TRAIL is required to induce apoptosis under combination treatment}

To elucidate if the caspase activation detected upon combination treatment with Gemcitabine and scFv62TRAIL ${ }^{\text {Lys }}$ is actually due to TRAIL activation, we performed experiments were the TRAIL moiety of the construct had been omitted. We used scFv62-Cys, a construct where the TRAIL sequence is absent and substituted by a single cysteine residue to allow labeling. 


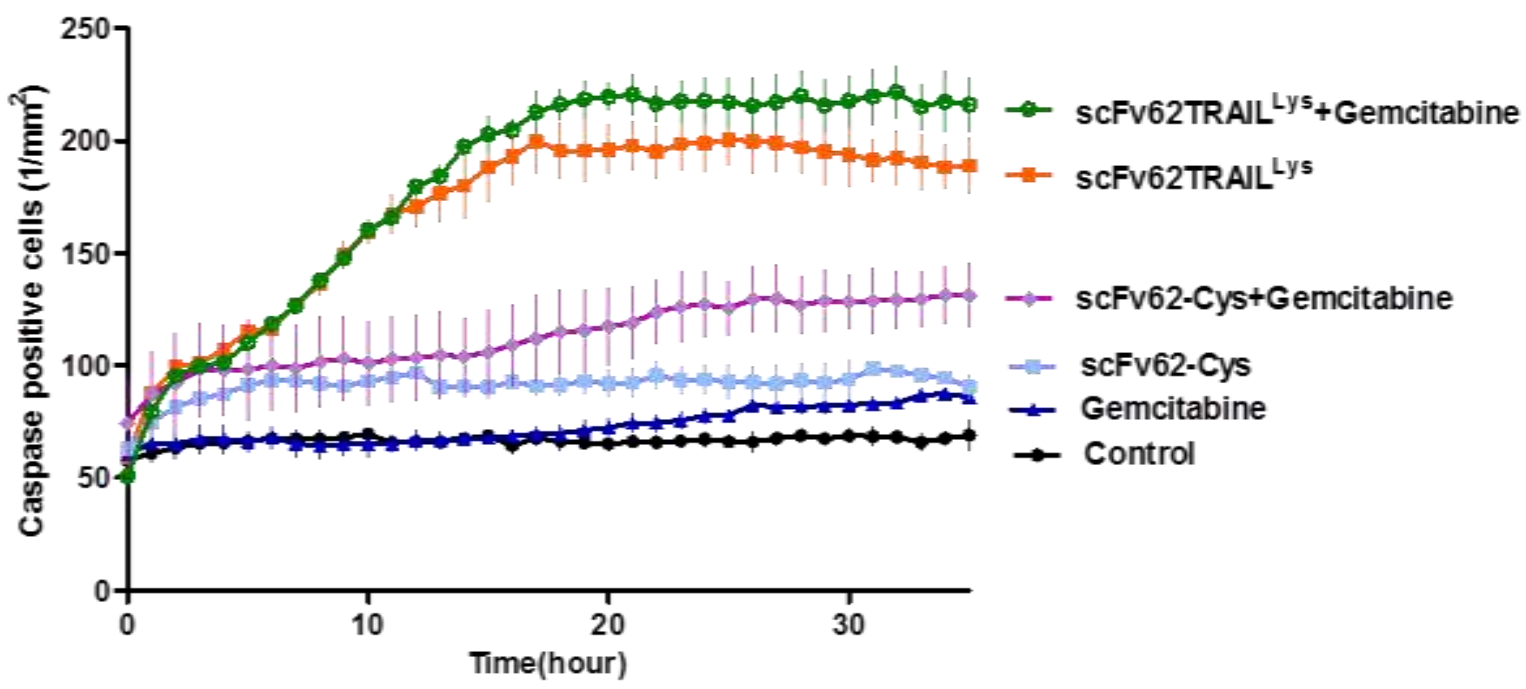

Figure 29: scFv62 without TRAIL ${ }^{\text {Lys }}$ does not induce apoptosis in Capan-1 cells.

scFv62-Cys induced a marginal increase in apoptosis when added alone to the culture medium; apoptosis was slightly increased when scFv62-Cys was combined with Gemcitabine. In any case, either alone or in combination, scFv62-Cys gave rise to significantly less apoptosis than what was induced by scFv62TRAIL ${ }^{\text {Lys }}$. We therefore conclude that at least a major fraction of the apoptosis induced by scFv62TRAIL ${ }^{\text {Lys }}$ requires the presence of TRAIL. Since the ScFv62-Cys antibody was produced under the same conditions as ScFv62TRAIL ${ }^{\text {Lys }}$, these experiments also ruled out the presence in the preparation of a contaminating apoptosis-inducing factor other than the construct itself.

\subsection{One-hour exposure to scFv62TRAIL ${ }^{\text {Lys }}$ is sufficient to trigger apoptosis}

To discern the kinetics of apoptosis during our treatment we performed a caspase assay wherein cells plated were pre-treated for 3 hours with Gemcitabine along with caspase-3/7 substrate. Subsequently, ScFv62TRAIL ${ }^{\text {Lys }}$ was added and incubated for either 1 hour, 3 hours or maintained for entire period of the experiment as described in the Methods section. It should be noted that Gemcitabine was present throughout the 
experiment and that it was the ScFv62TRAIL ${ }^{\text {Lys }}$ that was removed after the incubation time.

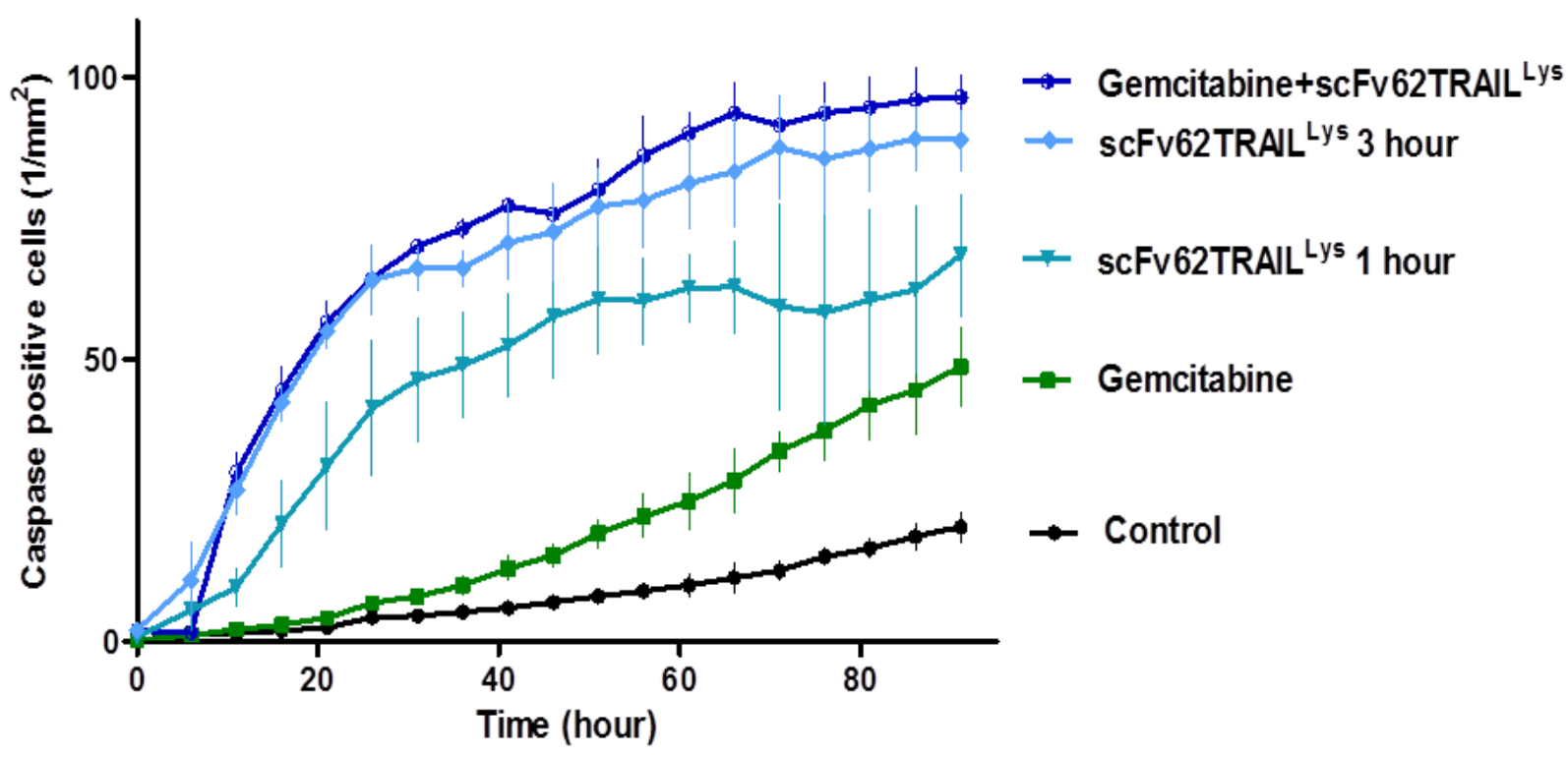

Figure 30: 1-hour incubation with scFv62TRAlL ${ }^{\text {Lys }}$ is sufficient to trigger apoptosis. High Caspase-3/7 activity in Capan-1 cells when treated with scFv62TRAIL ${ }^{\text {Lys }}$ for 3 hours with a pre-treatment with Gemcitabine.

As shown in Figure 30, 1 hour incubation was enough to trigger induction of apoptosis. It can also be observed that 3 hours of incubation produced the same level of apoptosis as when scFv62TRAIL ${ }^{\text {Lys }}$ was maintained throughout the experiment.

\section{Effects of ScFv62TRAIL ${ }^{\text {Lys }}$ and Gemcitabine on PDAC cell lines co-cultured with stellate cells.}

PDAC is unique to other solid tumours because of the presence of an intense stromal reaction, to which pancreatic stellate cells are major contributors. This stromal reaction and stellate cells play a role in chemo-resistance (Pandol et al. 2009). We wanted to test the effect of our treatment strategies on human stellate cells. For this purpose we used pancreatic stellate cells immortalized with telomerase and SV40 virus large T antigen (RLT-PSC). 


\section{1 sTRAIL, ScFv62-TRAIL ${ }^{\text {Lys }}$, and Gemcitabine trigger minimal apoptosis in RLT-PSC cells}

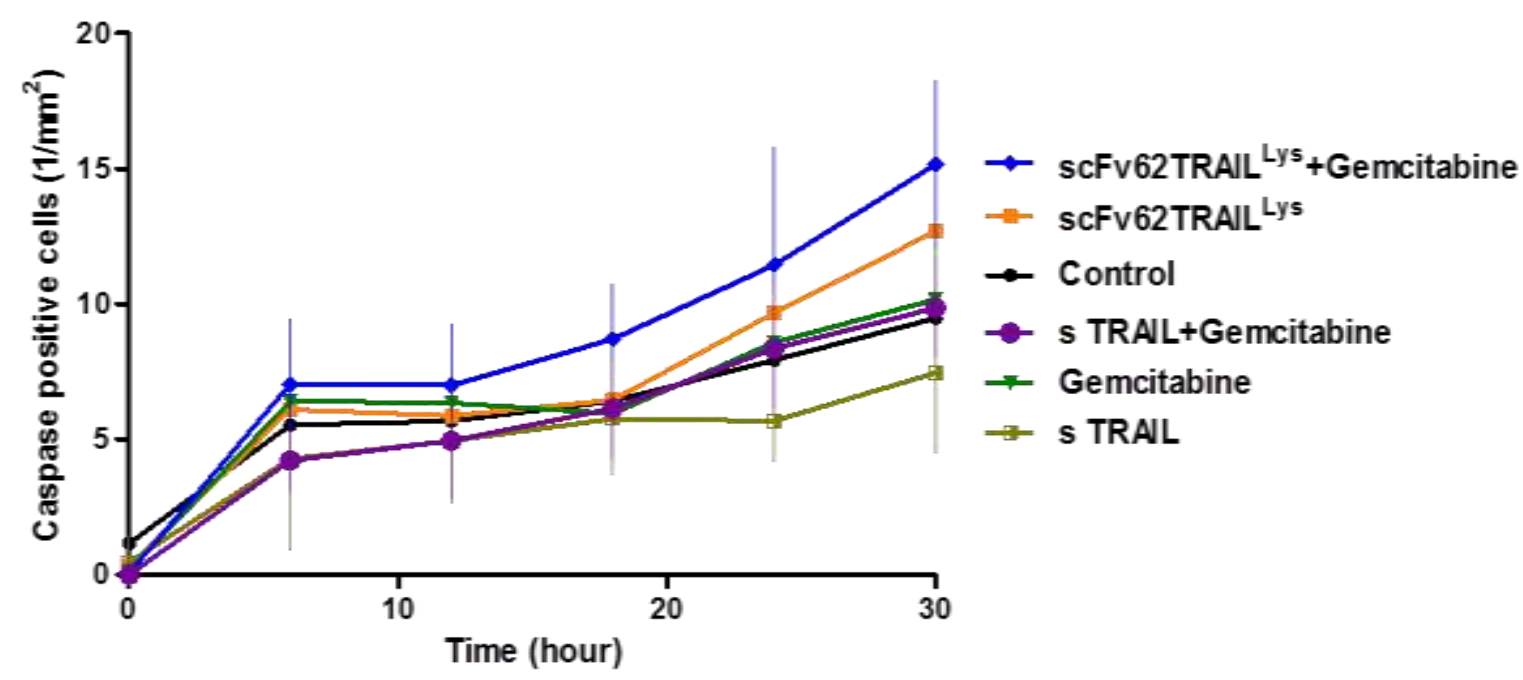

Figure 31: Caspase-3/7 activity did not increase in RLT-PSC on treatment up to 30 hours.

RLT-PSC cells were treated with ScFv62TRAIL ${ }^{\text {Lys }}$ alone and in combination with Gemcitabine along with the caspase- $3 / 7$ substrate $(5 \mu \mathrm{M})$. Figure 31 represents the caspase activity on the stellate cells up to 30 hours. Interestingly, we observed that there was no significant caspase activity induction with any of the treatment strategies on the stellate cells. 


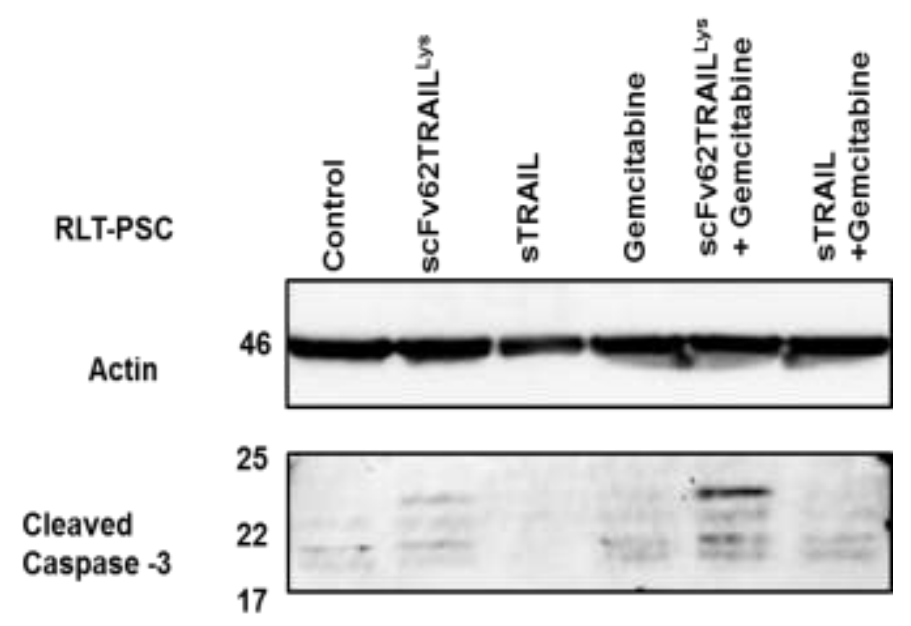

Figure 32: Immunoblot analysis of Cleaved Caspase-3. 30 $\mathrm{\mu g}$ total protein was loaded and Immunoblot was performed as described in the Materials and Methods section. Protein expression of cleaved caspase-3 (17kDa, 19kDa and $\sim 26 \mathrm{kDa}$ ) was detected in Ivsates from cells treated with combination treatment.

The marginal effects on caspase- 3 activation of the treatments on RLT-PSC cells were confirmed by western blot. Cells were treated with scFv62TRAIL ${ }^{\text {Lys }}$ alone or in combination with Gemcitabine for 12 hours, and then harvested and lysed for western blotting using anti-caspase-3 antibody as described in the Methods section. Cells treated with scFv62TRAIL ${ }^{\text {Lys }}$ and Gemcitabine, and scFv62TRAIL ${ }^{\text {Lys }}$ showed faint bands corresponding to active (cleaved) caspase-3 (17kDa and 19kDa) (Chandler et al. 1998). The abundance of cleaved fragments was not comparable to that seen in tumour cells (see Fig. 25). 


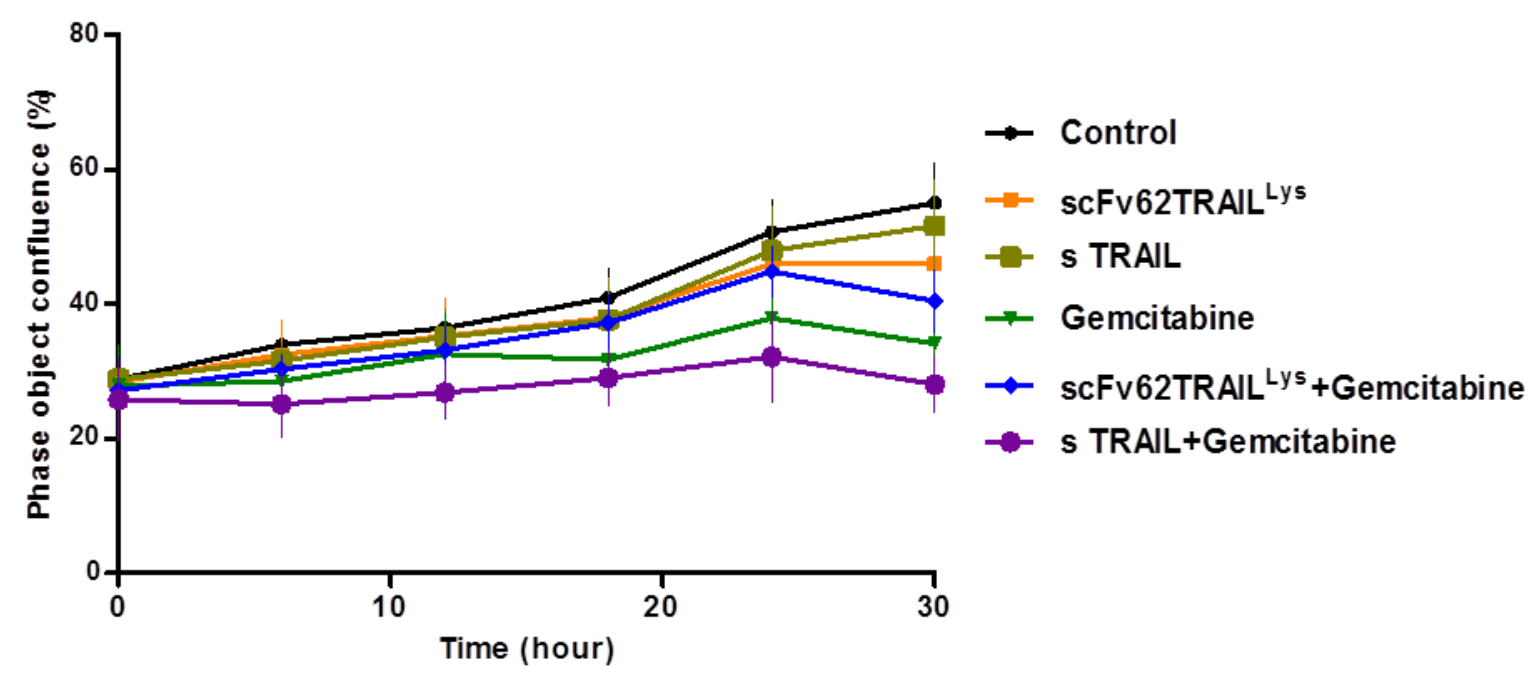

Figure 33: Gemcitabine inhibits proliferation of RLT-PSC cells. Confluence of RLTPSC up to 30 hours showed no difference between the different treatments; cells in the presence of Gemcitabine did not grow.

We went on to look into the rate of proliferation during treatment on RLT-PSC. For this purpose with the help of IncuCyte zoom, a processing definition for creating a confluence mask was generated. During the 30 hours the cells grew only slightly, but Gemcitabine in any combination abolished this proliferation.

\subsection{RLT-PSC sensitize PDAC cells towards combination treatment}

We then performed co-culture experiments of PDAC and PSCs, to investigate if the stellate cells would in fact make cancer cells resistant. To differentiate the two cell types, PSCs were transfected with nuclear mCherry 


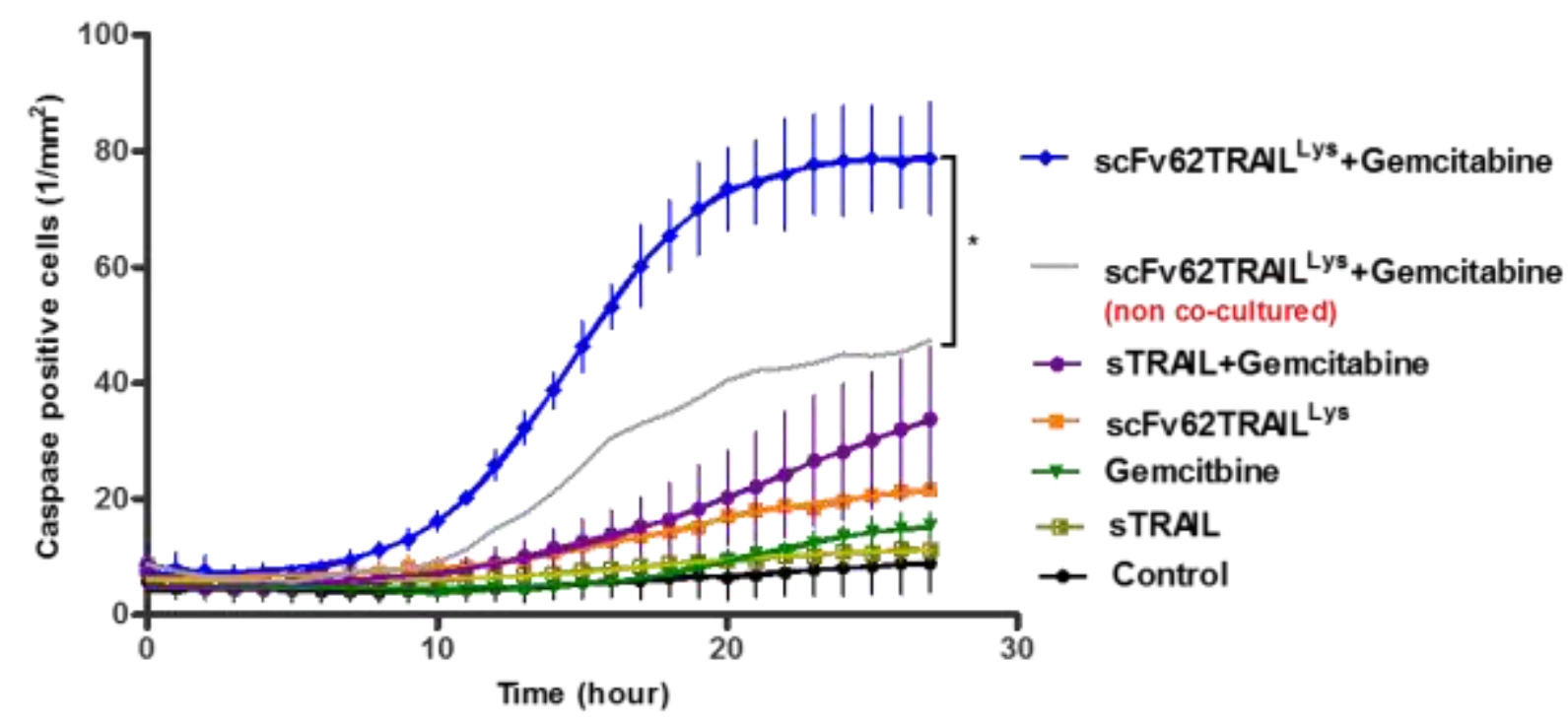

Figure 34 Caspase-3/7 activity doubled in Capan- 1 cells when co-cultured with stellate cells on treatment with combination therapy.

The mixed culture was treated with scFv62TRAIL Lys and Gemcitabine, alone or in combination, and caspase-3/7 activity was monitored over time. Under these conditions, control cells and single treatments behaved qualitatively similar to single cultures of Capan-1 cells. However, the combination of scFv62TRAIL Lys and Gemcitabine increased the number of Capan-1 apoptotic cells clearly more than when tumour cells were cultured alone ( 1.6 fold). Therefore, the stellate cells had a sensitizing effect on cancer cells. 


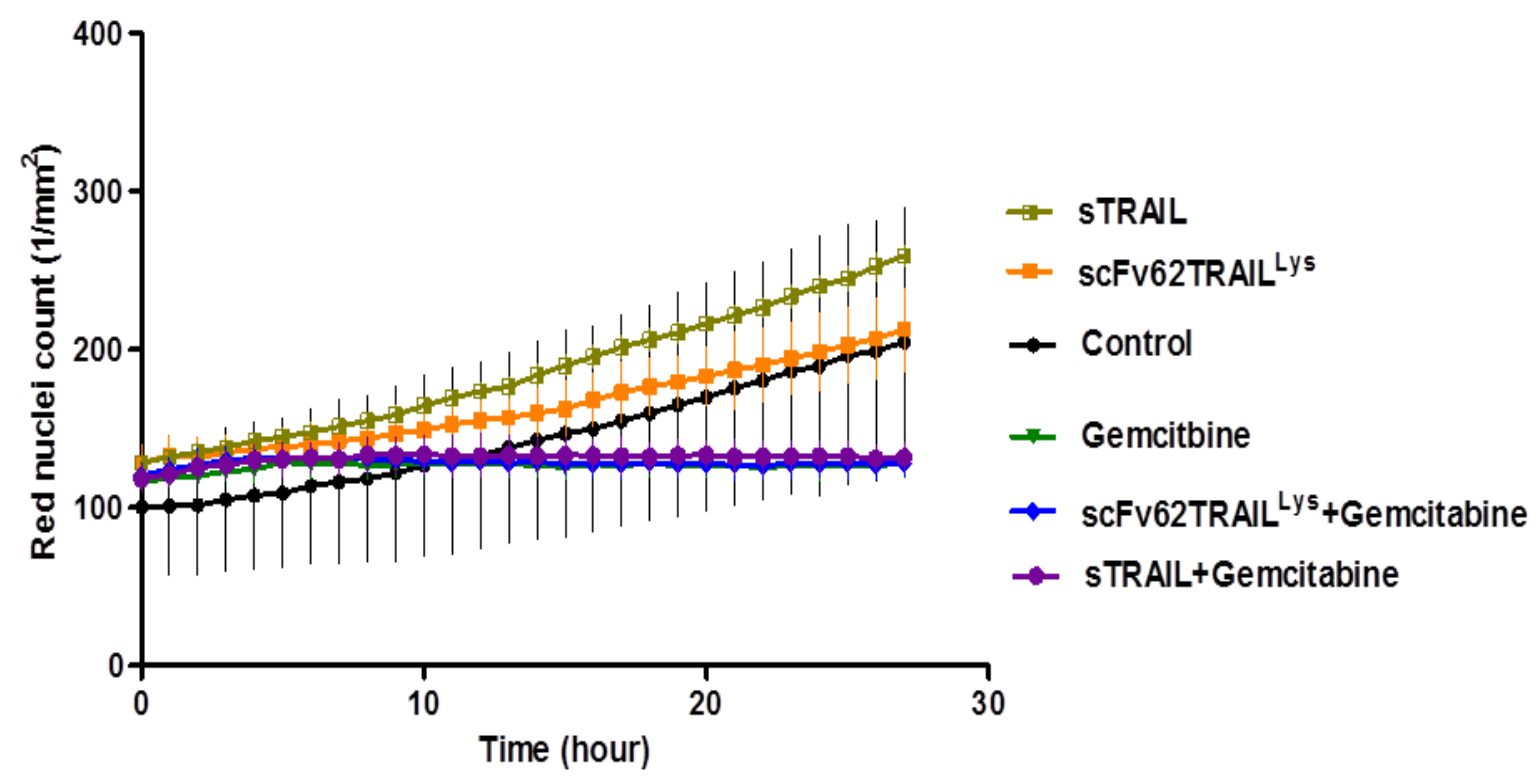

Figure 35: Stellate cells (RLT-PSC) tolerated the different treatments. No dramatic effect was detected with the treatment with scFv62TRAILLys alone or in combination in co-culture with Capan-1.

The increase in the abundance of apoptotic cells upon treatment with ScFv62 TRAIL ${ }^{\text {Lys }}$ in combination with Gemcitabine was due to tumour cells undergoing apoptosis, and not stellate cells. This was confirmed by monitoring the amount of red nuclei (PSCs) at the same time point, which showed that the presence of Gemcitabine arrested the growth of PSCs, and the number of red nuclei count remained constant. In the case of stellate cells, there was no significant difference between treatment with Gemcitabine alone or in combination. 


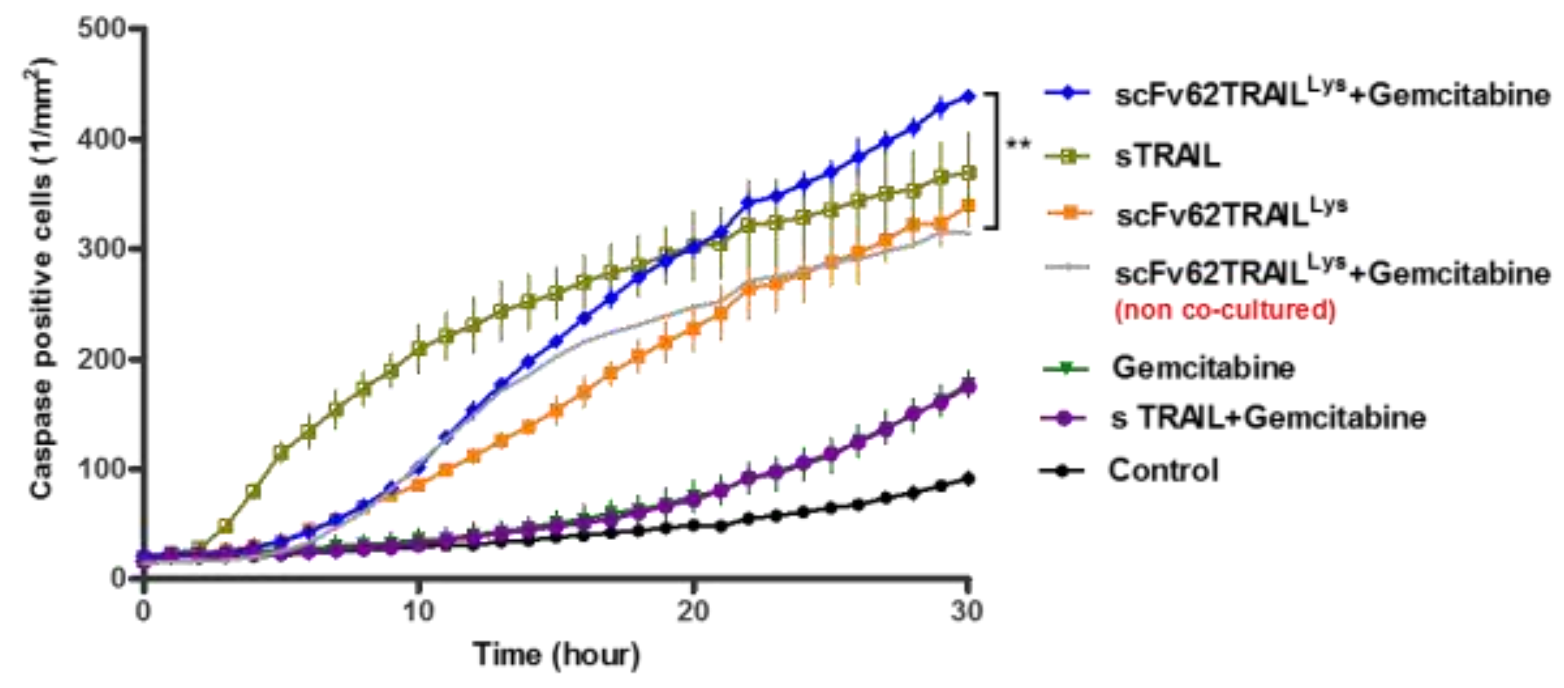

Figure 36: Caspase-3/7 activity in BxPC-3 co-cultured with stellate cells. The increase in apoptosis when compared to cultures without stellate cells on treatment with combination therapy was milder than the one observed in Capan-1.

Similarly, BxPC-3 and RLT-PSC cells (nucleus labelled with m-Cherry) were co-cultured and treated with scFv62TRAIL ${ }^{\text {Lys }}$ alone and in combination with Gemcitabine. As with Capan-1, in BxPC-3 cells that were co-cultured with stellate cells and then treated, the combination therapy once again had the highest caspase activity, and the effect was more intense than in monocultures of BxPC-3 cells. In case of these cells there was no significant difference in caspase-3/7 activity when compared to the non-co-cultured cells. 


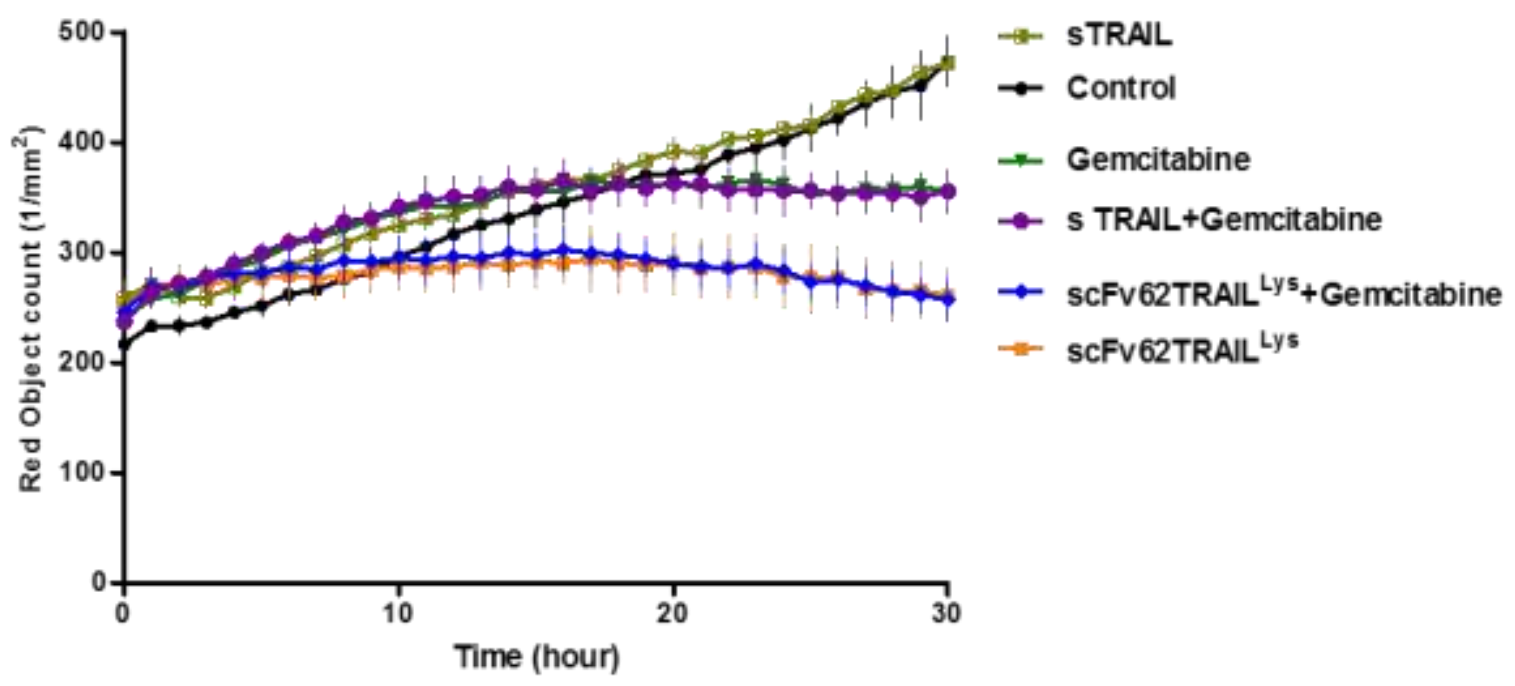

Figure 37: RLT-PSC in co-culture with BxPC-3 tolerated the different treatments. No dramatic effect on the number of stellate cells (red nuclei count) between treatments.

The effect of the treatment on the RLT-PSC cells was similar to what was observed in the previous experiment (Fig. 35) involving the co-culture experiment with Capan-1. Once again the amount of red nuclei of the PSCs in the same cultures remained constant indicating that Gemcitabine had the same effect in terms of arresting the growth of PSCs (Fig. 37). 


\section{ScFv62TRAIL ${ }^{\text {Lys }}$ does not increase expression of IL-8}

As mentioned in the Introduction, it is known that under some circumstances TRAIL can induce an increase in proliferation/invasion in tumour cells, and that this effect is mediated through an inflammatory signaling pathway; when this happens, TRAILtreated cells produce the pro-inflammatory cytokine IL-8 (Zhou et al. 2008, Zhou et al. 2013). To evaluate if this happens in our experimental models, we measured the levels of IL-8 in our cells after treatment with ScFv62TRAIL ${ }^{\text {Lys }}$.

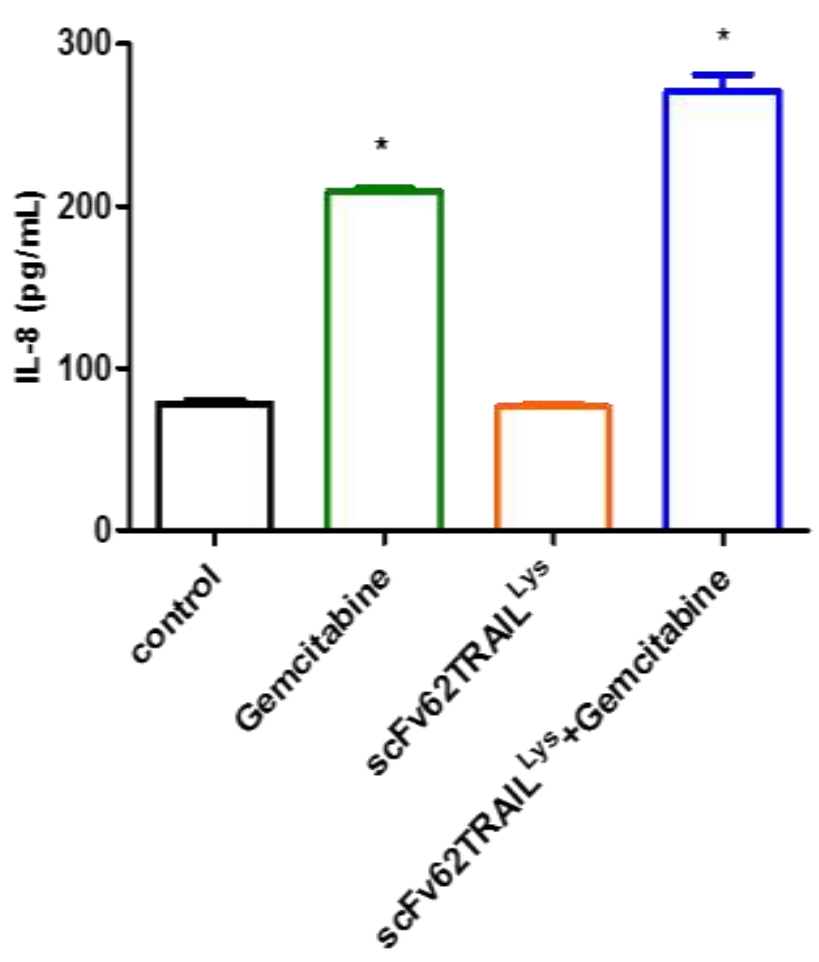

Figure 38: IL-8 expression after treatment. Capan-1 cells were treated with scFv62TRAILLys alone and in combination with Gemcitabine. Both the supernatant and cells were collected for total protein and IL-8 detection via ELISA. IL-8 expression was induced by Gemcitabine. 
Capan-1 cells were treated with ScFv62TRAIL ${ }^{\text {Lys }}$ alone or in combination with Gemcitabine for 15 hours. Cells were then harvested and lysed for quantification of total protein. The supernatant was also collected for detection of expression of IL-8. As shown in Figure 38, Gemcitabine induced an increase in IL-8 expression. Treatment with ScFv62TRAIL ${ }^{\text {Lys }}$ alone did not induce IL-8 expression when compared to control treated cells, and it did not increase significantly the levels of IL-8 when combined with Gemcitabine in comparison to Gemcitabine alone (Fig. 38)

\section{Effects of ScFv62-TRAIL ${ }^{\text {Lys }}$ on PDAC cells in 3D cultures}

Traditional 2D cell culture techniques have a limited predictive value; for example, they do not model the difficulty in access for the drugs to tumour cells that is available in a $3 \mathrm{D}$ structure. To address this, we tested our treatment strategy on a $3 \mathrm{D}$ cell culture model before progressing to in vivo tests.
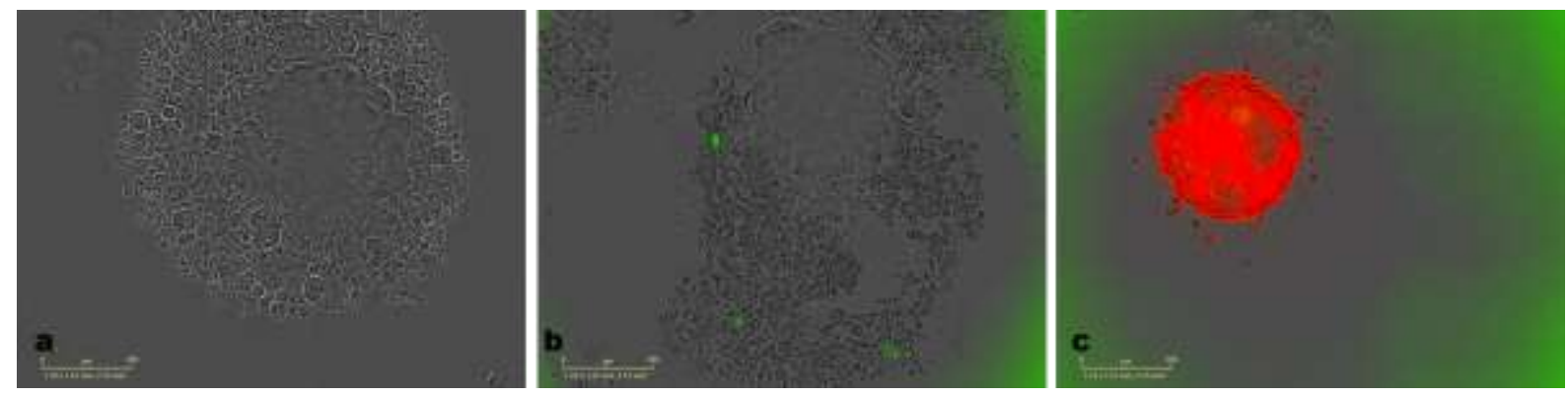

Figure 39: Capan-1 shows dependency on stellate cells to form compact spheroids. (a) Capan-1 "spheroid" alone; (b) shows the same spheroid after the addition of fresh medium. (c) shows Capan-1 plus RLT-PSC (red fluorescent) spheroid after addition of fresh medium

To generate a model closer to the in vivo situation, we attempted experiments in 3D cultures of tumour spheroids. Capan-1 cells were cultured in $2 \%$ matrigel in low 
Results

attachment plates and followed through live cell imaging as described in the Methods section. The presence of matrigel and the use of ultra-low attachment plates force the cells to attach to each other and for a so-called tumour spheroid. Figure 39 represents a spheroid formed by Capan-1 after 7 days; morphologically, the group of cells resembled a loose sphere. There were apparently few cell-to-cell attachments, because upon manipulation, for example addition of fresh medium, the cells completely disaggregated (Fig. 39). In contrast, when Capan-1 and RLT-PSC cells were cultured together, stellate cells formed a shell that encapsulated the tumour cells, and formed tight compact spheroids in as short as 3 days. Addition of fresh medium did not disturb the spheroid (Fig. 39).

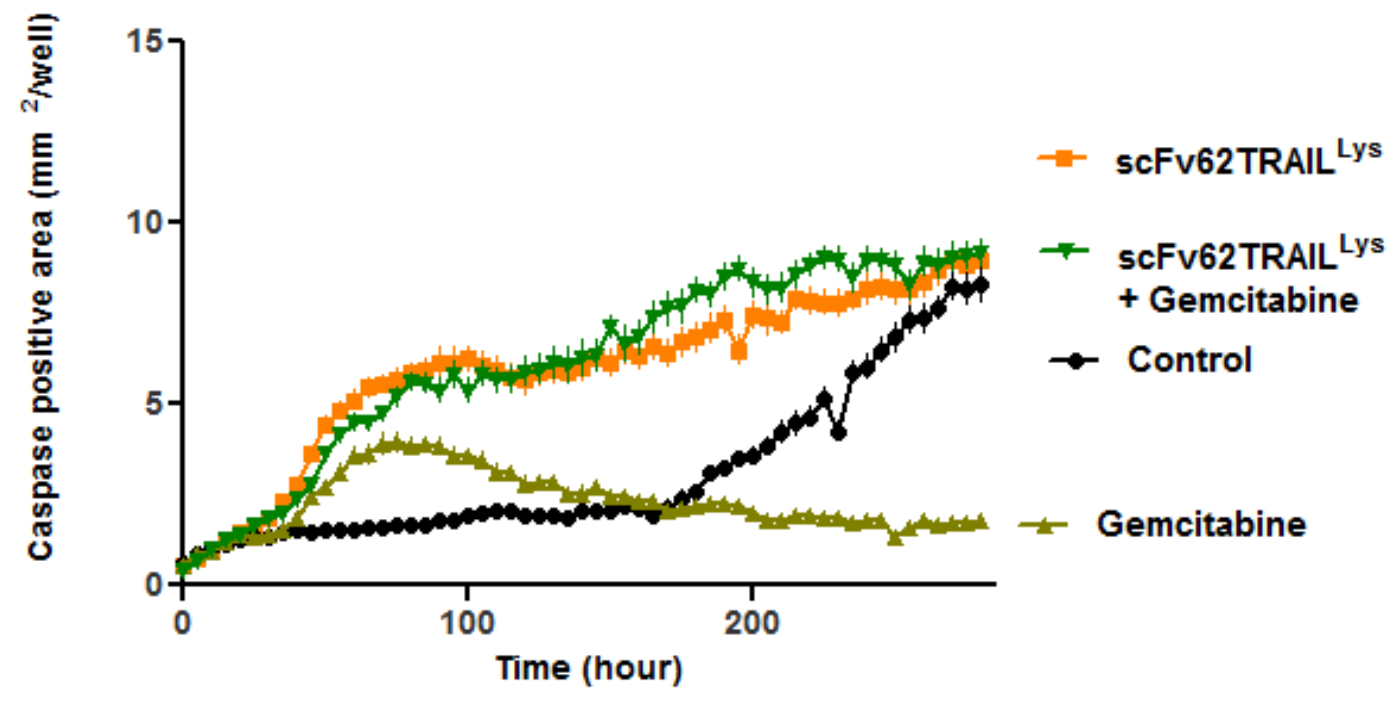

Figure 40: Increase in caspase activity in Capan-1 when co-cultured with RLTPSC. In 3D culture model system there is an increase in caspase activity in Capan-1 cells on treatment with ScFv62TRAIL ${ }^{\text {Lys }}$ alone.

Thus, spheroids were formed with Capan-1 and RLT-PSC in 3D spheroids, and treated when spheroids reached 400-500 $\mu \mathrm{m}$ in diameter. Under such conditions, Gemcitabine alone induced a marked caspase-3/7 activity. It apparently killed a majority of the cells within the first 60 hours, and caspase signal decreased thereafter (Fig. 40). We also saw an increase in caspase-3/7 activity on treatment with scFv62 TRAIL ${ }^{\text {Lys }}$ alone and in 
Results

combination with Gemcitabine. In contrast to the gemcitabine treatment alone, the caspase activity persisted and increased even after 60 hours. Using IncuCyte zoom software, we were able to quantify only an approximate number of apoptotic cells, because we could not accurately quantify the signal coming from deep areas of the spheroid.

To overcome this difficulty, we used modified Capan-1 cells that express constitutively GFP, in combination with red fluorescence-labeled stellate cells, and counted red and green particles in the spheroid. In these experiments, we observed a decrease in green (Capan-1) cells both upon treatment with Gemcitabine and in combination scFv62TRAIL Lys (Fig. 41)

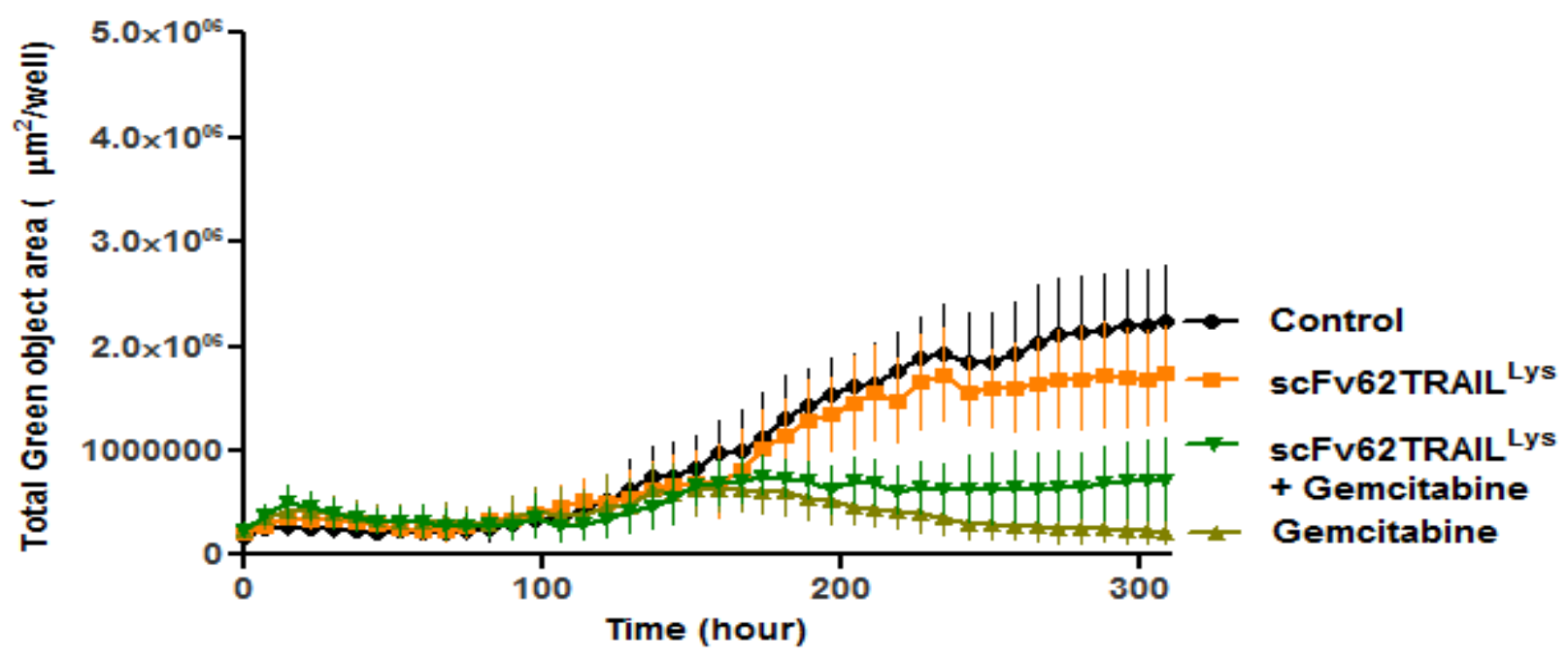

Figure 41: Decrease in growth rate of Capan-1 GFP-shRNA when co-cultured with RLT-PSC mCherry in 3D culture model. Proliferation of Capan-1 cells upon treatment with Gemcitabine alone and in combination with scFv62TRAIL ${ }^{\text {Lys }}$. 
In contrast, all treatments induced an arrest of red fluorescent cells (stellate cells; Fig. 42 ) in co-culture. This was again surprising, because when cultured alone RLT-PSC cell spheroids were not affected by scFv62TRAIL ${ }^{\text {Lys }}$ (Fig. 43)

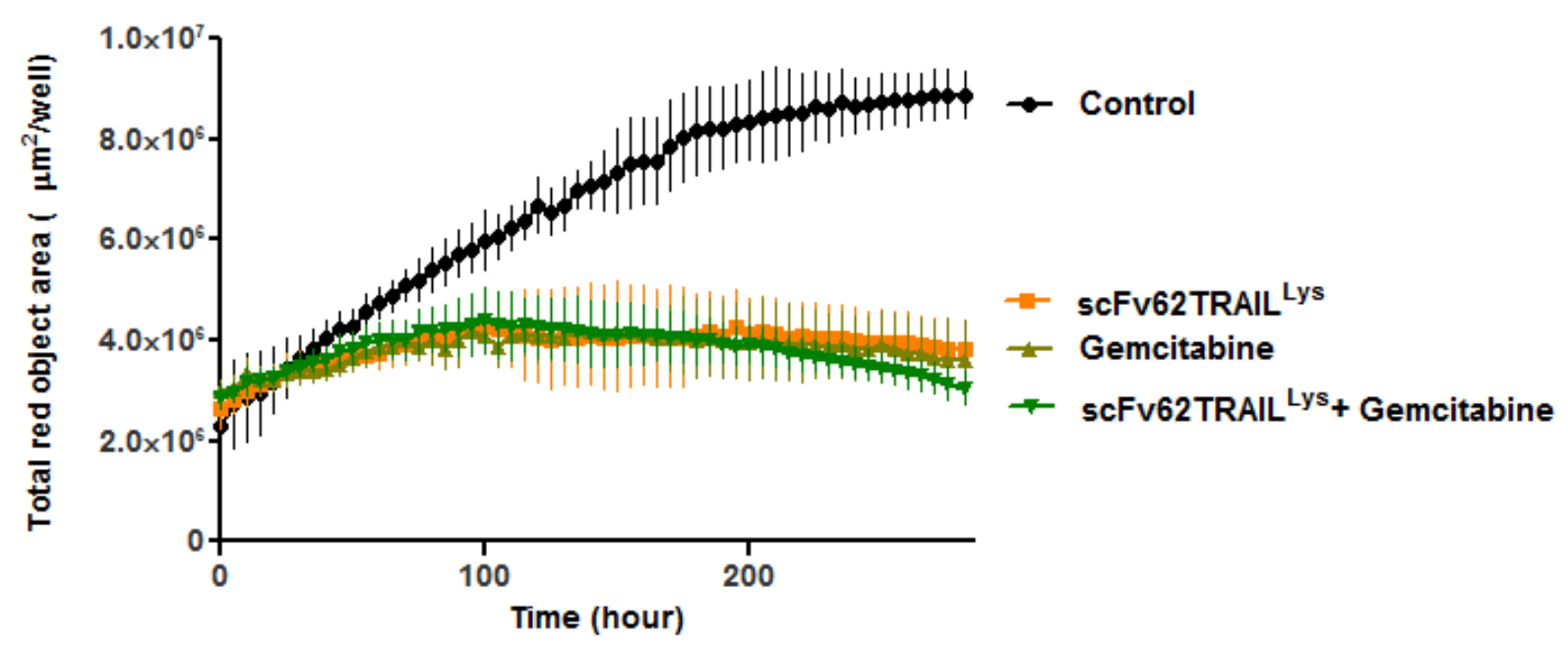

Figure 42: Arrest of the growth of stellate cells (RLT-PSC mCherry) in 3D spheroids with capan-1 cells.

When RTL-PSC cells were grown in spheroids alone, Gemcitabine arrested the growth, but ScFv62TRAIL ${ }^{\text {Lys }}$ alone did not (Fig. 43), rather induced a slight increase that was not due to the construct itself, but to other components in the preparation, because it was also induced by conditioned medium of the CHO-K1 cells used to produce scFv62TRAIL Lys (Fig. 45). When analyzing the whole duration of the experiment (see accompanying videos), we observed that tumour cells overgrew the RTL-PSC cells; given that these are needed to maintain the spheroid, it was not possible to detect a clear, compact spheroid after 50 hours. The effect was more dramatic in the presence of gemcitabine, which arrests the growth of RTL-PSC. In this time, the caspase 3-7 activity measured in the presence of scFv62TRAIL Lys was larger than with Gemcitabine. Nevertheless, the complexity of the system does not allow in reaching solid conclusions of these experiments, other than that the construct is also active in 3D cultures. 


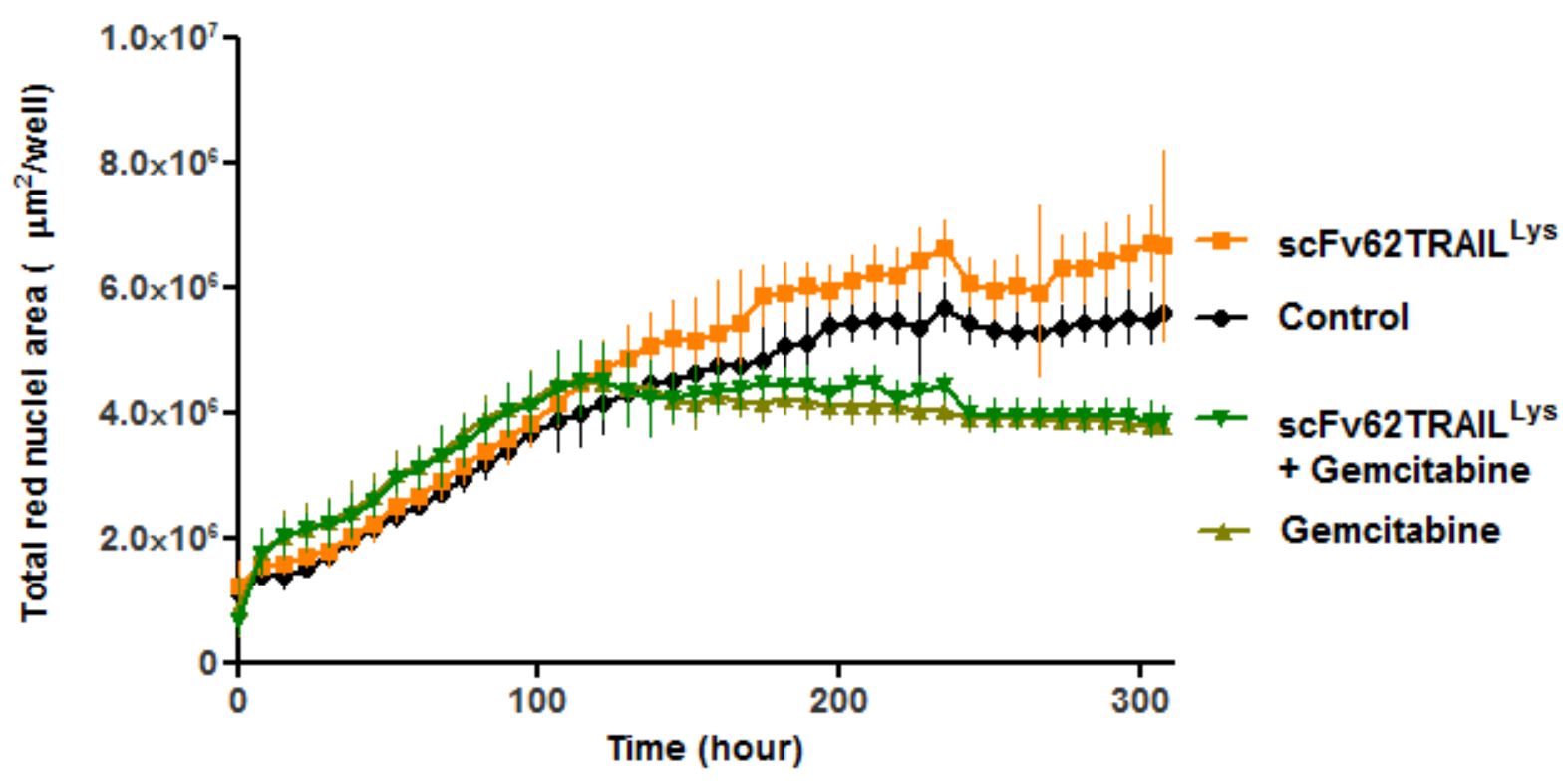

Figure 43: Reduction in proliferation was observed with the treatment with Gemcitabine alone and in combination with scFv62TRAIL ${ }^{\text {Lys }}$ (3D culture)

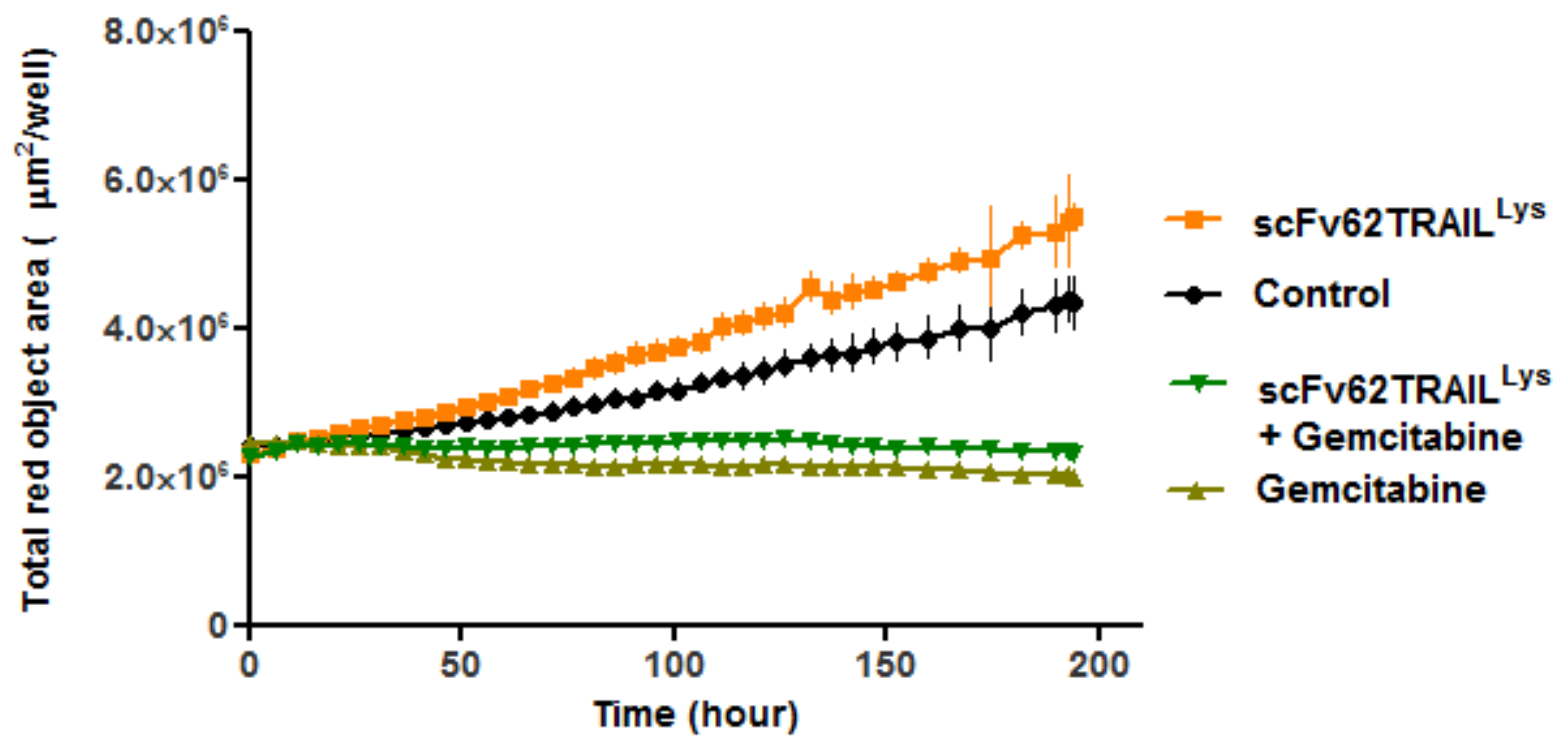

Figure 44: Reduction in proliferation was detected with the treatment with ScFv62TRAIL ${ }^{\text {Lys }}$ alone and in combination. 


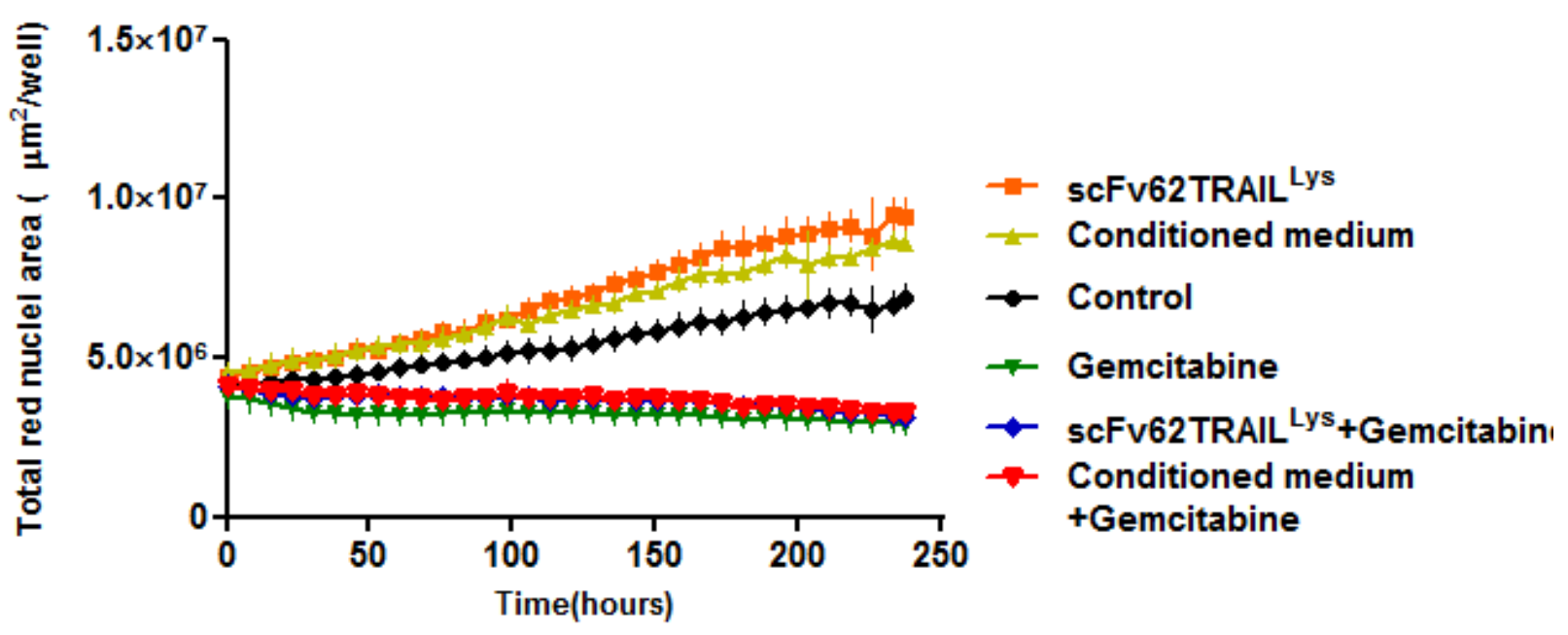

Figure 45: Conditioned medium induced growth in stellate cells in 3D culture model. 
Results

\section{Combination therapy reduced the rate of tumour growth in vivo}

As the combination treatment of our construct with Gemcitabine in both the 2D and 3D in-vitro system showed promise, we wanted to test if this is true even when applied to an in-vivo system. To this end we went ahead with applying a treatment strategy on sub cutaneous tumour models.

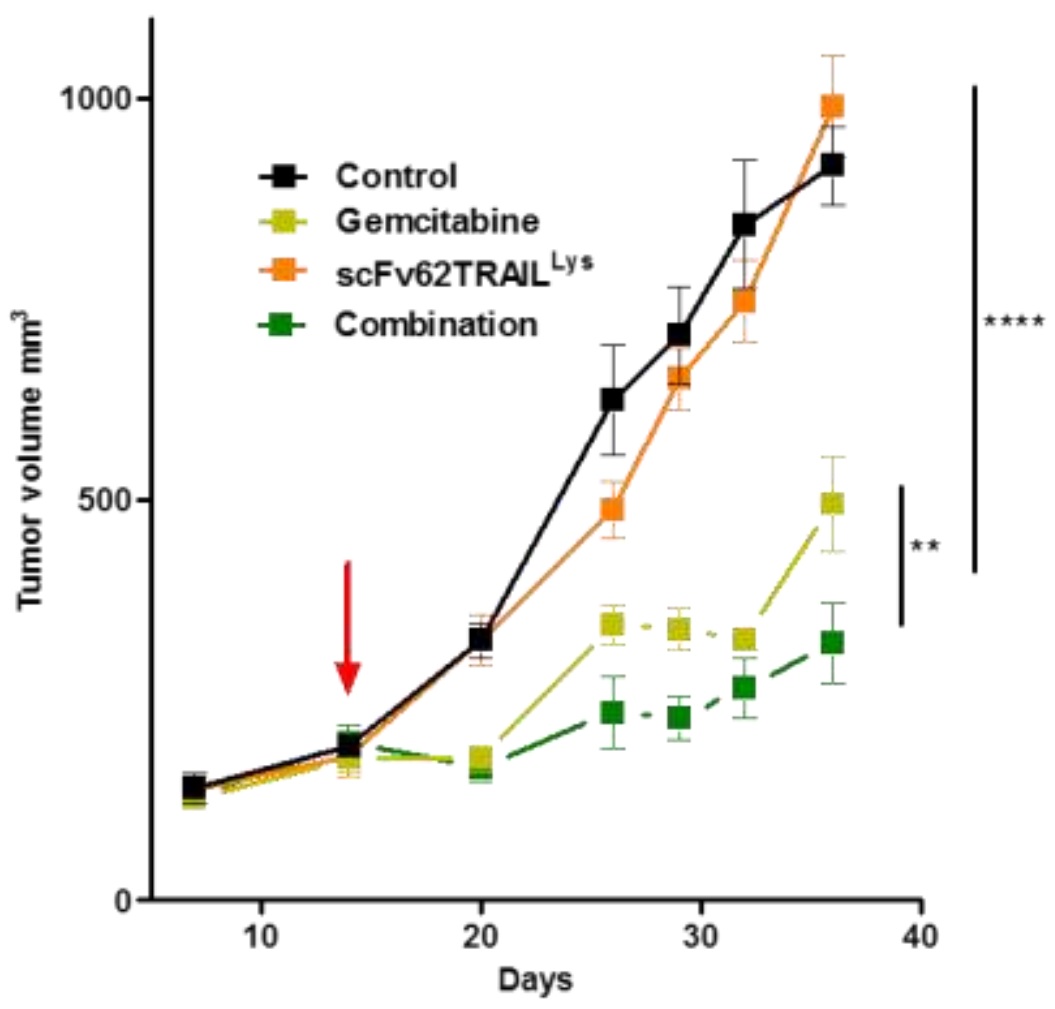

Figure 46: In vivo testing of our combination therapy demonstrated reduction in growth rate: $5 \times 10^{6}$ cells $/ 200 \mu$ of PBS of Capan- 1 was injected into the flanks of the each SCID mice. Two weeks after implantation they were treated with Gemcitabine $(80 \mathrm{mg} / \mathrm{kg})$ alone, scFv62TRAIL ${ }^{\text {Lys }}(200 \mu \mathrm{L} / \mathrm{mice})$ alone or Gemcitabine in combination with ScFv62TRAIL ${ }^{\text {Lys }}$ for a period of 4 weeks. 
Results

We injected $5 \times 10^{6}$ Capan- 1 cells subcutaneously on the flanks of nude mice. Two weeks after implantation the mice were treated with Gemcitabine $(80 \mathrm{mg} / \mathrm{kg})$ alone, ScFv62TRAIL Lys $(200 \mu \mathrm{L} /$ mice $)$ alone or Gemcitabine in combination with ScFv62TRAIL ${ }^{\text {Lys }}$ for a period of 4 weeks. As observed in Figure 46, which shows the tumour volume through the different treatment strategies, treatment with ScFv62TRAIL ${ }^{\text {Lys }}$ construct in combination with Gemcitabine induced a statistically significant decrease in tumour volume compared to controls as well as construct alone. Furthermore on combination treatment also had a significant decrease in tumour volume when compared to those treated with Gemcitabine alone.

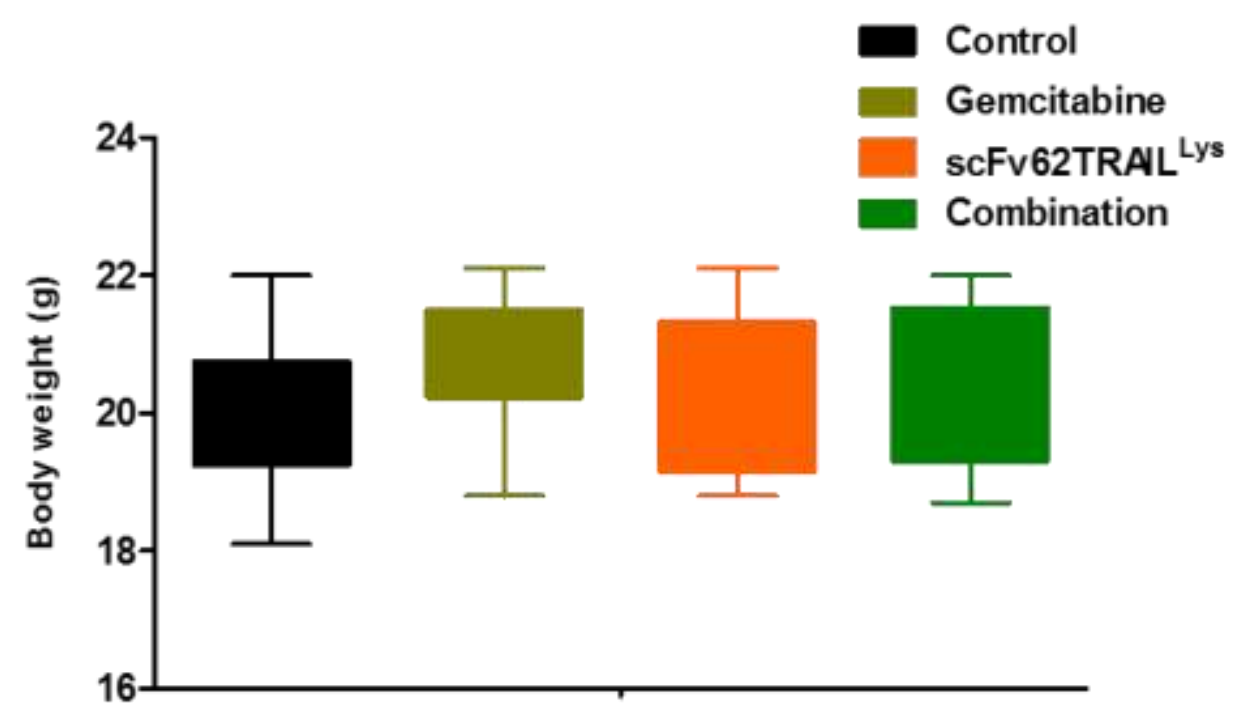

Figure 47: Monitoring the toxicity of the therapy showed no variation in treated versus control. Two weeks after implantation they were treated with Gemcitabine $(80 \mathrm{mg} / \mathrm{kg})$ alone, scFv62TRAIL ${ }^{\text {Lys }}(200 \mu \mathrm{L} / \mathrm{mice})$ alone or Gemcitabine in combination with scFv62TRAIL ${ }^{\text {Lys }}$ for a beriod of four weeks.

Importantly, as demonstrated by Figure 47, mice grew similarly in terms of body weight under all treatments, indicating no significant toxicity of any of the treatments. 


\section{DISCUSSION}

Our study investigated the functional role of $\mathrm{Kv} 10.1$ in PDAC and its potential therapeutic application. The functional role of the channel was studied in vitro by manipulating its expression levels. Due to its aberrant expression in tumours we could exploit Kv10.1 as an antigen and design and generate a bi-functional antibody recognizing the channel and targeting the apoptosis-inducing TRAIL to the tumour cells. We were successful in demonstrating the efficacy of the construct in combination with Gemcitabine both in vitro and in vivo in PDAC models.

The ion channel Kv10.1 is expressed during a short time period in cell division in normal tissues, and therefore not detectable (Urrego et al. 2016). In tumours, due to either a larger proliferative fraction or a dysregulation of its transcriptional control, Kv10.1 is often prominently expressed. Studies involving inhibition of channel function or expression in vitro led to a reduction in cell proliferation (Pardo et al. 1999, Weber et al. 2006, Gomez-Varela et al. 2007) and migration (Hammadi et al. 2012) and reduction in tumour progression in vivo (Downie et al. 2008).

Manipulation of Kv10.1 expression or function has never been done on PDAC cell lines to our knowledge. To address this question, we selected five human PDAC cell lines: AsPC-1, derived from ascites and poorly differentiated, Capan-1, derived from liver metastasis and well differentiated, PANC-1 BxPC-3 and MIA PaCa-2 derived from primary tumour and poorly differentiated (Deer et al. 2010). We went onto test the expression levels of Kv10.1 at both the RNA and protein levels (Fig. 11 and Fig. 12) Like in essentially all cell lines reported previously, expression of the channel was low, but consistently detectable by nested and quantitative real-time PCR. qPCR data revealed different expression levels between cell lines (PANC-1 $\approx$ Capan-1>AsPC1>BxPC-3>MIA PaCa-2), but in all cases the expression was low compared to the positive control (the neuroblastoma cell line SH-SY5Y) (Fig. 11). The low levels of expression could at least in part be due to the fact that the determinations were done in asynchronous cultures, and the expression of Kv10.1 is strongly modulated during cell cycle (Urrego et al. 2016). 
To test if this low expression was an indication of a marginal functional contribution of Kv10.1 to the phenotype of the cell lines, we set out to test the effects of Kv10.1 knockdown using siRNA on the proliferation rates of all five cell-lines. It was reasonable to hypothesize that this could be the case, since human PDAC was responsive to Kv10.1 inhibition in xenograft experiments (Gomez-Varela et al. 2007). Upon transient knock down of Kv10.1, AsPC-1 and BxPC-3 showed no change in proliferation rate. PANC-1 and Capan-1 showed a significant increase in proliferation, while the only

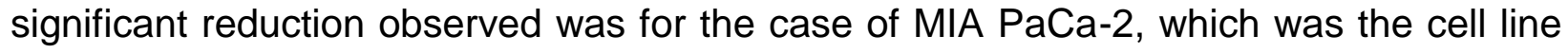
with the lowest expression of Kv10.1, but also the one that had highest proliferation rates.

Kv10.1 is also known to influence cell migration (Hammadi et al. 2012). We therefore tested if the migration of the five cell lines was affected by transient knockdown of Kv101. In this case, only BxPC-3 cells showed an effect by having a decrease in migration, but none of the cell lines expressing Kv10.1 more abundantly reduced its migration after Kv10.1 knockdown.

The lack of relevant effects was not due to transient knockdown, at least for Capan-1 cells. From these cells we were able to generate a stable cell line expressing a shRNA targeting Kv10.1. This cell line showed a modest but significant decrease in proliferation as compared to the control transduced cell line (transduced with only GFP), but no change on migration.

Similarly, cells stably overexpressing Kv10.1 (PANC-1 and MIA PaCa-2) did not show dramatic effects on proliferation; overexpression in Panc1 induced a small increase in migration.

In summary, the modest expression of Kv10.1 detected in the five PDAC cell lines does not seem to be crucial for their behavior in vitro, in terms of both proliferation and migration. Therefore, it would be unlikely that inhibition of Kv10.1 is a plausible strategy in PDAC in general, as it has been proposed for other tumours. Nevertheless, it still can be utilized as a marker to target other active molecules to the tumour cells.

Over the last two decades, antibody based therapy of both solid and haematological malignancies has shown success (Schrama et al. 2006). One of the main challenges for 
Discussion

this kind of therapy is to find antigens specifically overexpressed in human cancers. As stated before, Kv10.1 is aberrantly expressed in more than $70 \%$ of tumours from various origins (Hemmerlein et al. 2006, Ding et al. 2007, Wadhwa et al. 2009, Agarwal et al. 2010, Asher et al. 2010). Previous in vitro studies on various cell lines have indicated it to be located on the cell surface, which is a requisite for antibody-based therapy (Kohl et al. 2011).

In our study we used an in-house generated construct which comprises a single chain antibody specific to the external region of Kv10.1 (scFv62) linked to sTRAIL (Hartung et al. 2011). This construct was designed and engineered with a vision to specifically target cells harbouring Kv10.1; once scFv62 binds to the target, TRAIL receptors are activated inducing apoptosis. Recent studies have shown that although DR4 and DR5 are apoptosis-inducing receptors, DR5 is the main receptor activated by TRAIL (Reis et al. 2009). To further enhance the apoptotic potential of the construct we used a modified version that carries a point mutation in TRAIL at position 131 (Glycine to Lysine; scFv62TRAIL ${ }^{\text {Lys }}$ ). This point mutation increases the affinity of TRAIL towards DR4, but does not change its affinity towards DR5, thereby targeting a wider range of cancer cells that are sensitive to TRAIL induced apoptosis (Reis et al. 2009).

The goal of the study was to determine if a combination of ScFv62TRAIL Lys and Gemcitabine is able to increase efficacy of the chemotherapeutic drug. Gemcitabine is currently used as the first line chemotherapeutic drug for PDAC patients, but renders a modest clinical benefit, mainly due the acquisition of chemo-resistance by the tumour. To test this, we selected two of the cell lines described above. Capan-1, because it shows expression of Kv10.1 in vivo (Fig. 13) and is resistant to sTRAIL (Wicker et al. 2010), and BxPC-3, which shows little Kv10.1 expression both in vitro and in vivo (Fig. 13) but is sensitive to sTRAIL alone (Wang et al. 2007).

In cytotoxicity assays we were able to observe a marked loss of cell viability on the PDAC cells upon combination treatment (Gemcitabine + scFv62TRAIL ${ }^{\text {Lys }}$ construct). Under our experimental conditions, Gemcitabine alone did not induce significant toxicity. Soluble TRAIL alone induced the death of BxPC-3 cells, but not of Capan-1, as previously described; also as expected, both cell lines were sensitive to a combination between sTRAIL and Gemcitabine. Importantly, scFv62TRAIL ${ }^{\text {Lys }}$ induced the death of 
both cell lines, and the toxicity was potentiated by combination with Gemcitabine in Capan1 (Fig. 10). This is compatible with a scenario where scFv62TRAIL Lys mimics membrane-bound TRAIL, which is usually more efficient in inducing cell death than sTRAIL (Muhlenbeck et al. 2000, Kelley et al. 2001, Bremer et al. 2004, Bremer et al. 2008, ten Cate et al. 2009, de Bruyn et al. 2010); in this way, BxPC-3 cells would die in the presence of either sTRAIL or the TRAIL moiety present in the construct, while Capan-1 cells would need the presence of Gemcitabine, which in this case would preclude apoptosis-escape mechanisms.

Cell death under treatment occurred through an apoptotic mechanism that implies the activation of the caspase cascade pathway. Caspase-3/7 activation was measured by fluorescent reporters (Fig. 22 and 23) and western blot (Fig. 25), and apoptosis was confirmed by Annexin $\mathrm{V}$ binding assays (Fig. 26, 27 and 28). Also in favour of an apoptotic mechanism speaks the fact that a short exposure to the agent is enough to induce the same degree of caspase activation as a long exposure, but the time course is similar in both cases, indicating that the cells enter a no-return path in the first few hours and are thereafter committed to apoptosis (Fig. 20).

When monitoring caspase activity by fluorescence or by cleaved caspase detection, BxPC-3 cells that were treated with Gemcitabine in combination with sTRAIL had lower caspase activity than those treated with Gemcitabine alone (Fig. 13), even though the cytotoxicity was very similar in cells treated with sTRAIL alone or in combination (Fig. 11). It can also be appreciated that scFv62TRAIL ${ }^{\text {Lys }}$ alone has a higher caspase $3 / 7$ activation compared to sTRAIL, which in part could be attributed to the mutation introduced in TRAIL.

The activation of the apoptosis cascade by the fusion protein requires TRAIL. A single chain antibody (scFv62-Cys) did not produce comparable effects (Fig. 29).

Recent studies involving use of sTRAIL treatment both in vitro and in vivo have shown that TRAIL may in fact have dual role. Besides inducing pro-apoptotic signalling, it leads to the activation of other signalling pathways via the secretion of pro inflammatory cytokines such as, IL-8 or invasion promoting protein urokinase (Zhou et al. 2008, Zhou et al. 2013), resulting in increased tumour growth and invasion. However, it is unlikely 
that this will be the case when using scFv62TRAIL ${ }^{\text {Lys }}$. We detected an increase in IL-8 upon treatment with Gemcitabine alone or in combination (Fig. 38) but we did not detect an increase after treatment with ScFv62TRAIL Lys, strongly indicating that, unlike soluble TRAIL, our construct does not induce pro-inflammatory response via IL-8.

Pancreatic stellate cells (PaSc) play a major role in the desmoplastic reaction in PDAC (Apte et al. 2004). PaSc and pancreatic cancer cells share a symbiotic relationship and influence reciprocally their behaviour. It has been suggested that this could be the reason for the increased growth rate of the cancer, possibly metastasis and also the cause for chemo-resistance (Pandol et al. 2009). We therefore tested whether coculture with PaSc changes the response to scFv62TRAIL ${ }^{\text {Lys }}$, using red fluorescent immortalised PaSc, which could readily be identified and distinguished from tumour cells. Stellate cells themselves were insensitive to scFv62TRAIL ${ }^{\text {Lys }}$ and STRAIL, both when cultured alone or in combination. Gemcitabine induced a growth arrest in all cases, but did not impair viability. Combination of scFv62TRAIL ${ }^{\text {Lys }}$ with Gemcitabine did induce caspase activation after much longer incubation periods that those needed for cancer cells. At those late time points, the cultures had already reached confluence, and this makes the results difficult to interpret.

Nevertheless, co-culture with PaSc increased significantly the induction of apoptosis in Capan-1 cells by combination of scFv62TRAIL Lys and Gemcitabine (Fig. 34). Intriguingly, this sensitizing effect was only observed in the combination treatment and not with Gemcitabine alone, and was also much less evident in BxPC-3 cells (Fig. 36).

To achieve a more realistic model system in vitro, we next ventured into investigating the efficacy of the combination treatment in a $3 \mathrm{D}$ culture model. Interestingly, while BxPC-3 could form very tight spheroid on their own and even without matrigel, Capan-1 cells fail to form tight spheroids when cultured alone in matrigel. However, in cocultures, stellate cells formed a spheroid around the loosely packed Capan-1 cells. In these spheroids it was possible to identify stellate cells by their red fluorescence (Fig. 39) Treatment with Gemcitabine alone induced the extrusion of the cancer cells from the spheroid. This could be interpreted as an outgrowth of cancer cells (almost insensitive to Gemcitabine) while PaSCs suffer growth arrest and can no longer contain the cancer cells inside the spheroid. The arrest in growth is also observed in 3D culture 
system of only PaSCs. The cancer cells in turn respond by making way out of the spheroid into the medium thereby being more reachable and susceptible to the treatment, which is reflected in the increase in caspase $3 / 7$ activity.

These results encouraged us to translate this in an in vivo setting. We evaluated the treatment strategy on a sub-cutaneous model of Capan-1 in SCID mice. As expected we witnessed a reduction in the growth of the tumours treated with Gemcitabine alone; remarkably this reduction was further significantly increased in mice treated with scFv62TRAIL ${ }^{\text {Lys }}$ in combination with Gemcitabine, strongly indicating that scFv62TRAIL ${ }^{\text {Lys }}$ overcomes resistance to Gemcitabine also in vivo. The treatment did not induce major toxicity at the dosage used, and the body weight of mice did not differ much between treated and non-treated animals.

\section{Future work}

The major goal of this study was to investigate and develop a novel targeted therapy using Kv10.1 as a tumour marker for PDAC models. Using the first-line chemotherapeutic drug Gemcitabine in combination with the bi-functional antibody conjugated to TRAIL (scFv62TRAIL ${ }^{\text {Lys }}$ ) we are able to provide a potential blueprint for a treatment strategy in PDAC patients.

The study successfully demonstrated in both in vitro and in vivo models the efficacy of the construct alone and in combination with Gemcitabine. This has led to a path for future experiments that could further expand our knowledge and validate the current work.

Establishing a robust 3D in vitro culture model would give us mechanistic insight into the effect of the combination treatment and allow the use of medium- and highthroughput techniques and perform dose-response determinations to determine the concentration of each component that achieves best efficacy with least toxicity.

Although the in vivo results have been able to confirm the efficacy of the treatment additional studies on the tumour histology of the treated mice could enlighten and provide more information on changes at the morphologic or genomic level compared to control tumours. 
Discussion

Further in vivo models can also be tested to further the understanding on the efficacy of the construct. Other models like the orthotopic and transgenic which mimic the patient tumour more closely would further characterize this treatment strategy. In vivo models with other cell lines such as BxPC-3 could provide with useful insight into the efficacy of the drug in tumours that express Kv10.1 sparsely. Lastly, it would be interesting to implant both cancer and stellate cells to understand the role stellate cells play in the metastasis and resistance towards treatment. 


\section{REFERENCES}

Agarwal, J. R., et al. (2010). "The potassium channel Ether a go-go is a novel prognostic factor with functional relevance in acute myeloid leukemia." Mol Cancer 9: 18.

Aggarwal, B. B., et al. (2012). "Historical perspectives on tumor necrosis factor and its superfamily: 25 years later, a golden journey." Blood 119(3): 651-665.

Almasan, A. and A. Ashkenazi (2003). "Apo2L/TRAlL: apoptosis signaling, biology, and potential for cancer therapy." Cytokine Growth Factor Rev 14(3-4): 337-348.

Aoyagi, Y., et al. (2004). "Overexpression of TGF-beta by infiltrated granulocytes correlates with the expression of collagen mRNA in pancreatic cancer." Br J Cancer 91(7): 1316-1326.

Apte, M. V., et al. (1998). "Periacinar stellate shaped cells in rat pancreas: identification, isolation, and culture." Gut 43(1): 128-133.

Apte, M. V., et al. (1999). "Pancreatic stellate cells are activated by proinflammatory cytokines: implications for pancreatic fibrogenesis." Gut 44(4): 534-541.

Apte, M. V., et al. (2004). "Desmoplastic reaction in pancreatic cancer: role of pancreatic stellate cells." Pancreas 29(3): 179-187.

Apte, M. V., et al. (2013). "Extracellular matrix composition significantly influences pancreatic stellate cell gene expression pattern: role of transgelin in PSC function." Am J Physiol Gastrointest Liver Physiol 305(6): G408-417.

Asher, V., et al. (2010). "The Eag potassium channel as a new prognostic marker in ovarian cancer." Diagn Pathol 5: 78.

Assifi, M. M. and O. J. Hines (2011). "Anti-angiogenic agents in pancreatic cancer: a review." Anticancer Agents Med Chem 11(5): 464-469. 
Bachem, M. G., et al. (2005). "Pancreatic carcinoma cells induce fibrosis by stimulating proliferation and matrix synthesis of stellate cells." Gastroenterology 128(4): 907-921.

Balkwill, F. and A. Mantovani (2001). "Inflammation and cancer: back to Virchow?" Lancet 357(9255): 539-545.

Bardeesy, N. and R. A. DePinho (2002). "Pancreatic cancer biology and genetics." Nat Rev Cancer 2(12): 897-909.

Barton, C. M., et al. (1991). "Transforming growth factor alpha and epidermal growth factor in human pancreatic cancer." J Pathol 163(2): 111-116.

Bergmann, U., et al. (1995). "Insulin-like growth factor I overexpression in human pancreatic cancer: evidence for autocrine and paracrine roles." Cancer Res 55(10): 2007-2011.

Bremer, E., et al. (2004). "Target cell-restricted and -enhanced apoptosis induction by a scFv:sTRAIL fusion protein with specificity for the pancarcinoma-associated antigen EGP2." Int J Cancer 109(2): 281290.

Bremer, E., et al. (2008). "Potent systemic anticancer activity of adenovirally expressed EGFR-selective TRAIL fusion protein." Mol Ther 16(12): 1919-1926.

Brosens, L. A., et al. (2015). "Pancreatic adenocarcinoma pathology: changing "landscape"." ్ㅡ Gastrointest Oncol 6(4): 358-374.

Burris, H. A., 3rd, et al. (1997). "Improvements in survival and clinical benefit with gemcitabine as firstline therapy for patients with advanced pancreas cancer: a randomized trial." J Clin Oncol 15(6): 24032413.

Chandler, J. M., et al. (1998). "Different subcellular distribution of caspase-3 and caspase-7 following Fas-induced apoptosis in mouse liver." J Biol Chem 273(18): 10815-10818.

Chu, G. C., et al. (2007). "Stromal biology of pancreatic cancer." J Cell Biochem 101(4): 887-907. Clevers, H. (2006). "Wnt/beta-catenin signaling in development and disease." Cell 127(3): 469-480. 
Conroy, T., et al. (2011). "FOLFIRINOX versus gemcitabine for metastatic pancreatic cancer." $\underline{N}$ Engl J Med 364(19): 1817-1825.

Cunningham, D., et al. (2009). "Phase III randomized comparison of gemcitabine versus gemcitabine plus capecitabine in patients with advanced pancreatic cancer." J Clin Oncol 27(33): 5513-5518.

de Bruyn, M., et al. (2010). "Melanoma-associated Chondroitin Sulfate Proteoglycan (MCSP)-targeted delivery of soluble TRAIL potently inhibits melanoma outgrowth in vitro and in vivo." Mol Cancer 9: 301.

Deer, E. L., et al. (2010). "Phenotype and genotype of pancreatic cancer cell lines." Pancreas 39(4): 425435.

Degli-Esposti, M. A., et al. (1997). "The novel receptor TRAIL-R4 induces NF-kappaB and protects against TRAIL-mediated apoptosis, yet retains an incomplete death domain." Immunity 7(6): 813-820.

Di Renzo, M. F., et al. (1995). "Expression of the Met/hepatocyte growth factor receptor in human pancreatic cancer." Cancer Res 55(5): 1129-1138.

Diaz, L., et al. (2009). "Estrogens and human papilloma virus oncogenes regulate human ether-a-go-go-1 potassium channel expression." Cancer Res 69(8): 3300-3307.

Ding, X. W., et al. (2007). "Aberrant expression of ether a go-go potassium channel in colorectal cancer patients and cell lines." World J Gastroenterol 13(8): 1257-1261.

Distler, M., et al. (2014). "Precursor lesions for sporadic pancreatic cancer: PanIN, IPMN, and MCN." Biomed Res Int 2014: 474905.

Downie, B. R., et al. (2008). "Eag1 expression interferes with hypoxia homeostasis and induces angiogenesis in tumors." J Biol Chem 283(52): 36234-36240.

Dunne, R. F. and A. F. Hezel (2015). "Genetics and Biology of Pancreatic Ductal Adenocarcinoma." Hematol Oncol Clin North Am 29(4): 595-608.

Ebert, M., et al. (1994). "Induction and expression of amphiregulin in human pancreatic cancer." Cancer Res 54(15): 3959-3962. 
Elnemr, A., et al. (2001). "Human pancreatic cancer cells disable function of Fas receptors at several levels in Fas signal transduction pathway." Int J Oncol 18(2): 311-316.

Evans, J. D., et al. (2001). "Detailed tissue expression of bcl-2, bax, bak and bcl-x in the normal human pancreas and in chronic pancreatitis, ampullary and pancreatic ductal adenocarcinomas." Pancreatology 1(3): 254-262.

Falschlehner, C., et al. (2007). "TRAIL signalling: decisions between life and death." Int J Biochem Cell Biol 39(7-8): 1462-1475.

Frantz, C., et al. (2010). "The extracellular matrix at a glance." J Cell Sci 123(Pt 24): 4195-4200.

Garcia-Quiroz, J., et al. (2012). "Astemizole synergizes calcitriol antiproliferative activity by inhibiting CYP24A1 and upregulating VDR: a novel approach for breast cancer therapy." PLoS One 7(9): e45063.

Gavrilova-Ruch, O., et al. (2002). "Effects of imipramine on ion channels and proliferation of IGR1 melanoma cells." J Membr Biol 188(2): 137-149.

Goggins, M., et al. (2000). "BRCA2 is inactivated late in the development of pancreatic intraepithelial neoplasia: evidence and implications." Am J Pathol 156(5): 1767-1771.

Gomez-Varela, D., et al. (2007). "Monoclonal antibody blockade of the human Eag1 potassium channel function exerts antitumor activity." Cancer Res 67(15): 7343-7349.

Guerra, C., et al. (2007). "Chronic pancreatitis is essential for induction of pancreatic ductal adenocarcinoma by K-Ras oncogenes in adult mice." Cancer Cell 11(3): 291-302.

Gukovsky, I., et al. (1998). "Early NF-kappaB activation is associated with hormone-induced pancreatitis." Am J Physiol 275(6 Pt 1): G1402-1414.

Hamacher, R., et al. (2008). "Apoptotic pathways in pancreatic ductal adenocarcinoma." Mol Cancer 7: 64.

Hammadi, M., et al. (2012). "Human ether a-gogo K(+) channel 1 (hEag1) regulates MDA-MB-231 breast cancer cell migration through Orai1-dependent calcium entry." J Cell Physiol 227(12): 3837-3846. 
Hanahan, D. and R. A. Weinberg (2011). "Hallmarks of cancer: the next generation." Cell 144(5): 646674.

Hartung, F., et al. (2011). "Tumor cell-selective apoptosis induction through targeting of $\mathrm{K}(\mathrm{V}) 10.1$ via bifunctional TRAIL antibody." Mol Cancer 10: 109.

Hemmerlein, B., et al. (2006). "Overexpression of Eag1 potassium channels in clinical tumours." Mol Cancer 5: 41.

Hengartner, M. O. (2000). "The biochemistry of apoptosis." Nature 407(6805): 770-776.

Hernandez-Munoz, I., et al. (2008). "Pancreatic ductal adenocarcinoma: cellular origin, signaling pathways and stroma contribution." Pancreatology 8(4-5): 462-469.

Hezel, A. F., et al. (2006). "Genetics and biology of pancreatic ductal adenocarcinoma." Genes Dev 20(10): 1218-1249.

Hruban, R. H., et al. (2004). "An illustrated consensus on the classification of pancreatic intraepithelial neoplasia and intraductal papillary mucinous neoplasms." Am J Surg Pathol 28(8): 977-987.

Ichikawa, K., et al. (2001). "Tumoricidal activity of a novel anti-human DR5 monoclonal antibody without hepatocyte cytotoxicity." Nat Med 7(8): 954-960.

Itakura, J., et al. (1997). "Enhanced expression of vascular endothelial growth factor in human pancreatic cancer correlates with local disease progression." Clin Cancer Res 3(8): 1309-1316.

Johnstone, R. W., et al. (2008). "The TRAIL apoptotic pathway in cancer onset, progression and therapy." Nat Rev Cancer 8(10): 782-798.

Jones, S., et al. (2008). "Core signaling pathways in human pancreatic cancers revealed by global genomic analyses." Science 321(5897): 1801-1806.

Kaplan, W. D. and W. E. Trout, 3rd (1969). "The behavior of four neurological mutants of Drosophila." Genetics 61(2): 399-409. 
Kelley, R. F., et al. (2005). "Receptor-selective mutants of apoptosis-inducing ligand 2/tumor necrosis factor-related apoptosis-inducing ligand reveal a greater contribution of death receptor (DR) 5 than DR4 to apoptosis signaling." J Biol Chem 280(3): 2205-2212.

Kelley, S. K., et al. (2001). "Preclinical studies to predict the disposition of Apo2L/tumor necrosis factorrelated apoptosis-inducing ligand in humans: characterization of in vivo efficacy, pharmacokinetics, and safety." J Pharmacol Exp Ther 299(1): 31-38.

Kleeff, J., et al. (2007). "Pancreatic cancer microenvironment." Int J Cancer 121(4): 699-705.

Kleeff, J., et al. (2004). "Adenovirus-mediated transfer of a truncated fibroblast growth factor (FGF) type I receptor blocks FGF-2 signaling in multiple pancreatic cancer cell lines." Pancreas 28(1): 25-30.

Kohl, T., et al. (2011). "Rapid internalization of the oncogenic K+ channel K(V)10.1." PLoS One 6(10): e26329.

Koli, K., et al. (2008). "Transforming growth factor-beta activation in the lung: focus on fibrosis and reactive oxygen species." Antioxid Redox Signal 10(2): 333-342.

Korc, M., et al. (1992). "Overexpression of the epidermal growth factor receptor in human pancreatic cancer is associated with concomitant increases in the levels of epidermal growth factor and transforming growth factor alpha." J Clin Invest 90(4): 1352-1360.

Li, M. O., et al. (2006). "Transforming growth factor-beta regulation of immune responses." Annu Rev Immunol 24: 99-146.

Lin, H., et al. (2011). "Transcriptional and post-transcriptional mechanisms for oncogenic overexpression of ether a go-go K+ channel." PLoS One 6(5): e20362.

Liyanage, U. K., et al. (2006). "Increased prevalence of regulatory T cells (Treg) is induced by pancreas adenocarcinoma." J Immunother 29(4): 416-424.

Liyanage, U. K., et al. (2002). "Prevalence of regulatory T cells is increased in peripheral blood and tumor microenvironment of patients with pancreas or breast adenocarcinoma." J Immunol 169(5): 2756-2761. 
Lohr, M., et al. (2005). "Frequency of K-ras mutations in pancreatic intraductal neoplasias associated with pancreatic ductal adenocarcinoma and chronic pancreatitis: a meta-analysis." Neoplasia 7(1): 1723.

Louvet, C., et al. (2005). "Gemcitabine in combination with oxaliplatin compared with gemcitabine alone in locally advanced or metastatic pancreatic cancer: results of a GERCOR and GISCAD phase III trial." J Clin Oncol 23(15): 3509-3516.

MacFarlane, M. (2003). "TRAIL-induced signalling and apoptosis." Toxicol Lett 139(2-3): 89-97.

MacFarlane, M., et al. (2005). "Chronic lymphocytic leukemic cells exhibit apoptotic signaling via TRAILR1." Cell Death Differ 12(7): 773-782.

Magistrelli, P., et al. (2006). "Apoptotic index or a combination of Bax/Bcl-2 expression correlate with survival after resection of pancreatic adenocarcinoma." J Cell Biochem 97(1): 98-108.

Martin, S., et al. (2008). "Eag1 potassium channel immunohistochemistry in the CNS of adult rat and selected regions of human brain." Neuroscience 155(3): 833-844.

Martinez, R., et al. (2015). "Analysis of the expression of Kv10.1 potassium channel in patients with brain metastases and glioblastoma multiforme: impact on survival." BMC Cancer 15: 839.

Mazur, P. K., et al. (2010). "Notch2 is required for progression of pancreatic intraepithelial neoplasia and development of pancreatic ductal adenocarcinoma." Proc Natl Acad Sci U S A 107(30): 13438-13443.

Michl, P. and T. M. Gress (2012). "Improving drug delivery to pancreatic cancer: breaching the stromal fortress by targeting hyaluronic acid." Gut 61(10): 1377-1379.

Mihaljevic, A. L., et al. (2010). "Molecular mechanism of pancreatic cancer--understanding proliferation, invasion, and metastasis." Langenbecks Arch Surg 395(4): 295-308.

Miyara, M. and S. Sakaguchi (2007). "Natural regulatory T cells: mechanisms of suppression." Trends Mol Med 13(3): 108-116. 
Mollenhauer, J., et al. (1987). "Distribution of extracellular matrix proteins in pancreatic ductal adenocarcinoma and its influence on tumor cell proliferation in vitro." Pancreas 2(1): 14-24.

Moore, K. W., et al. (2001). "Interleukin-10 and the interleukin-10 receptor." Annu Rev Immunol 19: 683-765.

Moore, M. J., et al. (2007). "Erlotinib plus gemcitabine compared with gemcitabine alone in patients with advanced pancreatic cancer: a phase III trial of the National Cancer Institute of Canada Clinical Trials Group." J Clin Oncol 25(15): 1960-1966.

Muhlenbeck, F., et al. (2000). "The tumor necrosis factor-related apoptosis-inducing ligand receptors TRAIL-R1 and TRAIL-R2 have distinct cross-linking requirements for initiation of apoptosis and are nonredundant in JNK activation." J Biol Chem 275(41): 32208-32213.

Mullendore, M. E., et al. (2009). "Ligand-dependent Notch signaling is involved in tumor initiation and tumor maintenance in pancreatic cancer." Clin Cancer Res 15(7): 2291-2301.

Muniraj, T., et al. (2013). "Pancreatic cancer: a comprehensive review and update." Dis Mon 59(11): 368402.

Murphy, K. M., et al. (2002). "Evaluation of candidate genes MAP2K4, MADH4, ACVR1B, and BRCA2 in familial pancreatic cancer: deleterious BRCA2 mutations in 17\%." Cancer Res 62(13): 3789-3793.

Murtaugh, L. C. (2014). "Pathogenesis of pancreatic cancer: lessons from animal models." Toxicol Pathol 42(1): 217-228.

Nakajima, E., et al. (2011). "Calpain, not caspase, is the causative protease for hypoxic damage in cultured monkey retinal cells." Invest Ophthalmol Vis Sci 52(10): 7059-7067.

Nozawa, H., et al. (2006). "Infiltrating neutrophils mediate the initial angiogenic switch in a mouse model of multistage carcinogenesis." Proc Natl Acad Sci U S A 103(33): 12493-12498. 
Ogawa, T., et al. (2002). "Anti-tumor angiogenesis therapy using soluble receptors: enhanced inhibition of tumor growth when soluble fibroblast growth factor receptor-1 is used with soluble vascular endothelial growth factor receptor." Cancer Gene Ther 9(8): 633-640.

Ottenhof, N. A., et al. (2011). "Molecular characteristics of pancreatic ductal adenocarcinoma." Patholog Res Int 2011: 620601.

Ouadid-Ahidouch, H. and A. Ahidouch (2008). "K+ channel expression in human breast cancer cells: involvement in cell cycle regulation and carcinogenesis." J Membr Biol 221(1): 1-6.

Ouadid-Ahidouch, H., et al. (2016). "Kv10.1 K channel: from physiology to cancer." Pflugers Arch. Ouadid-Ahidouch, H., et al. (2001). "Changes in the K+ current-density of MCF-7 cells during progression through the cell cycle: possible involvement of a h-ether.a-gogo K+ channel." Receptors Channels 7(5): 345-356.

Paciucci, R., et al. (1998). "Activation of the urokinase plasminogen activator/urokinase plasminogen activator receptor system and redistribution of E-cadherin are associated with hepatocyte growth factor-induced motility of pancreas tumor cells overexpressing Met." Am J Pathol 153(1): 201-212.

Pandol, S., et al. (2009). "Desmoplasia of pancreatic ductal adenocarcinoma." Clin Gastroenterol Hepatol 7(11 Suppl): S44-47.

Pardo, L. A., et al. (1998). "Cell cycle-related changes in the conducting properties of r-eag K+ channels." J Cell Biol 143(3): 767-775.

Pardo, L. A., et al. (1999). "Oncogenic potential of EAG K(+) channels." EMBO J 18(20): 5540-5547.

Pitti, R. M., et al. (1996). "Induction of apoptosis by Apo-2 ligand, a new member of the tumor necrosis factor cytokine family." J Biol Chem 271(22): 12687-12690.

Prasad, S., et al. (2014). "Targeting death receptors for TRAIL by agents designed by Mother Nature." Trends Pharmacol Sci 35(10): 520-536. 
Provenzano, P. P., et al. (2012). "Enzymatic targeting of the stroma ablates physical barriers to treatment of pancreatic ductal adenocarcinoma." Cancer Cell 21(3): 418-429.

Ramos Gomes, F., et al. (2015). "Alternatively Spliced Isoforms of KV10.1 Potassium Channels Modulate Channel Properties and Can Activate Cyclin-dependent Kinase in Xenopus Oocytes." J Biol Chem 290(51): 30351-30365.

Reis, C. R., et al. (2009). "Enhancement of antitumor properties of rhTRAIL by affinity increase toward its death receptors." Biochemistry 48(10): 2180-2191.

Reni, M., et al. (2013). "Maintenance sunitinib or observation in metastatic pancreatic adenocarcinoma: a phase II randomised trial." Eur J Cancer 49(17): 3609-3615.

Ristorcelli, E. and D. Lombardo (2010). "Targeting Notch signaling in pancreatic cancer." Expert Opin Ther Targets 14(5): 541-552.

Ross, R. (1989). "Platelet-derived growth factor." Lancet 1(8648): 1179-1182.

Rucki, A. A. and L. Zheng (2014). "Pancreatic cancer stroma: understanding biology leads to new therapeutic strategies." World J Gastroenterol 20(9): 2237-2246.

Ryan, D. P., et al. (2014). "Pancreatic adenocarcinoma." N Engl J Med 371(22): 2140-2141.

Schmid-Kotsas, A., et al. (1999). "Lipopolysaccharide-activated macrophages stimulate the synthesis of collagen type I and C-fibronectin in cultured pancreatic stellate cells." Am J Pathol 155(5): 1749-1758.

Schmitz-Winnenthal, F. H., et al. (2005). "High frequencies of functional tumor-reactive T cells in bone marrow and blood of pancreatic cancer patients." Cancer Res 65(21): 10079-10087.

Schrama, D., et al. (2006). "Antibody targeted drugs as cancer therapeutics." Nat Rev Drug Discov 5(2): 147-159.

Seo, Y., et al. (2000). "High expression of vascular endothelial growth factor is associated with liver metastasis and a poor prognosis for patients with ductal pancreatic adenocarcinoma." Cancer $\mathbf{8 8 ( 1 0 ) : ~}$ 2239-2245. 
Shih, H. P., et al. (2013). "Pancreas organogenesis: from lineage determination to morphogenesis." Annu Rev Cell Dev Biol 29: 81-105.

Soderstrom, T. S., et al. (2002). "Mitogen-activated protein kinase/extracellular signal-regulated kinase signaling in activated T cells abrogates TRAIL-induced apoptosis upstream of the mitochondrial amplification loop and caspase-8." J Immunol 169(6): 2851-2860.

Solinas, G., et al. (2009). "Tumor-associated macrophages (TAM) as major players of the cancer-related inflammation." J Leukoc Biol 86(5): 1065-1073.

Stoeltzing, O., et al. (2003). "Regulation of hypoxia-inducible factor-1alpha, vascular endothelial growth factor, and angiogenesis by an insulin-like growth factor-I receptor autocrine loop in human pancreatic cancer." Am J Pathol 163(3): 1001-1011.

Su, G. H., et al. (1999). "Germline and somatic mutations of the STK11/LKB1 Peutz-Jeghers gene in pancreatic and biliary cancers." Am J Pathol 154(6): 1835-1840.

Szegezdi, E., et al. (2006). "TRAIL sensitisation by arsenic trioxide is caspase-8 dependent and involves modulation of death receptor components and Akt." Br J Cancer 94(3): 398-406.

Tan, A. C., et al. (2009). "Characterizing DNA methylation patterns in pancreatic cancer genome." Mol Oncol 3(5-6): 425-438.

Tanaka, S. (2016). "Molecular Pathogenesis and Targeted Therapy of Pancreatic Cancer." Ann Surg Oncol 23 Suppl 2: 197-205.

ten Cate, B., et al. (2009). "A novel AML-selective TRAIL fusion protein that is superior to Gemtuzumab Ozogamicin in terms of in vitro selectivity, activity and stability." Leukemia 23(8): 1389-1397.

Toyokuni, S., et al. (1995). "Persistent oxidative stress in cancer." FEBS Lett 358(1): 1-3.

Trivedi, R. and D. P. Mishra (2015). "Trailing TRAIL Resistance: Novel Targets for TRAIL Sensitization in Cancer Cells." Front Oncol 5: 69. 
Urrego, D., et al. (2016). "Periodic expression of Kv10.1 driven by pRb/E2F1 contributes to G2/M progression of cancer and non-transformed cells." Cell Cycle 15(6): 799-811.

Vaccaro, V., et al. (2015). "Metastatic pancreatic cancer: Is there a light at the end of the tunnel?" World J Gastroenterol 21(16): 4788-4801.

van Heek, N. T., et al. (2002). "Telomere shortening is nearly universal in pancreatic intraepithelial neoplasia." Am J Pathol 161(5): 1541-1547.

Vaquero, E. C., et al. (2004). "Reactive oxygen species produced by NAD(P)H oxidase inhibit apoptosis in pancreatic cancer cells." J Biol Chem 279(33): 34643-34654.

Venkitaraman, A. R. (2002). "Cancer susceptibility and the functions of BRCA1 and BRCA2." Cell 108(2): 171-182.

Wadhwa, S., et al. (2009). "Differential expression of potassium ion channels in human renal cell carcinoma." Int Urol Nephrol 41(2): 251-257.

Wagner, M., et al. (1998). "Suppression of fibroblast growth factor receptor signaling inhibits pancreatic cancer growth in vitro and in vivo." Gastroenterology 114(4): 798-807.

Wang, P., et al. (2007). "Inhibition of RIP and c-FLIP enhances TRAIL-induced apoptosis in pancreatic cancer cells." Cell Signal 19(11): 2237-2246.

Warmke, J., et al. (1991). "A distinct potassium channel polypeptide encoded by the Drosophila eag locus." Science 252(5012): 1560-1562.

Watari, N., et al. (1982). "Morphological studies on a vitamin A-storing cell and its complex with macrophage observed in mouse pancreatic tissues following excess vitamin A administration." Okajimas Folia Anat Jpn 58(4-6): 837-858.

Weber, C., et al. (2006). "Silencing the activity and proliferative properties of the human Eagl Potassium Channel by RNA Interference." J Biol Chem 281(19): 13030-13037. 
Wicker, C. A., et al. (2010). "BITC Sensitizes Pancreatic Adenocarcinomas to TRAIL-induced Apoptosis." Cancer Growth Metastasis 2009(2): 45-55.

Widlak, P. (2000). "The DFF40/CAD endonuclease and its role in apoptosis." Acta Biochim Pol 47(4): 1037-1044.

Wiley, S. R., et al. (1995). "Identification and characterization of a new member of the TNF family that induces apoptosis." Immunity 3(6): 673-682.

Wilson, J. S., et al. (2014). "Stars and stripes in pancreatic cancer: role of stellate cells and stroma in cancer progression." Front Physiol 5: 52.

Wormann, S. M. and H. Algul (2013). "Risk factors and therapeutic targets in pancreatic cancer." Front Oncol 3: 282.

Yip, D., et al. (2006). "Chemotherapy and radiotherapy for inoperable advanced pancreatic cancer." Cochrane Database Syst Rev(3): CD002093.

Zhang, M., et al. (2015). "The Roles of ROS and Caspases in TRAIL-Induced Apoptosis and Necroptosis in Human Pancreatic Cancer Cells." PLoS One 10(5): e0127386.

Zhou, D. H., et al. (2008). "The potential molecular mechanism of overexpression of uPA, IL-8, MMP-7 and MMP-9 induced by TRAIL in pancreatic cancer cell." Hepatobiliary Pancreat Dis Int 7(2): 201-209.

Zhou, D. H., et al. (2013). "TRAlL-induced expression of UPA and IL-8 strongly enhanced by overexpression of TRAF2 and Bcl-xL in pancreatic ductal adenocarcinoma cells." Hepatobiliary Pancreat Dis Int 12(1): 94-98. 


\section{ABBREVIATION}

\begin{tabular}{|c|c|}
\hline $\mathrm{Aa}$ & Amino acid \\
\hline $\mathrm{Ab}$ & Antibody \\
\hline Amp & Amplicillin \\
\hline$\alpha-S M A$ & alpha-smooth muscle actin \\
\hline ATCC & American type cell culture collection \\
\hline BAK & Bcl-2 homologues antagonist killer \\
\hline $\mathrm{Bcl}-2$ & B- cell lymphoma 2 \\
\hline BAX & $\mathrm{Bcl}-2$ associated $\mathrm{X}$ protein \\
\hline Bid & PRO apoptotic $\mathrm{Bcl}-2$ protein \\
\hline $\mathrm{Bp}$ & Base pair \\
\hline BFB & Breakage-fusion-bridge \\
\hline BSA & Bovine serum albumin \\
\hline cDNA & Complementary DNA \\
\hline cFLIP & cellular FLICE-inhibitory protein \\
\hline CBR & Clinical benefit response \\
\hline $\mathrm{CHO}$ & Chinese hamster ovary \\
\hline CNS & Central Nervous System \\
\hline $\mathrm{Da}$ & Dalton \\
\hline DAPI & 4', 6- diamidino - 2- phenylindole- dihydrochloride \\
\hline DcR & Decoy receptor \\
\hline DD & Death domain \\
\hline DED & Death effector domain \\
\hline $\mathrm{DHH}$ & Desert Hedgehog \\
\hline DISC & Death-inducing signaling complex \\
\hline DMEM & Dubleco's modified eagle's medium \\
\hline DNA & Deoxynucleotide acid \\
\hline DMSO & Dimethylsufoxide \\
\hline dNTP & 2'-deoxynucleoside-5'-triphosphate \\
\hline DR & Death receptor \\
\hline Eag-1 & Ether-a-go-go (Kv10.1) \\
\hline E.coli & Escherichia coli \\
\hline ECL & Enhance chemical luminescence \\
\hline EDTA & Ethylenediamine teraacetic acid \\
\hline EFS & Event free survival rate \\
\hline ECM & Extra cellular matrix \\
\hline EMT & Epithelial-to-mesenchymal transition \\
\hline ELISA & Enzyme linked immunoabsorbant assay \\
\hline ER & Estrogen receptors \\
\hline $\mathrm{F}$ & Forward \\
\hline FACs & Fluorescence activated cell sorter \\
\hline FADD & Fas-associated death domain protein \\
\hline FCS & Fetal calf serum \\
\hline FGF & Fibroblast growth factor \\
\hline
\end{tabular}




\begin{tabular}{|c|c|}
\hline $\begin{array}{l}\text { FITC } \\
5-F U\end{array}$ & $\begin{array}{l}\text { Fluorescein Isothiocynat } \\
5 \text { Fluorouracil }\end{array}$ \\
\hline g & Gram \\
\hline$g$ & Acceleration of gravity \\
\hline GFAP & Glial fibrillary acid protein \\
\hline GFP & Green Fluorescent protein \\
\hline Gly & Glycine \\
\hline h & Hour \\
\hline HEK & Human embryonic kidney \\
\hline HGF & Hepatocyte growth factor \\
\hline HRP & Horse radish peroxidase conjugates \\
\hline HPV & Human papillomavirus \\
\hline IAP & Inhibitor of apoptosis proteins \\
\hline IGF & Insulin growth factor \\
\hline $\mathrm{IHH}$ & Indian Hedgehog \\
\hline Kv10.1 & Voltage gated potassium channel \\
\hline L & Liter \\
\hline $\mathrm{LOH}$ & Loss of Heterozygosity \\
\hline$\mu$ & Micro \\
\hline $\mathrm{m}$ & Milli \\
\hline M & Molar \\
\hline$\mu \mathrm{g}$ & Micro gram \\
\hline$\mu \mathrm{L}$ & Micro liter \\
\hline memTRAIL & Membrane TRAIL \\
\hline Min & Minute \\
\hline MMP & Matrix metalloproteinases \\
\hline mTOR & Mammalian target of rapamycin \\
\hline na & Nano \\
\hline NGF & Nerve growth factor \\
\hline$N F-\kappa B$ & Nuclear factor for $\kappa$ gene in B Lymphocytes \\
\hline OD & Optical density \\
\hline OPG & Osteoprotegrin \\
\hline ORR & Object response rate \\
\hline OS & Overall survival \\
\hline $\mathrm{PaCa}$ & Pancreatic cancer \\
\hline PAGE & Polyacrylamide gel electrophoresis \\
\hline Panln & Pancreatic intraepithelial neoplasia \\
\hline PaSCs/PSCs & Pancreatic stellate cells \\
\hline PDAC & Pancreatic ductal adenocarcinoma \\
\hline PBS & Phosphate-buffered saline \\
\hline PCR & Polymerase chain reaction \\
\hline PFS & Progressive free survival \\
\hline $\mathrm{PI}$ & Promidium lodide \\
\hline PI3K & phosphoinositide 3 kinase MRD \\
\hline PS & Phosphatidyserine \\
\hline PTC & Patched \\
\hline
\end{tabular}




$\begin{array}{ll}\text { PTEN } & \text { Phosphatase and tensin homolog } \\ \text { R } & \text { Reverse } \\ \text { RNA } & \text { Ribonucleic acid } \\ \text { ROS } & \text { Reactive oxygen species } \\ \text { RPM } & \text { Revolutions per minute } \\ \text { RT } & \text { Room temperature } \\ \text { RT-PCR } & \text { Reverse transcriptase PCR } \\ \text { S } & \text { Second } \\ \text { SCFv } & \text { Single chain variable fragment } \\ \text { SDS } & \text { Sodium dodecylsulfate } \\ \text { SHH } & \text { Sonic Hedgehog } \\ \text { ShRNA } & \text { Short hairpin RNA } \\ \text { SiRNA } & \text { Small interfering RNA } \\ \text { sTRAIL } & \text { Soluble TRAlL } \\ \text { TAMs } & \text { Tumour associated macrophages } \\ \text { TBS } & \text { Tris - buffered saline } \\ \text { TGF } \beta & \text { Transforming growth factor beta Heh } \\ \text { Tm } & \text { Melting temperature } \\ \text { TRAIL } & \text { TNF- related apoptosis inducing ligand } \\ \text { Tregs } & \text { T regulatory cells up } \\ \text { UPL } & \text { Universal probe library } \\ \text { UV } & \text { Ultraviolet } \\ \text { V } & \text { Volt } \\ \text { VEGF } & \text { Vascular endothelial growth factor } \\ \text { wt } & \text { Wild-type } \\ \text { XIAP } & \text { X-linked inhibitor of apoptosis }\end{array}$




\section{Farrah Zahed}

Fzahed@em.mpg.de

EDUCATION

Apr 2013 to Present

Sep 2008 to Sep 2009

Aug 2005 to May 2007

Jun 2002 to Jun 2005

\section{CURRICULUM VITAE}

$+4917687603607$

Karolinenweg 14, 37075 Göttingen

Germany

PhD in Molecular Medicine

Georg-August-Universität, Göttingen (Germany)

Masters By Research (MRes) in Medical and Molecular biosciences

Newcastle University, Newcastle Upon Tyne (United Kingdom)

Master of Science (MSc) in Applied Genetics

M.S.Ramaiah college, Bangalore (India)
Bachelor of Science (BSc) in Biotechnology, Chemistry and Microbiology

M.S.Ramaiah college, Bangalore (India)

\section{RESEARCH EXPERIENCE}

Apr 2013 to Present

Dissertation: "Therapeutic strategies targeting Kv10.1 in PDAC"

Department of Molecular Biology of Neuronal Signals, Oncophysiology Group, Max-Planck-Institute of Experimental Medicine, Göttingen, Germany. Supervisor: Prof. Dr. Luis Pardo.

Applied Methods: Mammalian cell culture, Flow cytometry, Western blot, Caspase assays, IncuCyte - Cell based assay - co- 
culturing, 3D in-vitro model, In-vivo transplantations, Immunohistochemistry.

May 2011 to Mar 2012

Research associate - Mitra biotech Pvt Ltd, Bangalore India.

Applied Methods: Mammalian cell culture, qPCR, Microarray

Dec 2009 to Sep 2010

Research Fellowship: "Investigating the role of Lrig2 in PDGF induced proliferation of MEF and glial progenitor cells"

Department of radiation sciences, Oncology laboratory, Umea (Sweden) Supervisor: Dr. Hakan Hedman

Applied Methods: Cell culturing, Flow cytometry, Handling transgenic (RCAS n-TVA) mice.

Sep 2008 to Sep 2009

MRes Thesis Project: "Molecular cytogenetic characterization of relapsed childhood acute lymphoblastic leukemia".

Leukaemia Research Cytogenetics Group, Northern Institute for Cancer Research, Newcastle University, Newcastle upon Tyne (United Kingdom). Supervisor: Prof. Anthony V Moorman

Applied Methods: Fluorescent in-situ hybridization (FISH).

\section{PUBLICATION}

Urrego D, Tomczak AP, Zahed F, Stuhmer W, Pardo LA. 2014 Potassium channels in cell cycle and cell proliferation. Phil. Trans. R. Soc. B 369: 20130094 